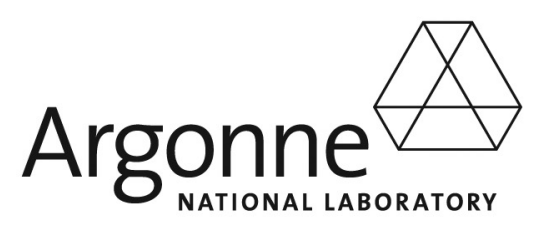

ANL-05/62

\title{
Practical Superconductor Development for Electrical Power Applications Annual Report for FY 2005
}

\author{
Materials Science Division
}


About Argonne National Laboratory

Argonne is a U.S. Department of Energy laboratory managed by The University of Chicago

under contract W-31-109-Eng-38. The Laboratory's main facility is outside Chicago, at

9700 South Cass Avenue, Argonne, Illinois 60439. For information about Argonne,

see www.anl.gov.

\section{Availability of This Report}

This report is available, at no cost, at http://www.osti.gov/bridge. It is also available

on paper to the U.S. Department of Energy and its contractors, for a processing fee, from:

U.S. Department of Energy

Office of Scientific and Technical Information

P.O. Box 62

Oak Ridge, TN 37831-0062

phone (865) 576-8401

fax (865) 576-5728

reports@adonis.osti.gov

\section{Disclaimer}

This report was prepared as an account of work sponsored by an agency of the United States Government. Neither the United States Government nor any agency thereof, nor The University of Chicago, nor any of their employees or officers, makes any warranty, express or implied, or assumes any legal liability or responsibility for the accuracy, completeness, or usefulness of any information, apparatus, product, or process disclosed, or represents that its use would not infringe privately owned rights. Reference herein to any specific commercial product, process, or service by trade name, trademark, manufacturer, or otherwise, does not necessarily constitute or imply its endorsement, recommendation, or favoring by the United States Government or any agency thereof. The views and opinions of document authors expressed herein do not necessarily state or reflect those of the United States Government or any agency thereof, Argonne National Laboratory, or The University of Chicago. 


\section{Practical Superconductor Development for Electrical Power Applications Annual Report for FY 2005}

by U. Balachandran, ${ }^{\star}$ C. Cheon, ${ }^{\star}$ H. Claus, ${ }^{* \star}$ S.E. Dorris, ${ }^{\star}$ J.M. Hiller, ${ }^{*}$ K.E. Gray, ${ }^{\star *}$ R.E. Koritala, ${ }^{\star}$ Y. Lei, ${ }^{\star}$ B. Ma, ${ }^{\star}$ S.H. Majumdar, ${ }^{\star}$ S. Majumdar, ${ }^{*}$ V.A. Maroni, ${ }^{\star \star \star}$ D.J. Miller, ${ }^{\star \star}$ A.P. Paulikas, ${ }^{\star \star}$ J.P. Singh, ${ }^{\star}$ S.P. Srinivasan, ${ }^{\star}$ S. Trasobares, ${ }^{\star \star}$ K.K. Uprety, ${ }^{\star}$ B.W. Veal, ${ }^{* \star}$ V. Vlasko-Vlasov, ${ }^{* *}$ and U. Welp, ${ }^{* \star}$ A.M. Wolsky ${ }^{\star \star * \star}$

December 2005

Work supported by U.S. Department of Energy Office of Electricity Delivery and Energy Reliability

* Energy Technology Division

** Materials Science Division

*** Chemical Engineering Division

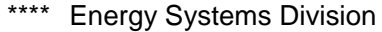





\section{CONTENTS}

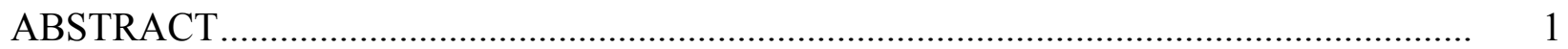

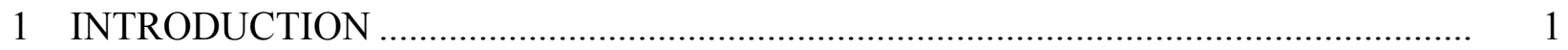

2 COORDINATED CHARACTERIZATION OF COATED CONDUCTORS .................. 3

2.1 MOCVD Coated Conductors ..................................................................................... 4

2.2 MOD Coated Conductors …………………………….......................................... 10

3 REVERSIBLE OXIDATION OF THE YBCO COATED CONDUCTOR ………….......... 17

3.1 Experimental Procedures .................................................................................... 17

3.2 Low Magnetic Field Measurements......................................................................... 18

3.3 High Magnetic Field Measurements ........................................................................ 26

4 RESIDUAL STRESSES IN MULTILAYERED COATED CONDUCTORS .................. 30

4.1 Finite Element Analysis of Coated Conductors..................................................... 30

4.2 Influence of Processing Methods on Residual Stress ............................................... 33

5 HTS PROGRAM TECHNICAL EVALUATION/SUPPORT ……………….................. 42

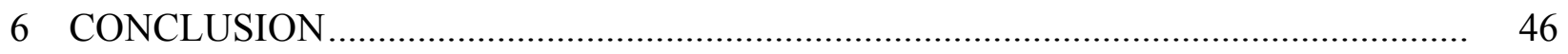

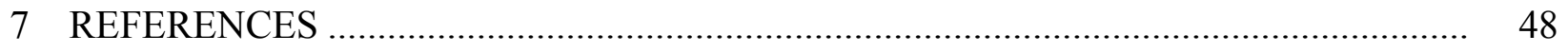

8 PUBLICATIONS, PATENTS, REPORTS, KEY INTERACTIONS IN FY 2005 ............ 51

$8.1 \quad$ Peer Reviewed Publications in FY 2005 .......................................................... 51

8.2 Patents Issued in FY 2005........................................................................ 52

8.3 Reports Issued in FY 2005 .......................................................................... 52

8.4 Key Interactions in FY 2005 .......................................................................... 53 


\title{
PRACTICAL SUPERCONDUCTOR DEVELOPMENT FOR ELECTRICAL POWER APPLICATIONS ANNUAL REPORT FOR FY 2005
}

\begin{abstract}
High-critical-temperature superconductors are ideally suited for electric power applications that require large current carrying capacity, often in the presence of high magnetic fields. This report describes progress at Argonne National Laboratory (ANL) in the research and development of practical superconducting components and devices. In FY 2005, these efforts focused primarily on characterizing and improving second-generation superconductors made with $\mathrm{YBa}_{2} \mathrm{Cu}_{3} \mathrm{O}_{7-\mathrm{X}}(\mathrm{YBCO})$ in several different architectures.
\end{abstract}

\section{INTRODUCTION}

The Department of Energy/Office of Electricity Delivery and Energy Reliability (DOE/OE) superconductivity program seeks to establish the technology that will enable broadscale commercialization of high- $\mathrm{T}_{\mathrm{c}}$ superconductors (HTSs) in a wide variety of electric power applications. The principal objective of this program is to develop methods to fabricate and use structurally reliable HTSs for generating, transmitting, and storing electrical energy. Research efforts within the OE program are focused on improving the electrical performance properties of HTS materials through the elucidation and manipulation of processing methods and the development of practical methods for mass-producing commercial conductors. In this program, the science and technology associated with fabricating long-length conductors is a major point of emphasis. Cooperative relationships that tie together industrial, national laboratory, and academic partners are integral to the success of the OE/HTS program.

HTS embodiments in the form of coated conductor-type tape must satisfy several requirements. The conductor must be able to carry kilo-amp level currents at high voltage and, for some applications, in the presence of large magnetic fields. It must also be strong, flexible, and cryogenically stable. Potential applications for such conductors include transmission lines, motors, generators, transformers, magnetic energy storage units, and power electronics devices. The present obstacles to the large scale use of the YBCO coated conductor include low critical current density in large applied magnetic fields, relatively poor mechanical properties, and difficulty in efficiently fabricating long (kilometer) lengths with uniform properties.

The OE/HTS program at ANL focuses on providing detailed electromagnetic, chemical, and structural characterization of second-generation YBCO coated conductors fabricated by alternative processing routes as a means to improve the processing methods and systematically eliminate each of the progress-limiting obstacles. This report reviews technical progress in (1) developing and utilizing a coordinated suite of characterization methods to evaluate localized superconductivity in coated conductors (produced by industrial and national laboratory collaborators) and to identify the causes of localized reduced performance in these conductors, 
(2) devising methods/procedures to eliminate performance-limiting defects, (3) exploring processing modifications that enhance in-field performance, (4) examining the mechanical properties of YBCO-coated conductors, and (5) assessing the state-of-the art in selected areas of HTS technology application. 


\section{COORDINATED CHARACTERIZATION OF COATED CONDUCTORS $\left(\mathrm{C}^{4}\right)$}

The ANL work on "coordinated characterization of coated conductors" seeks to correlate local superconducting performance with observations derived from the application of a suite of materials characterization tools. These tools span the range from scanning and transmission electron microscopy (SEM and TEM) of the YBCO superconductor microstructure to energy dispersive spectroscopy (EDS) and Raman microscopy studies of precursor phase development and to paralleling evaluations of substrates and buffer layers. Remarkable improvements in the performance and end-to-end uniformity of coated conductor tapes have been reported recently [1-3]. However, to understand the micro-structural features that provide such improvements, as well as those that are deleterious, it is necessary to correlate them with local superconductivity.

The $\mathrm{C}^{4}$ program uses two techniques to quantify local superconducting properties. One technique involves the use of patterned rings to measure the superconducting critical current density (Jc) over a range of magnetic field and temperature. Although the spatial resolution is $\sim 1 \mathrm{~mm}$, this non-contact technique is amenable to sequential processing studies, such as the optimization of YBCO oxygen content. The second non-contact technique, magneto-optical imaging (MOI), is used to evaluate the local Jc with a spatial resolution of $\sim 1$ micron. Thus, MOI has been particularly useful to guide further electron microscopy and Raman examinations. As an example, in FY 2004, the first fully-adapted $\mathrm{C}^{4}$ studies identified several types of YBCO/buffer-layer interactions and correlated them with diminished performance compared to regions where the buffer layer was intact [1].

Moreover, the introduction of artificial pinning centers has become a paramount thrust of the OE superconducting wire development program. Here, the direct correlation of local Jc with defect densities, shapes, and size distributions, connected by theory, is vital to ensure that each type of defect is properly interpreted in terms of its influence on conductor performance. This new direction for $\mathrm{C}^{4}$ is expected to take on considerably greater importance during FY 2006 and beyond.

Characterization tools that are in situ and nondestructive have high value, and the ANL $\mathrm{C}^{4}$ program has concentrated on these. MOI is a non-destructive probe that can be used to examine localized Jc in both the absence and the presence of a protective silver cap layer. Also, the use of contact-free measurement methods for Jc determination in patterned samples is amenable to studies that require further high-temperature processing. Raman-based techniques developed in the $\mathrm{C}^{4}$ program are being implemented as non-destructive, in-situ probes of precursor evolution on reel-to-reel fabrication lines (e.g., at SuperPower, Inc. [2b]). Raman also provides insights into superconductivity in the $\mathrm{YBCO}$, but it requires removal of the silver sheath. In the past, TEM has been primarily a destructive probe. Presently, however, novel sample preparation techniques using a focused ion beam (FIB) allow for the extraction of tiny TEM specimens with minimal local disruption of the coated conductor. These FIB techniques are now fully implemented in the $\mathrm{C}^{4}$ program, and the high value of using them for cross section examination and three-dimensional imaging is being demonstrated on a consistent basis. 
The $\mathrm{C}^{4}$ program is heavily dependent on receiving top-quality coated conductor specimens from industrial partners and from collaborators at other national laboratories participating in the OE/HTS program. Argonne works in close coordination with SuperPower, Inc., and American Superconductor through formal Cooperative Research and Development Agreements (CRADAs) and plans to strengthen existing ties with the Oak Ridge National Laboratory (ORNL), the Los Alamos National Laboratory (LANL), and the Brookhaven National Laboratory (BNL) as appropriate. In the cases of the national laboratories, two types of beneficial interactions are apparent: (1) the use of the unique features of the $\mathrm{C}^{4}$ characterization tools and approaches coupled to the ORNL, LANL, and BNL capability to make high quality coated conductor specimens, and (2) the inter-laboratory collaborations on characterization that occur in the 2G Wire Development Group (2G-WDG) headed by American Superconductor.

The results presented in Section 2 exemplify the types of studies being performed in the $\mathrm{C}^{4}$ program at Argonne. A report is presented on the examination of fully-processed metalorganic-chemical-vapor-deposited (MOCVD) YBCO films on buffered, ion-beam-assisteddeposition (IBAD) templates fabricated by SuperPower, Inc. Then, a description is given of electron microscopy and Raman microscopy data obtained for specimens of $\mathrm{YBCO}$ and $\mathrm{Er}^{3+}$ added YBCO coated conductor produced by the metal organic deposition (MOD) method under development at American Superconductor using RABiTS-based substrates.

\subsection{MOCVD COATED CONDUCTORS}

During FY 2005, a number of MOCVD-type coated conductor tapes supplied by SuperPower, Inc. were examined in considerable detail. Typically, tape specimens were extracted from $\geq 50$-m-long lengths of conductor composed of YBCO (ca. $1 \rightarrow 1.5 \mu \mathrm{m}$ thick) on $\mathrm{CeO}_{2}$-buffered IBAD templates supported on a nickel alloy substrate $[1,2]$. The characterization of such tapes generally proceeds in the following way. After fabrication, SuperPower measures the critical current (Ic) along selected lengths of the tape in approximately $1-\mathrm{cm}$ increments, and then forwards specimens from the measured lengths to Argonne for detailed characterization using the cadre of $\mathrm{C}^{4}$ tools outlined above. Figure 1 diagrams what the Ic versus position data tend to look like for typical samples. Of particular interest in Fig. 1, for example, is the drop-off region near the $40 \mathrm{~m}(4000 \mathrm{~cm})$ position. In this region the Ic drops by nearly a third in zero field and in moderate fields (i.e., fractions of a Tesla) as well.

Key questions to be addressed regarding the data trend in Fig. 1 include (1) what causes the occasional random drops in Ic, and (2) what can be done to raise the overall Ic to even higher values? To explore the first question, FIB/SEM/TEM and Raman measurements were made in the vicinity of the minimum, and the maximum points of the ca. $40-\mathrm{m}$ position Ic dip as indicated in the lower inset in Fig. 1. This particular tape sample was one that SuperPower prepared by a multi-pass MOCVD process, yielding a film composed of three individually deposited $0.4-\mu \mathrm{m}$-thick YBCO layers. SEM images of FIB-cut cross sections from the 3732 and $3742 \mathrm{~cm}$ segments (see Fig. 2) indicate that there is more second phase between the YBCO layers in the lower Ic segment than there is in the higher Ic segment. Also, the morphology of the topmost YBCO layer for the lower Ic segment appears to be more disrupted by ragged columnar grains 


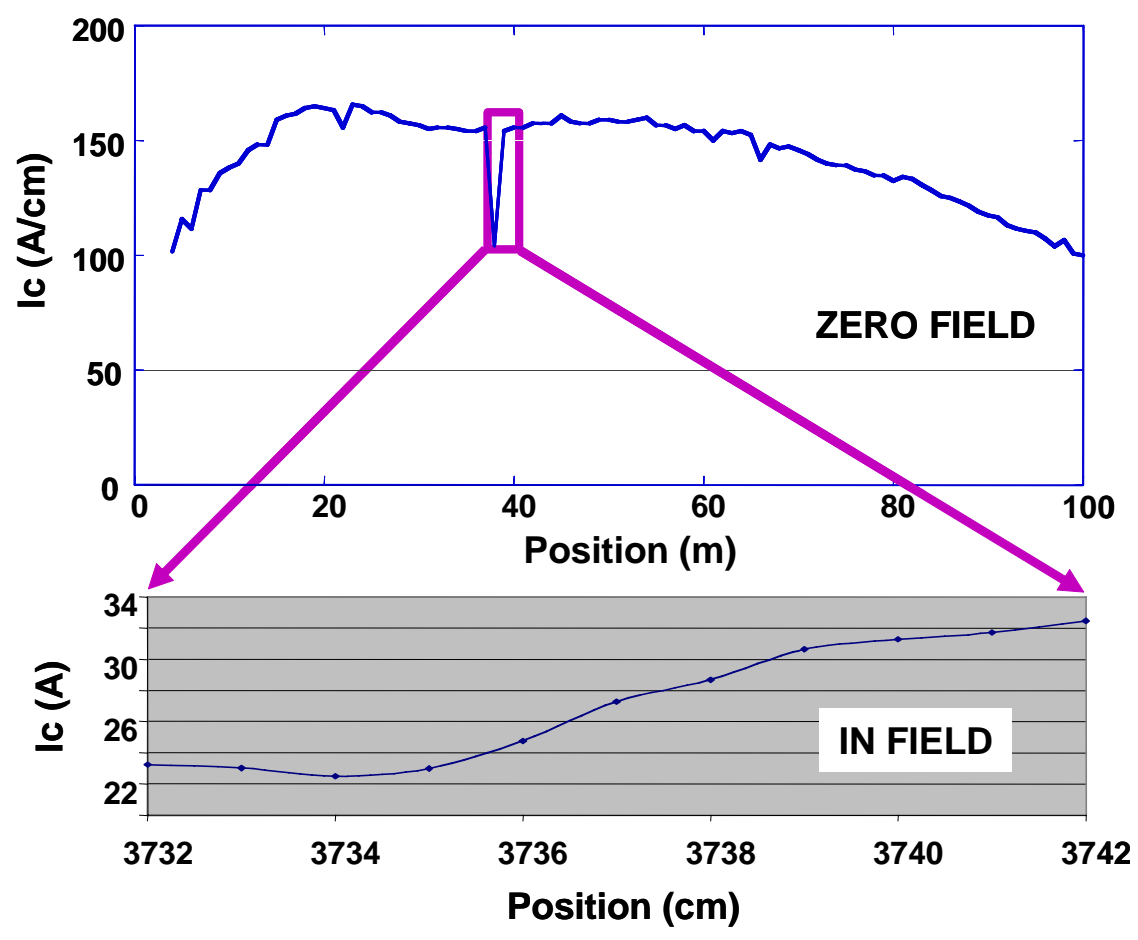

FIGURE 1 Top Inset: Critical current profile over a 100-m length of an MOCVD YBCO tape produced by SuperPower, Inc. Bottom Inset: Expanded plot of a selected 10-cm section around the drop-off feature in the top inset. The 3732- and 3742-cm tape increments are the ones referred to in the text as the "lower Ic" and "higher Ic" segments.

than does the topmost YBCO layer in the higher Ic segment. Clearly, the higher Ic segment $(3742 \mathrm{~cm})$ is more uniform (layer-to-layer), better textured, and freer of second phase precipitates than is the lower Ic segment $(3732 \mathrm{~cm})$.

The results of higher magnification TEM examinations shown in Fig. 3 confirm the more prominent occurrence of interfacial second phase decorations (ISPDs) along YBCO/YBCO interfaces in the lower Ic segment. However, it is also clear in the TEM images that both segments (higher and lower Ic) contain numerous columnar growth domains. These columnar growths are a-axis oriented YBCO grains that often extend through the entire thickness of an individual YBCO layer and seem to increase in number from the bottom layer to the top layer. Two other noteworthy observations from the SEM and TEM images of the higher and lower Ic segments are that there is relatively little porosity and no obvious grain boundary meandering in any of the MOCVD-deposited YBCO layers. These observations are typical of $\mathrm{C}^{4}$ findings for MOCVD-coated conductor tapes produced by SuperPower.

Raman microscopy measurements on the lower and higher Ic segments confirm that the a-axis grain structure is more prominent in the topmost YBCO layer than in the underlying layers. This was demonstrated by using the FIB to make slanted cuts (referred to hereinafter as "wedges") through the entire YBCO film and buffer layer (surface-to-substrate) as depicted in 


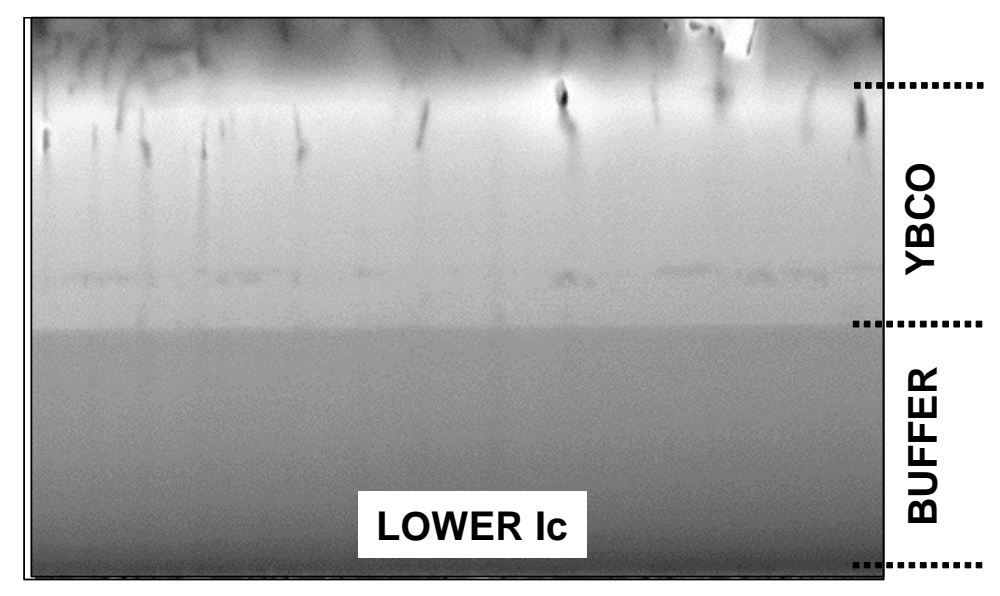

$1.0 \mu \mathrm{m}$

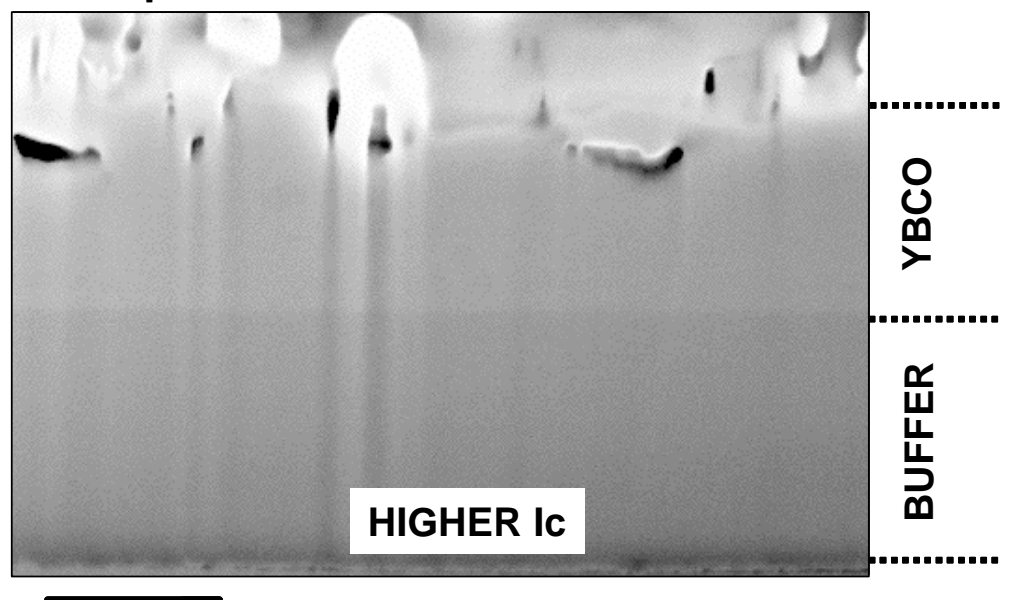

$1.0 \mu \mathrm{m}$

FIGURE 2 SEM images of FIB-cut cross sections from the lower and higher Ic segments.

Fig. 4. With this slope-cut architecture it is possible to obtain an averaged Raman spectrum of the entire YBCO film (through thickness) that can be compared to representative Raman spectra obtained from the top surface. It is known from prior studies [4] that the observed Raman spectra of YBCO films emanate from the uppermost 0.2 to $0.3 \mu \mathrm{m}$ of YBCO because the excitation laser $(633 \mathrm{~nm})$ does not penetrate more than about $0.3 \mu \mathrm{m}$ of YBCO. The wedge embodiment in Fig. 4 allows the taking of Raman spectra across a surface (the wedge) that should be representative of the entire YBCO film.

The plots in Fig. 5 show a comparison of the top surface and wedge surface Raman spectra for the lower and higher Ic segments. The assignments indicated in these plots are based on extensive analyses/interpretations of the Raman spectra of YBCO films reported previously [4-5]. The appearance of the $\mathrm{O} 4$ mode of orthorhombic $\mathrm{YBCO}$ near $500 \mathrm{~cm}^{-1}$ for the collection 
LOWER Ic

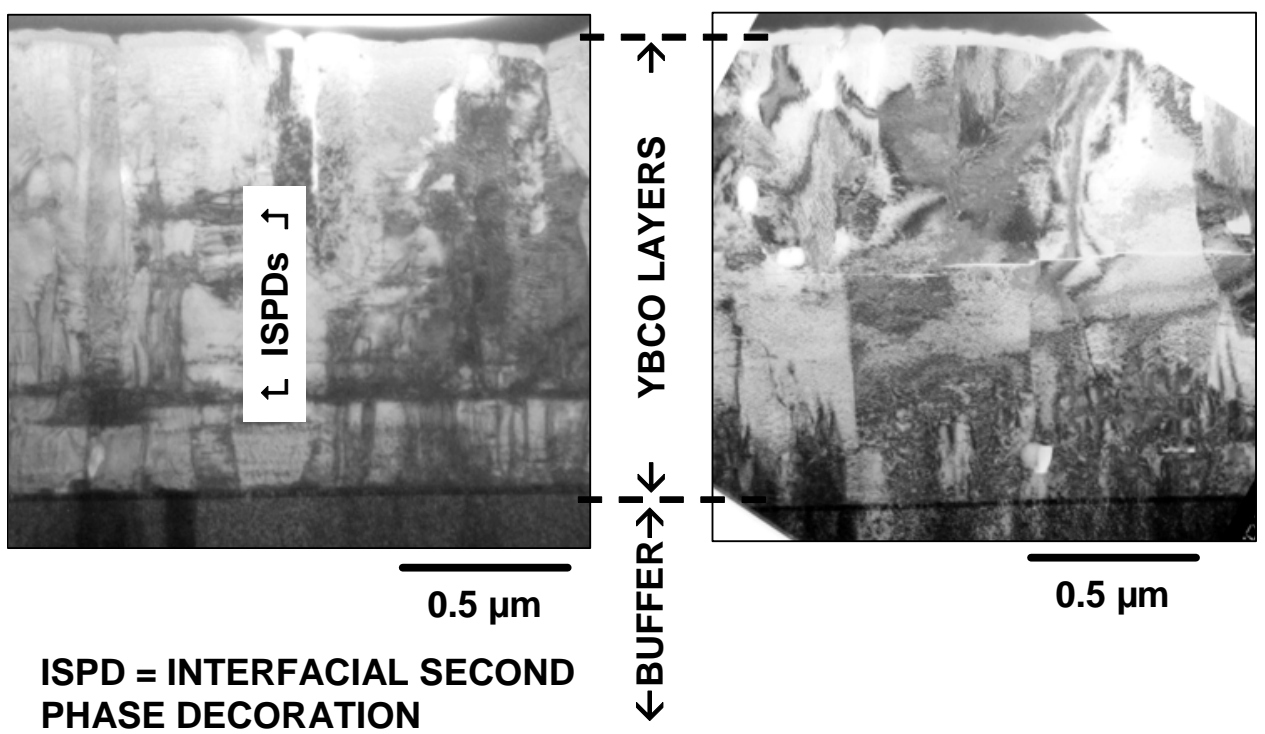

FIGURE 3 TEM images of representative domains in the FIB-cut sections from the lower and higher Ic segments.

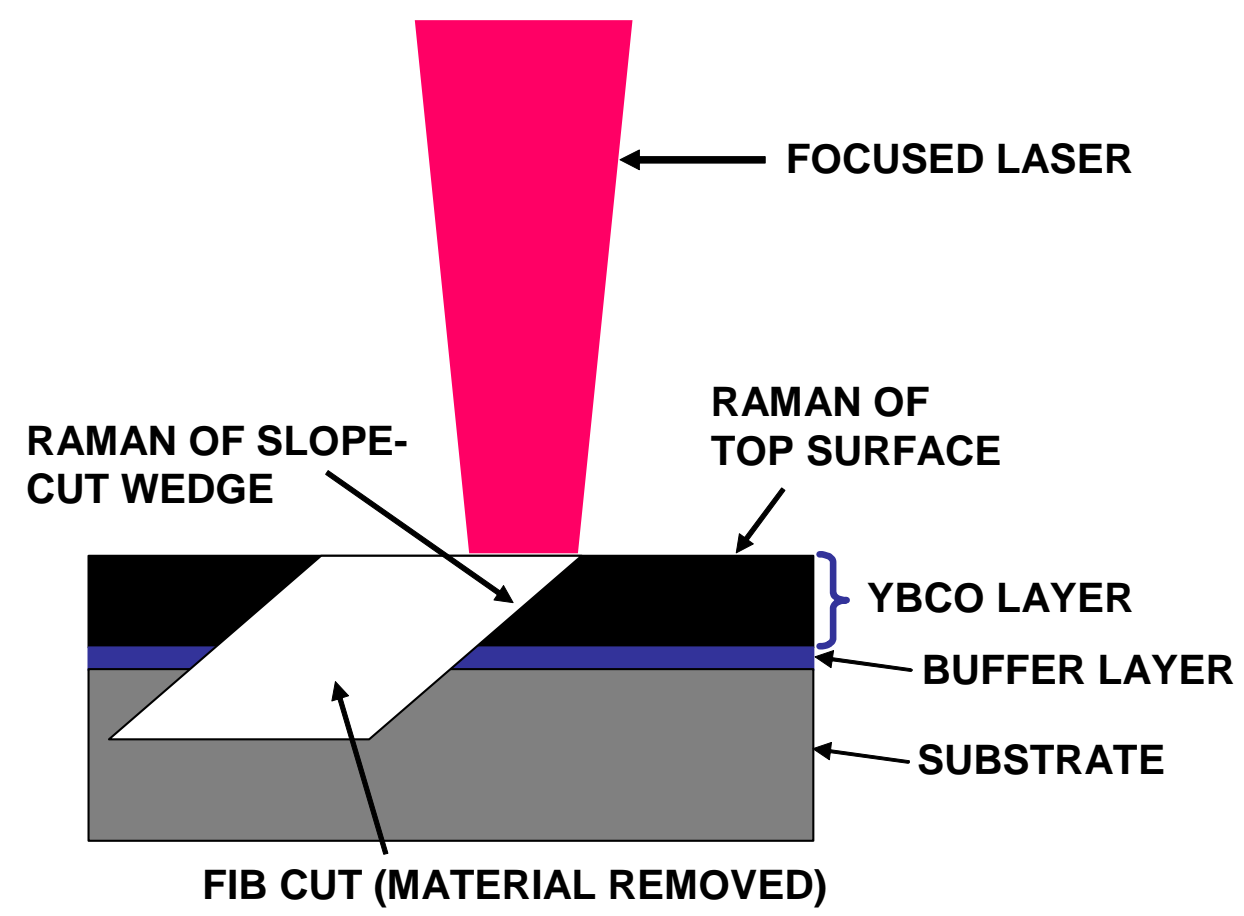

FIGURE 4 Schematic drawing of the FIB-cut wedge embodiment used to obtain through-thickness averaged Raman spectra of YBCO films on coated conductor specimens. 


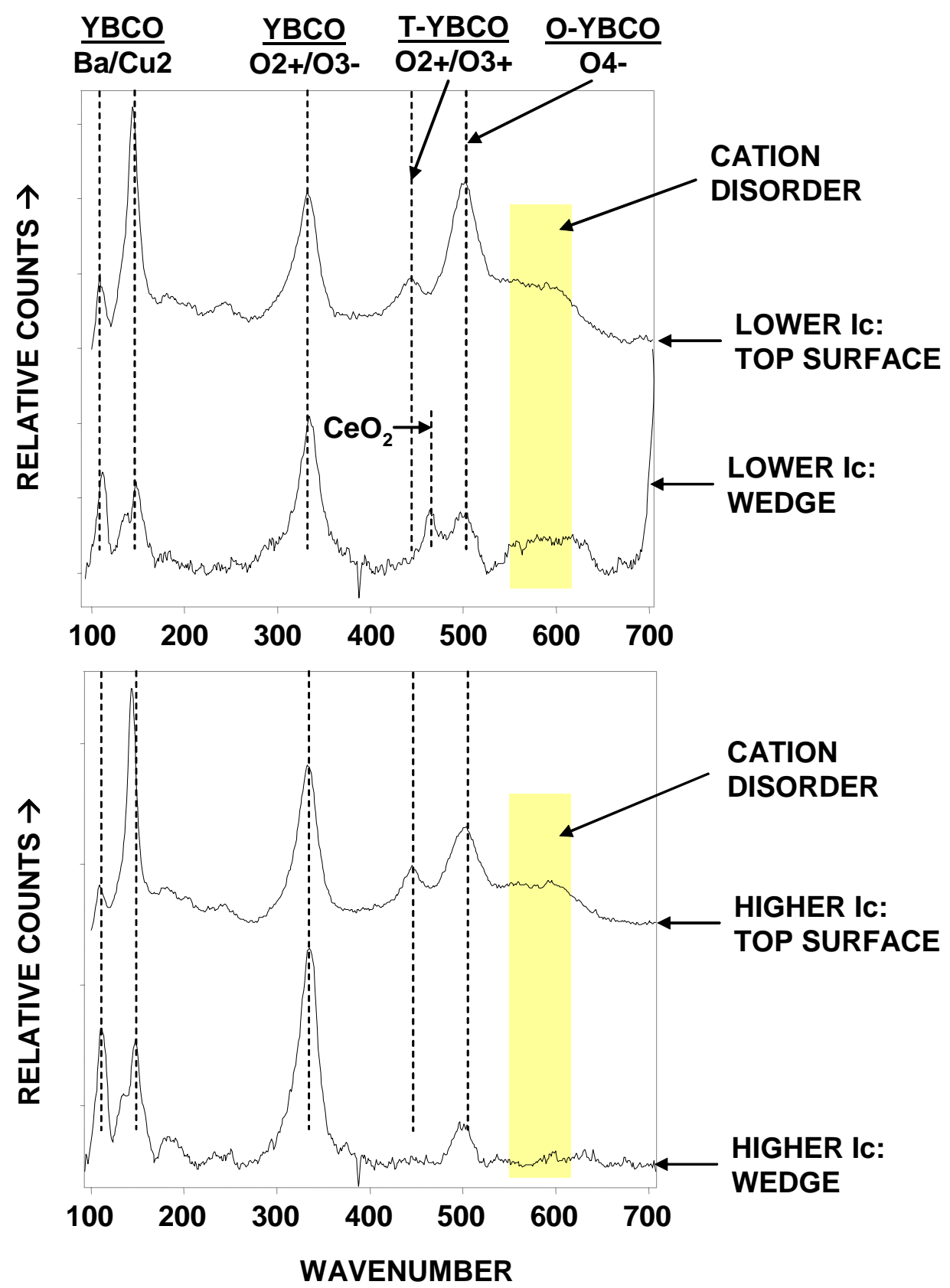

FIGURE 5 Representative Raman spectra of the top surface and of typical wedge surfaces for the lower and higher Ic segments. 
geometry used to make these measurements (i.e., laser propagation path parallel to the YBCO $\mathrm{c}$-axis $[4,5])$ indicates that some of the YBCO grains have severely tilted c-axes. Comparison of the intensity of the $\mathrm{O} 4$ mode with that of the $335 \mathrm{~cm}^{-1} \mathrm{O} 2+/ \mathrm{O} 3-$ mode of YBCO provides a means of gauging the relative amount of c-axis tilted grains [4]. It is clear in Fig. 5 that the top surface Raman spectra show a greater relative intensity of the $\mathrm{O} 4$ mode than do the wedge surface spectra for both the lower Ic and the higher Ic segments, indicating that there are more tilted YBCO grains in the top layer than there are on average (through thickness) for both segments. It is also apparent from these two sets of Raman spectra that the YBCO near the top surface contains some phase-separated tetragonal YBCO, as is evidenced by the reduced intensity of the $\mathrm{Ba}$ mode, the appearance of the $\mathrm{O} 2+/ \mathrm{O} 3+$ mode of tetragonal $\mathrm{YBCO}$, and the somewhat lower frequency of the $\mathrm{Cu} 2$ mode [4,5] in the top-surface Raman spectra for both segments. The reason(s) for this apparent depletion of oxygen in the YBCO lattice near the top of the film are under investigation. Possible causes that are being investigated include the etching process used to remove silver cap layers prior to Raman study, sample warming during the FIB milling process, and the influence of near-surface orthorhombic/tetragonal phase separation on oxygen incorporation into the YBCO lattice.

An additional observation made in the course of studying the higher and lower Ic segments of the sample discussed above is that there is also SEM/EDS and Raman evidence for minor but detectable amounts of residual carbon phases in MOCVD-produced YBCO films. In post-MOCVD films, the carbon appears to be amorphous/soot-like; in post-oxygenated films, carbonate is occasionally observed. Figure 6 contains a collection of Raman and SEM/EDS data that exemplify the manifestations of carbon seen in the course of $\mathrm{C}^{4}$ examinations of MOCVDcoated conductor specimens. For example, the EDS spectrum in the upper right inset confirms the presence of carbon. The series of Raman spectra (left inset) show (a) evidence for $\mathrm{BaCO}_{3}$ in one location, (b) a location where amorphous carbon bands are observed, (c) a location that appears to be free of carbon phases, and (at the bottom of the inset) the difference spectrum obtained after normalized scaling of spectra (b) and (c) followed by subtraction of spectrum (c) from spectrum (b). (The " $X$ " marks show the normalization points for the scaling process.) The residual spectral features in the difference spectrum between 1100 and $1700 \mathrm{~cm}^{-1}$ resemble spectra that are typically observed for various forms of amorphous carbon. The surface and cross-section SEM images reveal the presence of "volcano"-like tubes that erupt upward away from the substrate surface, possibly evidencing the escape of gas (e.g., $\mathrm{CO}_{2}$ ) during oxygenation of the post-MOCVD YBCO product. In the coming year, extensive analytical measurements will be made to determine the amount, type, and source of carbon in the MOCVD YBCO films produced by SuperPower.

In collective summary of the $C^{4}$ examinations of SuperPower's long-length MOCVDcoated conductor tapes performed in FY 2005 at Argonne, it is generally apparent that the MOCVD-type deposition process produces a dense (low porosity), uniform YBCO film. These films, whether deposited in a single pass through the MOCVD chamber or by multi-pass layering, show domains of columnar YBCO grain growth (a-axis grains) that increase in number through thickness from the substrate surface to the topmost layer. Grain boundary connectivity appears to be well developed, with little tangible evidence of meandering boundaries. Carbon-containing phases, possibly residues from the precursor pyrolysis reaction, are observed in a uniformly 


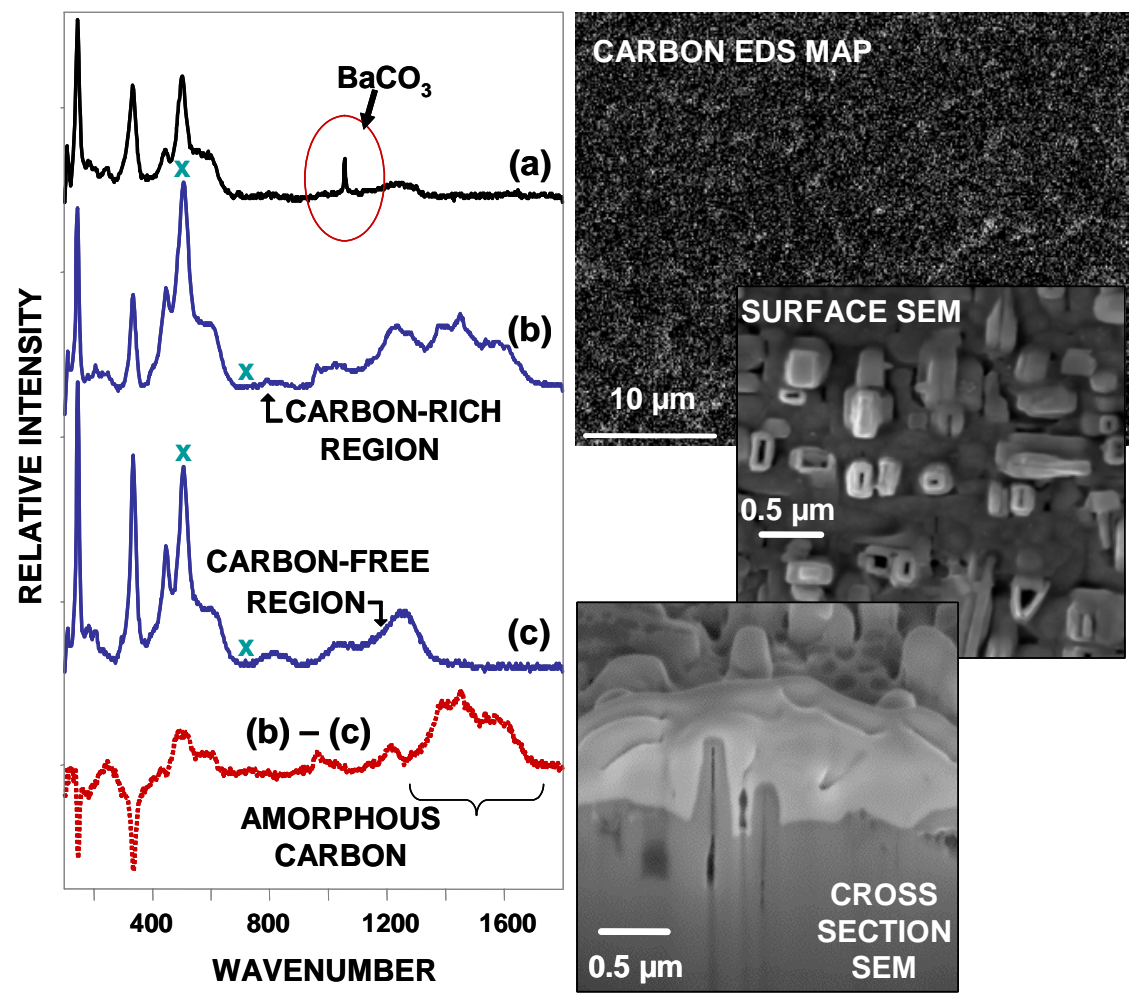

FIGURE 6 Upper Right Inset: Carbon EDS map of a typical postMOCVD-deposited YBCO film surface. Lower Right Insets: SEM images (surface and cross section) of the volcano-like eruptions observed in some regions of MOCVD-deposited YBCO films. Left Inset: Raman spectra obtained from selected regions of MOCVD product films.

distributed pattern throughout most of the films examined at Argonne to date. The extent to which these carbonaceous residues have any adverse effect on the performance of the MOCVDcoated conductor manufactured by SuperPower is currently under investigation.

\subsection{MOD COATED CONDUCTORS}

FY $2005 \mathrm{C}^{4}$ efforts on the MOD/RABiTS-coated conductor being developed by American Superconductor (AMSC) [3] were directed at elucidating the mechanisms of flux pinning in MOD YBCO thin films. This work involved close cooperation between AMSC and Argonne staff, wherein dozens of tape specimens produced at AMSC were forwarded to Argonne for comprehensive examination of micro-structural, phase composition, and texture characteristics. These characteristics were compared/contrasted with the measured in-field current carrying properties of the respective samples to identify the key process-related variables that promote flux pinning. A major point of emphasis has involved the determination of factors that influence the field angle dependence of flux pinning in YBCO thin films, with emphasis on uniformly enhancing flux pinning at all field angles. 
Numerous studies (by many groups worldwide) spanning more than a decade have shown that the addition of rare earth oxides to YBCO generally leads to measurable increases in the flux pinning strength when the conductor is placed in a magnetic field $(\mathrm{H})$. Extensive studies conducted by AMSC in conjunction with scientists at Los Alamos National Laboratory (LANL) on their MOD-type YBCO films on RABiTS substrates revealed that the while the addition of certain rare earth cations (e.g., $\mathrm{Er}^{3+}$ ) to their MOD precursor improved the current-carrying capacity (Ic in A/cm-width) in the $\mathrm{H} / / \mathrm{c}$ configuration, the value of Ic in the $\mathrm{H} / / \mathrm{ab}$ configuration dropped off relative to that of rare-earth-free MOD YBCO films. The $\mathrm{C}^{4}$ work on these types of samples at Argonne has focused on developing an understanding of what influences the angular dependence of flux pinning in the absence and presence of added rare earth cations.

The data in Fig. 7 (measured by Civale et al. at LANL) illustrate how $\mathrm{Er}^{3+}$ additions affect the Ic of MOD YBCO films as a function of angle with respect to the magnetic field direction. With increasing $\mathrm{Er}^{3+}$ addition, the Ic concurrently increases in the $\mathrm{H} / / \mathrm{c}$ configuration while decreasing in the $\mathrm{H} / / \mathrm{ab}$ configuration. SEM images of FIB-cut cross sections from these samples (see Fig. 8) reveal how the number of non-superconducting precipitates (the nominally spherical white nano-dots in the Fig. 8 images) increases with increasing $\mathrm{Er}^{3+}$ addition. But, TEM measurements (see Fig 9) show that while the number of precipitates in the flux-pinningeffective size domain does indeed increase with increasing $\mathrm{Er}^{3+}$ addition, there is a corresponding decrease in the number of planar defects (indicated by the white arrow heads in Fig. 9). The results of a numerical analysis of the relative number of planar defects as a function of $\mathrm{Er}^{3+}$ addition performed on TEM images for the $0 \%, 25 \%$, and $50 \% \mathrm{Er}^{3+}$-added samples are tabulated

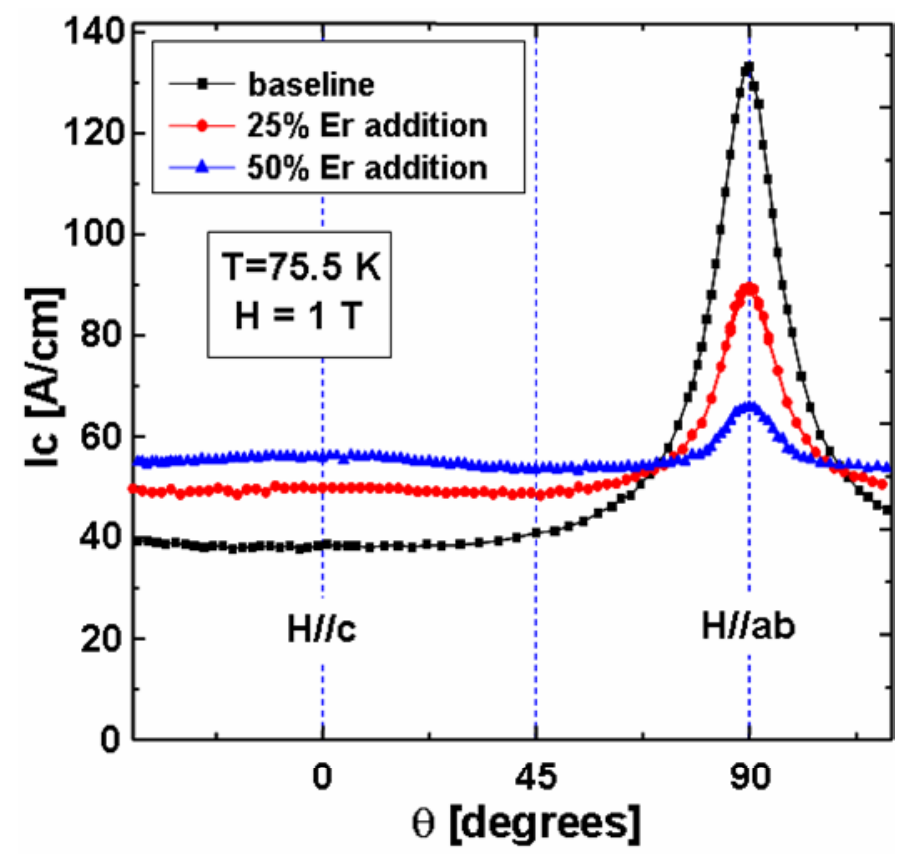

FIGURE 7 Plot of Ic versus magnetic field angle (at 75.5 $\mathrm{K}$ and 1 Tesla) for MOD YBCO films containing various amounts of added $\mathrm{Er}^{3+}$. (Data courtesy of $\mathrm{L}$. Civale et al., LANL.) 


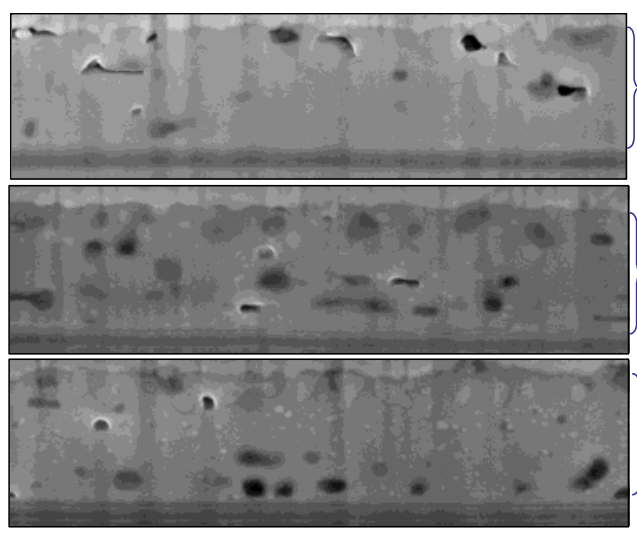

0\% Er Added

$56 \mathrm{~A} / \mathrm{cm}-\mathrm{w}$ at $65 \mathrm{~K}, 2 \mathrm{~T}$

(baseline)

$25 \%$ Er Added

$81 \mathrm{~A} / \mathrm{cm}-\mathrm{W}$ at $65 \mathrm{~K}, 2 \mathrm{~T}$

$50 \%$ Er Added

$100 \mathrm{~A} / \mathrm{cm}-\mathrm{W}$ at $65 \mathrm{~K}, 2 \mathrm{~T}$

$0.5 \mu \mathrm{m}$

FIGURE 8 SEM images of a FIB-cut cross sections from $0 \%, 25 \%$, and $50 \% \mathrm{Er}^{3+}$-added MOD samples produced by American Superconductor. Note the increase in Ic value with increasing $\mathrm{Er}^{3+}$ addition.

0\% Er ADDED

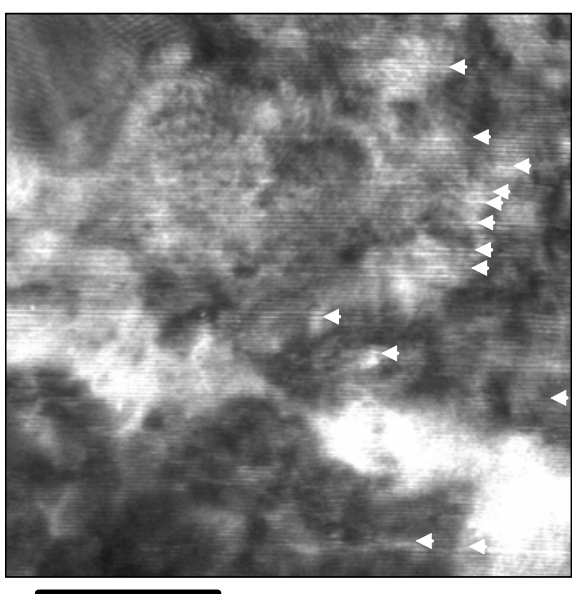

$50 \mathrm{~nm}$
$50 \%$ Er ADDED

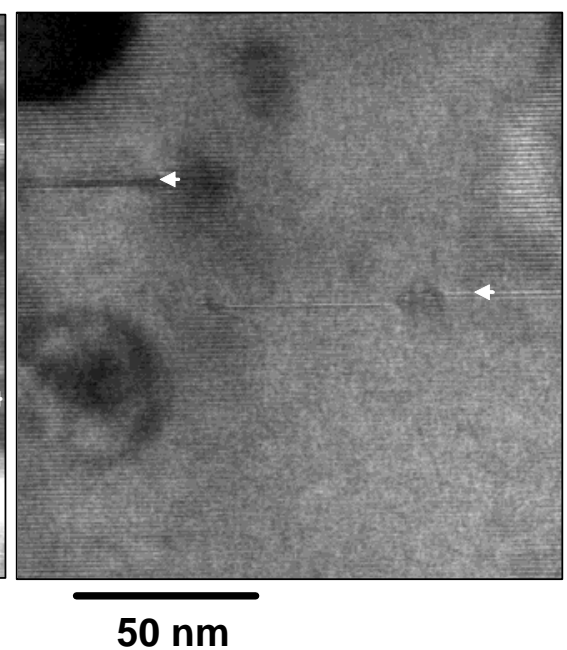

FIGURE 9 TEM images of representative domains in FIB-cut cross sections of the $0 \%$ and $50 \% \mathrm{Er}^{3+}$-added specimens. The white arrow heads mark the locations of planar defects. 
in Table 1. The presumption here is that the planar defects enhance $\mathrm{H} / / \mathrm{ab}$ pinning, while the second phase nano-dots enhance $\mathrm{H} / / \mathrm{c}$ pinning. Ideally, one wants to inoculate the YBCO matrix with nano-dots without simultaneously losing the planar defect structure. The reason(s) for the fall-off in the number of planar defects with increasing $\mathrm{Er}^{3+}$ addition is a matter that requires conclusive investigation.

Energy filtered TEM (EFTEM) examination of the $\mathrm{Er}^{3+}$-added specimens performed in conjunction with high-precision EDS shows conclusively that the nano-dots are composed of $(\mathrm{Y}, \mathrm{Er})_{2} \mathrm{O}_{3}$, and that the $\mathrm{Er}^{3+}$ content in the $\mathrm{YBCO}$ matrix tends to increase with increasing $\mathrm{Er}^{3+}$ addition. This is demonstrated in Fig. 10, which shows the Y/Er and Ba EFTEM maps of the superconducting phase (the "matrix") for the $50 \% \mathrm{Er}^{3+}$-added sample, together with EDS spectra of the matrix for all three samples listed in Table 1 (normalized to the $\mathrm{Cu}-\mathrm{k} \alpha$ line). Note the concurrent increase in the Er line intensity and the decrease in the $\mathrm{Y}$ line intensity relative to the $\mathrm{Cu}-\mathrm{k} \beta$ intensity with increasing Er addition.

Figure 11 presents SEM images and EDS maps taken from the surfaces of the $25 \%$ and $50 \% \mathrm{Er}^{3+}$-added specimens together with similar images for a $100 \% \mathrm{Er}^{3+}$-added specimen. These images show that with progressively increasing $\mathrm{Er}^{3+}$ addition, the excess $\mathrm{Er}+\mathrm{Y}$ tends to segregate to the grain boundaries. The inset in the upper right corner of Fig. 11 is a plot of how the Ic varies with $\mathrm{Er}^{3+}$ addition at $65 \mathrm{~K}$ and $\mathrm{H}=2 \mathrm{~T}$. Note that Ic drops off for $\mathrm{Er}^{3+}$ additions greater than $50 \%$, indicating that the beneficial effect of rare earth addition eventually reverses, presumably because of the extensive $(\mathrm{Y}, \mathrm{Er})_{2} \mathrm{O}_{3}$ grain boundary segregation and related microstructural effects.

Raman spectra of the $\mathrm{Er}^{3+}$-added series of samples also produced some interesting insights. In addition to the normal first order Raman spectrum of MOD YBCO typically observed in $\mathrm{C}^{4}$ investigations [4-5], a crystal field excitation (CFE) spectrum of the $\mathrm{Er}^{3+}$ in the $(\mathrm{Y}, \mathrm{Er})_{2} \mathrm{O}_{3}$ nano-dots was also detected. This effect is shown in Fig. 12, which presents Raman spectra for (top to bottom) $\mathrm{ErBa}_{2} \mathrm{Cu}_{3} \mathrm{O}_{7-\mathrm{X}}$ (ErBCO), YBCO with 50\% added $\mathrm{Er}^{3+}$, $\mathrm{Y}_{0.5} \mathrm{Er}_{0.5} \mathrm{Ba}_{2} \mathrm{Cu}_{3} \mathrm{O}_{7-\mathrm{X}}$, and $\mathrm{Er}_{2} \mathrm{O}_{3}$. The spectral features observed for pure $\mathrm{Er}_{2} \mathrm{O}_{3}$ are part of the CFE spectrum for $\mathrm{Er}^{3+}$ cations on non-centrosymmetric $\mathrm{C}_{2}$ sites of the $\mathrm{Er}_{2} \mathrm{O}_{3}$ lattice [6]. (This particular CFE spectrum emanates from the $\mathrm{Er}^{3+}{ }^{4} \mathrm{~F}_{9 / 2}$ state [6a].) The same CFE spectral features are evident in the Raman spectrum of $\mathrm{Y}_{0.5} \mathrm{Er}_{0.5} \mathrm{Ba}_{2} \mathrm{Cu}_{3} \mathrm{O}_{7-\mathrm{X}}$, indicating the presence of some second phase $(\mathrm{Er}, \mathrm{Y})_{2} \mathrm{O}_{3}$ crystallites in the film microstructure. The $\mathrm{Er}^{3+} \mathrm{CFE}$ spectrum is much stronger in the case of $\mathrm{YBCO}$ with $50 \%$ added $\mathrm{Er}^{3+}$ as expected because of the appreciable

TABLE 1 Planar defect density and spacing as a function of $\mathbf{E r}^{3+}$ addition

\begin{tabular}{cccc}
\hline \% Er Added & $\begin{array}{c}\text { Number of Planar } \\
\text { Defects per } \mathbf{~} \mathbf{m}\end{array}$ & $\begin{array}{c}\text { Average Spacing } \\
\mathbf{( n m )}\end{array}$ & $\begin{array}{c}\text { Standard } \\
\text { Deviation }\end{array}$ \\
\hline & & & \\
0 & 64 & 16 & 4 \\
25 & 24 & 42 & 11 \\
50 & 9 & 111 & 29 \\
\hline
\end{tabular}



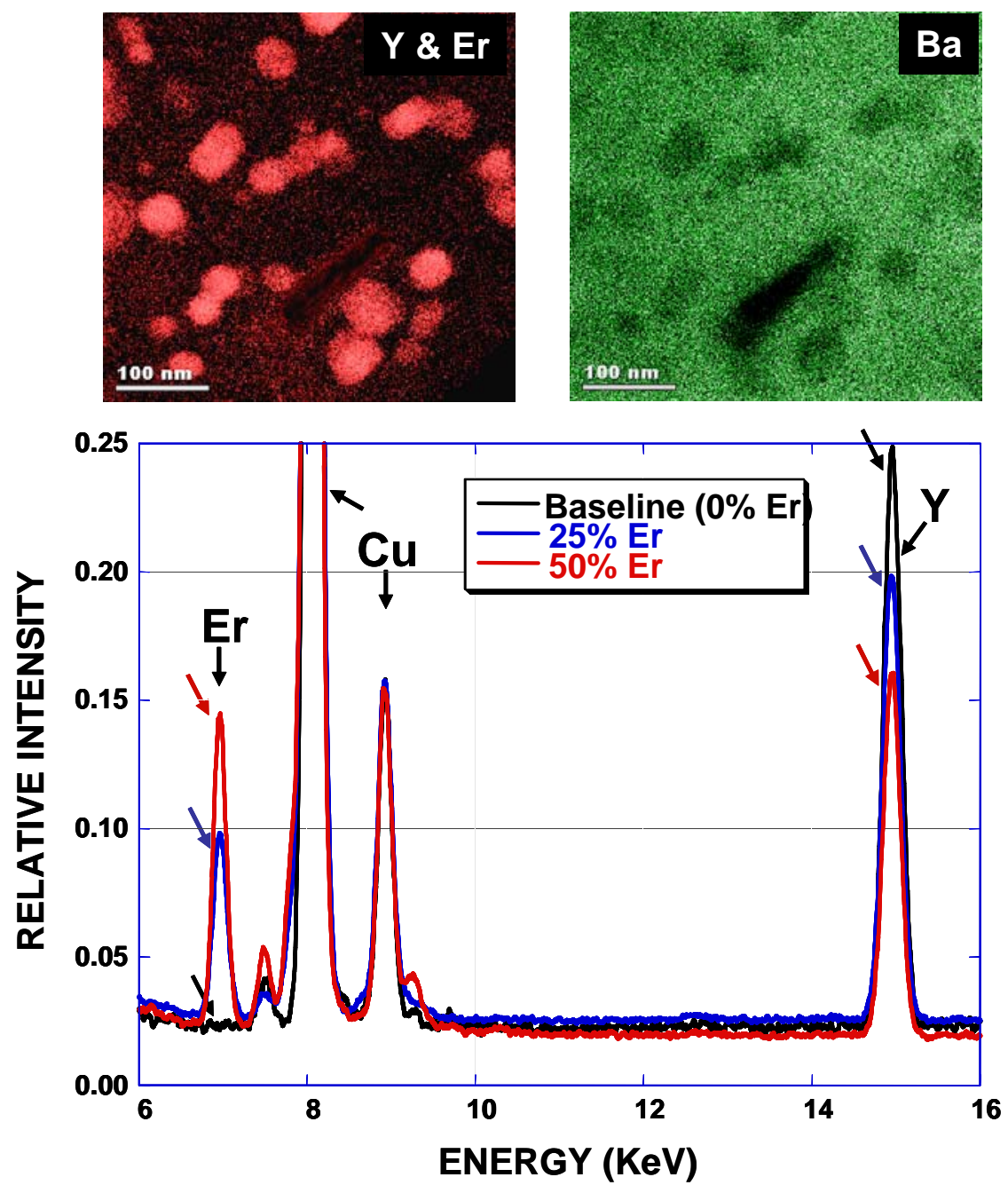

FIGURE 10 Top Insets: Energy filtered TEM images showing the distribution of Y/Er and Ba in a typical $\mathrm{Er}^{3+}$-added MOD-type YBCO film produced by American Superconductor. Note that the Y/Er are prominent in the nano-dot precipitates, whereas Ba and also Cu (map comparable to the Ba map) are not. Bottom: EDS spectra of samples in Table 1.

amount of $(\mathrm{Er}, \mathrm{Y})_{2} \mathrm{O}_{3}$ that separates out as second phase nano-dots (per Figs. 8 and 10). The absence of the CFE spectral features for $\mathrm{ErBa}_{2} \mathrm{Cu}_{3} \mathrm{O}_{7-\mathrm{X}}$ gives several important pieces of information. First of all, it implies that the ErBCO contains little or no $\mathrm{Er}_{2} \mathrm{O}_{3}$ precipitates. Secondly, it shows that the CFE features observed for $\mathrm{Y}_{0.5} \mathrm{Er}_{0.5} \mathrm{Ba}_{2} \mathrm{Cu}_{3} \mathrm{O}_{7-\mathrm{X}}$ and for $\mathrm{YBCO}$ with $50 \%$ added $\mathrm{Er}^{3+}$ are not attributable to $\mathrm{Er}^{3+}$ cations in the superconducting phase. An additional strong implication of these results is that there are very few (if any) $\mathrm{Er}^{3+}$ cations on noncentrosymmetric sites (e.g., $\mathrm{Cu} 2$ or $\mathrm{Ba}$ sites) in the $\mathrm{MBCO}$ lattice. $\mathrm{Er}^{3+}$ cations on such noncentrosymmetric sites would be expected to generate a $\mathrm{CFE}$ signature that is distinguishable from that of $\mathrm{Er}_{2} \mathrm{O}_{3}$. 


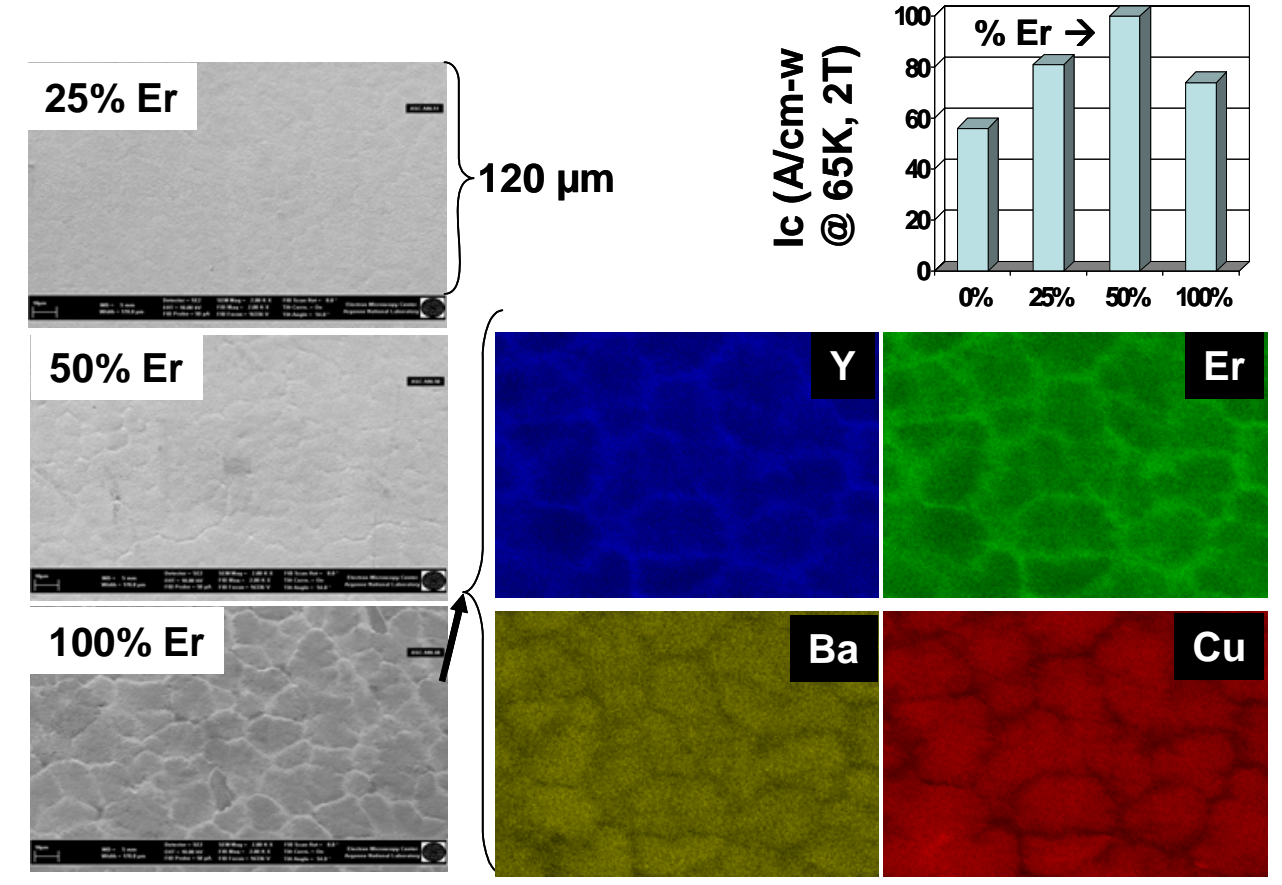

FIGURE 11 Left Side Insets: SEM images of the surface of three $\mathrm{Er}^{3+}$ added MOD-type YBCO films. Note the increasing grain boundary segregation of precipitates with increasing $\mathrm{Er}^{3+}$ addition. Lower Right Quadrant Insets: Y, Er, Ba, and Cu EDS maps for the $100 \% \mathrm{Er}^{3+}$-added sample showing that the grain boundary precipitates are predominantly $(\mathbf{Y , E r})_{2} \mathrm{O}_{3}$.

In summary, FY 2005 measurements performed on specimens of the MOD/RABiTS-type YBCO coated conductor indicated that the precursor formulation and processing conditions being explored by AMSC produce a variety of second phase chemistries and microstructures. Specifically, $\mathrm{C}^{4}$ examination of samples with and without added $\mathrm{Er}^{3+}$ shows that $\mathrm{Er}^{3+}$ addition leads to $(\mathrm{Y}, \mathrm{Er})_{2} \mathrm{O}_{3}$ nano-dot precipitates in the (Y,Er)BCO matrix, but with a corresponding steady decrease in the number of planar defects as the $\mathrm{Er}^{3+}$ content is increased. 


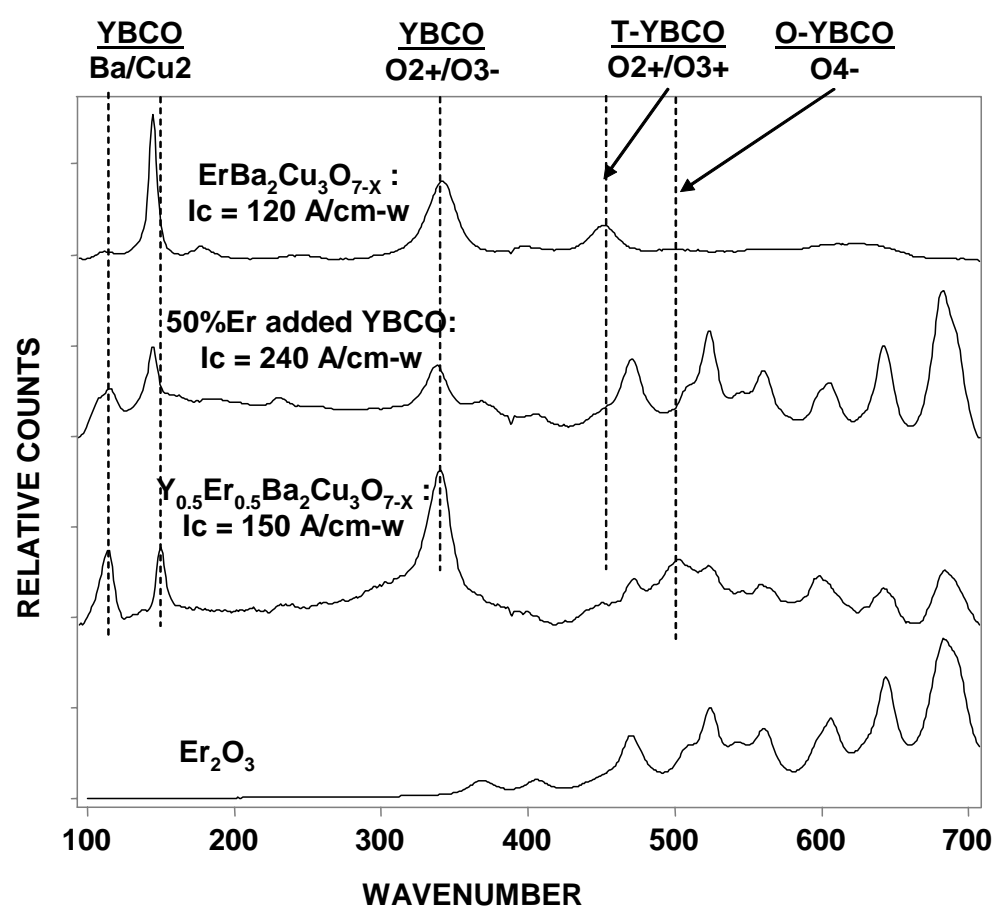

FIGURE 12 Raman spectra of (top to bottom) $\mathrm{ErBa}_{2} \mathrm{Cu}_{3} \mathrm{O}_{7-\mathrm{x}}$, YBCO containing $50 \%$ added $\mathrm{Er}^{3+}, \mathrm{Y}_{0.5} \mathrm{Er}_{0.5} \mathrm{Ba}_{2} \mathrm{Cu}_{3} \mathrm{O}_{7-\mathrm{X}}$, and $\mathrm{Er}_{2} \mathrm{O}_{3}$. The spectral features in the $\mathrm{Er}_{2} \mathrm{O}_{3}$ spectrum are due to crystal field excitations associated with the ${ }^{4} \mathbf{F}_{9 / 2}$ state of $\mathrm{Er}^{3+}$. Note that these same features also appear in the Raman spectra of the $\mathrm{YBCO}$ plus $50 \%$ added $\mathrm{Er}^{3+}$ sample and the $\mathbf{Y}_{0.5} \mathrm{Er}_{0.5} \mathrm{Ba}_{2} \mathrm{Cu}_{3} \mathrm{O}_{7-\mathrm{X}}$ sample. 


\section{REVERSIBLE OXIDATION OF THE YBCO COATED CONDUCTOR}

It is well established that doping of grain boundaries (GBs) by calcium or oxygen greatly affects the critical current $\left(\mathrm{I}_{\mathrm{c}}\right)$ in $\mathrm{YBa}_{2} \mathrm{Cu}_{3} \mathrm{O}_{\mathrm{x}}$ (YBCO) films containing grain boundaries [7-11]. The highest critical current across GBs is observed at the highest doping level. This behavior has also been observed for oxygen doping of single-crystal YBCO films [12]. Calcium doping also improves the critical current of coated conductors [13]. In FY 2005, a systematic study was performed to determine how the oxygen doping level affects the critical current of coated conductors. A contact-free method was used to measure the critical current of a ring sample, in order to demonstrate the hypothesis that in the over-doped regime, where the transition temperature decreases by as much as $4 \mathrm{~K}$ with increasing doping, the critical current continues to increase, reaching its maximum in the most over-doped state.

\subsection{EXPERIMENTAL PROCEDURES}

The coated conductor used in this study was fabricated by the inclined substrate deposition (ISD) method [14]. A biaxially textured ISD-MgO film $\approx 1-\mu \mathrm{m}$ thick, acting as template film, was deposited on a non-textured polycrystalline Hastelloy C276 substrate by electron-beam evaporation at room temperature with an inclination angle of $55^{\circ}$. An additional $\approx 0.25$ - $\mu \mathrm{m}$-thick $\mathrm{MgO}$ film was grown epitaxially on top of the ISD layer at elevated temperature $\left(\approx 700^{\circ} \mathrm{C}\right)$ with zero inclination angle. $\mathrm{A} \mathrm{SrRuO}_{3}$ buffer layer and the YBCO film $(\approx 1.3-\mu \mathrm{m}$ thick) were deposited by pulsed laser deposition. Finally, a protective silver film of $\approx 2 \mu \mathrm{m}$ was deposited as a top layer by electron-beam evaporation. The result was a biaxially textured YBCO-coated conductor sample with c-axis tilted $\approx 32^{\circ}$ away from the substrate normal. Details of the fabrication conditions and layer-by-layer orientation relationship are reported elsewhere [15]. Primary oxygen annealing was carried out after the deposition of the silver layer at $450^{\circ} \mathrm{C}$ in 700 Torr oxygen for $1 \mathrm{hr}$, followed by slow cooling to room temperature in the same gas atmosphere.

For the measurements of the critical current, a 5-mm-diameter disk was core-drilled from a coated conductor sample. A ring, 4-mm OD and 3-mm ID, was then produced from the disk employing a stainless steel ring mask and a miniature sand blaster that removed all layers from the exposed part of the sample down to the substrate. The YBCO rings (with the protective Ag-cover intact) produced this way were very robust and survived many secondary heat treatments without any deterioration. The cross section of the ring was $1.33 \mu \mathrm{m} \times 0.5 \mathrm{~mm}=$ $6.65 \times 10^{-6} \mathrm{~cm}^{2}$.

The study of supercurrent transport was carried out using the persistent-current magnetization technique [16]. The screening of the applied field induces a supercurrent circulating around the ring and, thus, a magnetic moment that is proportional to the supercurrent. This technique was employed previously to investigate epitaxial film rings containing artificial GBs [10], as well as melt-textured rings with artificial GBs [16]. For small applied fields $(<5 \mathrm{mT})$, the measurements were performed in a non-commercial SQUID magnetometer [16], and at higher fields, in a commercial vibrating-sample magnetometer. The current distribution in 
the samples was determined by the MOI technique, which allows visualization of the flux patterns produced by the persistent current [17].

To change the oxygen concentration from the slightly under-doped to the well overdoped regime, the samples were oxygenated at various temperatures in the range $300^{\circ} \mathrm{C}$ to $550^{\circ} \mathrm{C}$ and quenched. This procedure worked well for YBCO single crystals and melt-textured samples $[12,18,19]$. However, for thin film samples the quenching procedure did not yield reproducible results, probably because the diffusion rates in thin films are high compared to the quenching rate so that the oxygen concentration of the films changed during quenching. To circumvent this problem, a novel scheme was devised for the secondary oxygenation of thin film samples. A container with a tight lid was fabricated from porous melt-textured YBCO. The oxygen concentration of the container was then fixed to that desired for the film by giving it the appropriate oxygenation treatment. The thin film was then placed inside the container, and the loaded container was placed in the furnace under the same oxygenation condition that the container was exposed to originally. The annealing time that was found to be sufficient for the film to come in equilibrium with the container was between 1 hour and 1 day, depending on the temperature. The loaded container was then quenched in liquid nitrogen. In this way, it was possible to reversibly change the oxygen concentration of a single coated-conductor sample from the under-doped to the over-doped regime and back.

\subsection{LOW MAGNETIC FIELD MEASUREMENTS}

Initial measurements focused on the variation and reversibility of the superconducting transition temperature, $\mathrm{T}_{\mathrm{C}}$, with oxygen doping. Figure 13 shows the superconducting transition of the ring in a magnetic field of $1 \mu \mathrm{T}$ (parallel to the ring axis) after oxygenation at various temperatures. The lowest $\left(\mathrm{T}_{\mathrm{C}}=87.4 \mathrm{~K}\right)$ is obtained for the lowest oxygenation temperature, i.e., the highest oxygen concentration. As the oxygenation temperature is increased, $\mathrm{T}_{\mathrm{C}}$ increases up to $91.2 \mathrm{~K}$ after $450^{\circ} \mathrm{C}$ oxygenation. Oxygenation above $450^{\circ} \mathrm{C}$ causes $\mathrm{T}_{\mathrm{C}}$ to decrease again (under-doped state). Most of the superconducting transitions in Fig. 13 are very narrow (only a few tens of a degree wide) indicating that the sample is very homogeneous. After quenching from 475 and also $500^{\circ} \mathrm{C}$ some broadening is observed, presumably because the quench process is not fast enough relative to the oxygen diffusion rate at these high temperatures. Also shown in Fig. 13 is the transition of the as-made state. This transition is identical with the transition obtained after the $300^{\circ} \mathrm{C}$ oxygenation (not shown), indicating that the oxidation in the pulsedlaser-deposition chamber produces samples with a very high degree of over-doping. The almost $4 \mathrm{~K}$ variation in $\mathrm{T}_{\mathrm{C}}$ from the optimally doped state to the most over-doped state reflects the high degree of over-doping that can be achieved for this sample. A similar variation in $\mathrm{T}_{\mathrm{C}}(91.2 \mathrm{~K}$ for the optimally doped state and $87.6 \mathrm{~K}$ for the most over-doped state) has been previously observed in high-quality YBCO single crystals [18]. However, the magnitude of the Tc suppression in the over-doped state depends on sample preparation method.

A separate investigation revealed that the magnitude of $\mathrm{T}_{\mathrm{C}}$ suppression in the over-doped state of single crystals depends on the nature of the crystal growth process. For example, in Au-doped YBCO single crystals, the decrease of $\mathrm{T}_{\mathrm{C}}$ in the over-doped regime depends 


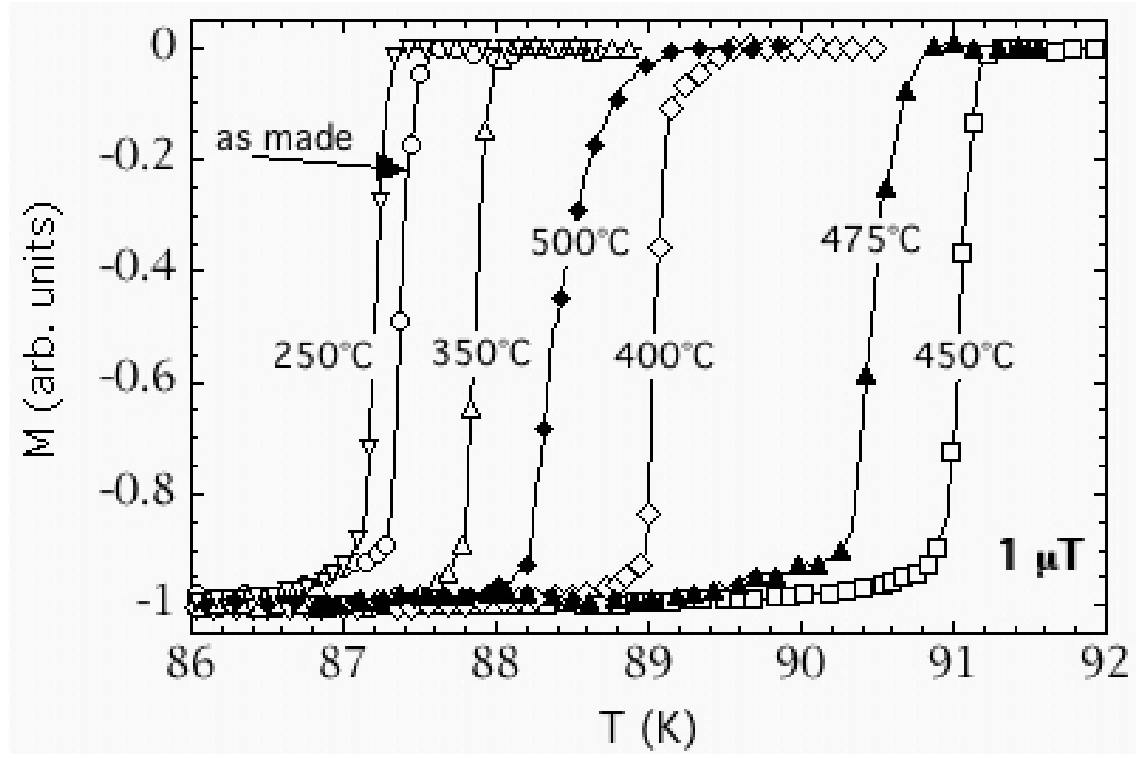

FIGURE 13 Superconducting transition of a coated conductor in the as-made state and after oxygenation at various temperatures. Open symbols are for oxygenation states in the over-doped regime: solid symbols, in the under-doped regime. The data were obtained during warming in a field of $1 \mu \mathrm{T}$ after initially cooling in zero field to low temperatures.

sensitively on the growth rate of the crystal [19]. At high growth rates, $\mathrm{T}_{\mathrm{C}}$ shows the typical maximum at the optimum doping level, whereas for low growth rates no such maximum is observed, with $\mathrm{T}_{\mathrm{C}}$ increasing monotonically with increasing oxygen concentration. The origin of this behavior is not understood today [19]. This sample-dependent over-doping behavior is probably related to the different amounts of $\mathrm{T}_{\mathrm{C}}$ suppression in the over-doped state for thin YBCO films, as reported in the literature.

To obtain information about the critical current of the ring sample, its magnetization was measured in various applied fields. Figure 14a displays typical SQUID magnetization measurements of the coated conductor ring (in a state after oxygenation at $300^{\circ} \mathrm{C}$ ). The ring is initially cooled in zero field to low temperature. A magnetic field, as indicated in the figure, is then applied, then the sample is warmed at a rate of about $0.3 \mathrm{~K} / \mathrm{min}$ while the magnetic moment of the current loop is monitored. At low temperatures, where the induced current is much smaller than the critical current of the ring, the induced persistent current is mainly concentrated near the outer rim of the ring, the penetration depth being determined by the temperature-dependent critical current density of the ring. The field is well shielded from the bore of the ring, and the flux enters only at its periphery. With increasing temperature (decreasing critical current) the current (and associated magnetic flux front) penetrates deeper and deeper into the ring. The inset (Fig. 14a, left side) shows a schematic of the ring, with $\boldsymbol{a}$ being the inner radius of the ring and $\boldsymbol{b}$ being the outer radius. The current flows in the part of the ring bounded by $\boldsymbol{b}$ and $\boldsymbol{r}$, with $\boldsymbol{r}$ decreasing with increasing temperature. The slight decrease in the magnitude of the magnetic 

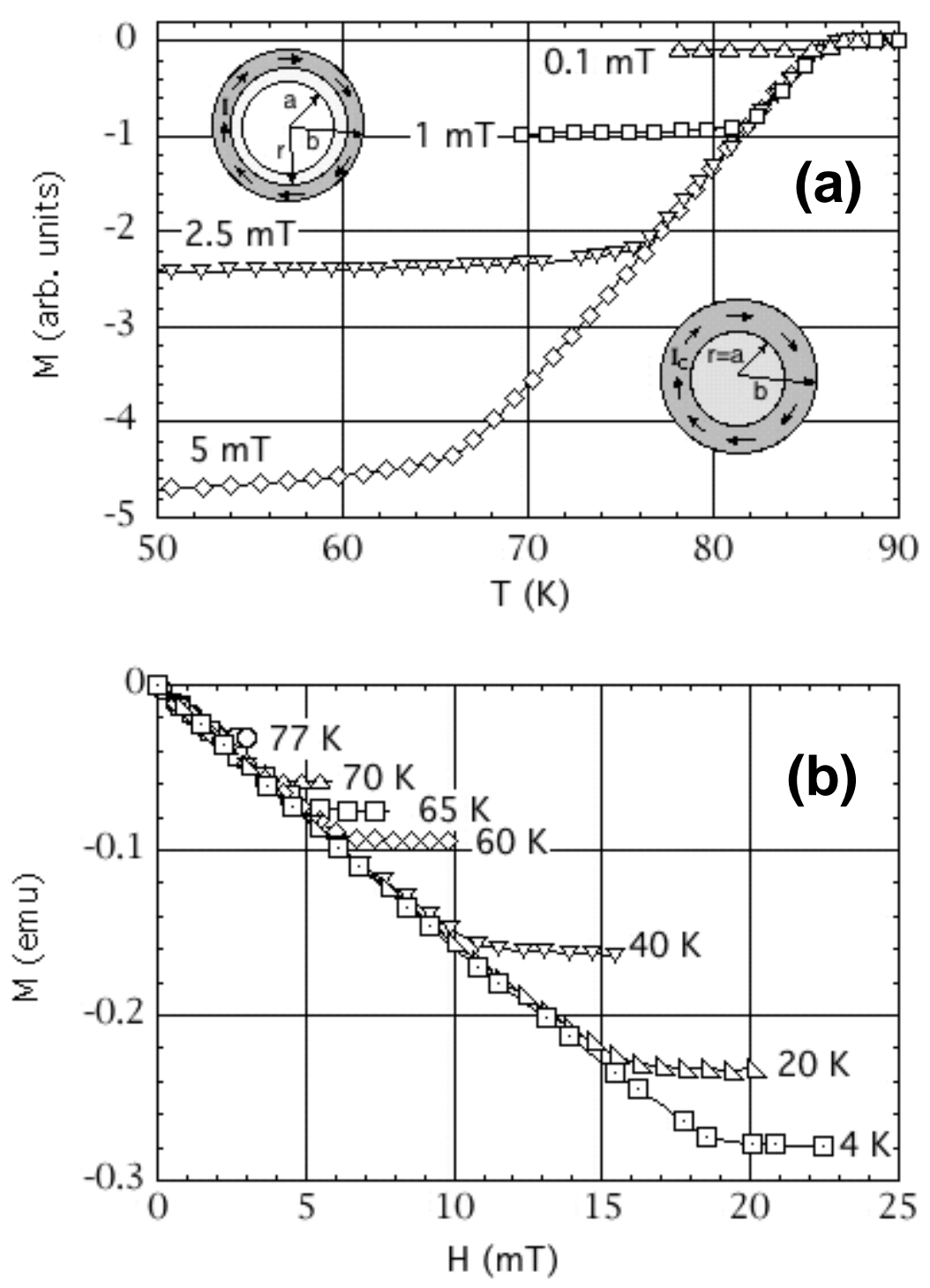

FIGURE 14 a. SQUID magnetization measurement of the sample in the $300^{\circ} \mathrm{C}$ oxygenation state. The data were obtained during warming in various magnetic fields, after initially cooling in zero field to low temperatures. The two insets schematically show the current flow in the ring at low and high temperatures (below and above the kink temperature) as explained in the text. $b$. VSM measurements of the sample in the same oxygenation state as in Fig. 14a. The data were taken with increasing field after initial cooling in zero field from above $T_{C}$ to the measurement temperature. 
moment in this regime is due to the decrease in the average diameter of the current loop, the total current remaining constant. Eventually, the flux front reaches the inner rim of the ring when $\boldsymbol{r}$ equals $\boldsymbol{a}$ (see the inset in Fig. 14a, right side). At that moment the field starts to penetrate into the bore of the ring. This event is reflected by the kink in Fig. 14a at about $66 \mathrm{~K}$ for the $5 \mathrm{mT}$ curve. At the kink temperature, the current induced by the applied magnetic field equals the critical current of the ring at this temperature. At temperatures above the kink, the critical current of the ring now limits the circulating current. This critical current decreases monotonically with increasing temperature, giving rise to a monotonically decreasing magnetic moment. In smaller applied fields, the induced current at low temperatures is accordingly smaller, and the kink therefore occurs at a correspondingly higher temperature. To obtain the kink temperatures in very small fields, it is more convenient to plot magnetic moment versus field (M versus $H$ ), instead of versus temperature (T). This way the kinks are easily identified down to $1 \mu \mathrm{T}$ and below.

The highest field available in the low-field SQUID magnetometer was $5 \mathrm{mT}$. To follow the critical current to lower temperatures (higher critical currents), measurements were performed with a VSM magnetometer. Here, it is more convenient to measure $\mathrm{M}$ versus $\mathrm{H}$ at constant temperature, as shown in Fig. 14b. After cooling each time in zero field from above $\mathrm{T}_{\mathrm{C}}$ to the temperature chosen, the magnetic field was increased by discrete steps between $0.15 \mathrm{mT}$ (corresponding to the smallest current step of $1 \mathrm{~mA}$ of the power supply) and $1 \mathrm{mT}$, depending on the temperature. After each field step, the magnetic field was allowed to stabilize for a period of 5 to 20 seconds before the magnetization was recorded. With increasing magnetic field, the induced persistent current and the associated magnetic moment of the current loop increased. This increase ends abruptly when the induced current equals the critical current of the ring at the temperature of the measurement. This change is reflected by a sharp kink in the magnetization curve. At fields above the kink, the circulating persistent current remained constant was equal to the critical current of the ring. Continued increase of the magnetic field above the range shown here would eventually suppress the critical current, and the magnetic moment would decrease accordingly (see below).

To obtain the critical current of the ring, the current induced by the applied magnetic field was determined using the formula derived by Brandt et al. [20] for narrow thin films:

$$
\mathrm{I}=\pi \mathrm{RH} /(\ln (8 \mathrm{R} / \mathrm{w})-0.5)
$$

where $\mathrm{R}$ is the mean radius of the ring, $\mathrm{w}$ the width of the ring, and $\mathrm{H}$ the applied field. For the ring geometry used in the present study, this yields a current of I $(\mathrm{A})=1.55 \times \mathrm{H}(\mathrm{mT})$. If the current is distributed uniformly across the ring, which happens at the kink temperature, this yields a current density $\mathrm{J}\left(10^{6} \mathrm{~A} / \mathrm{cm}^{2}\right)=0.23 \times \mathrm{H}(\mathrm{mT})$. For example, in $5 \mathrm{mT}$ the kink in $\mathrm{M}$ versus $\mathrm{T}$ in Fig. $14 \mathrm{a}$ occurs at $66 \mathrm{~K}$. Thus, the critical current at $66 \mathrm{~K}$ is $\mathrm{I}_{\mathrm{C}}=1.55 \times 5 \mathrm{~A}=7.8 \mathrm{~A}$, and the critical current density $\mathrm{J}_{\mathrm{C}}=1.15 \times 10^{6} \mathrm{~A} / \mathrm{cm}^{2}$.

By combining the VSM with the SQUID measurements, it is possible to follow the critical current versus temperature over many orders of magnitude. Figure 15 displays the critical current determined from the measurements in Fig. 14 using the above Brandt formula. In the temperature range where the two experimental methods overlap, they yield identical results. 


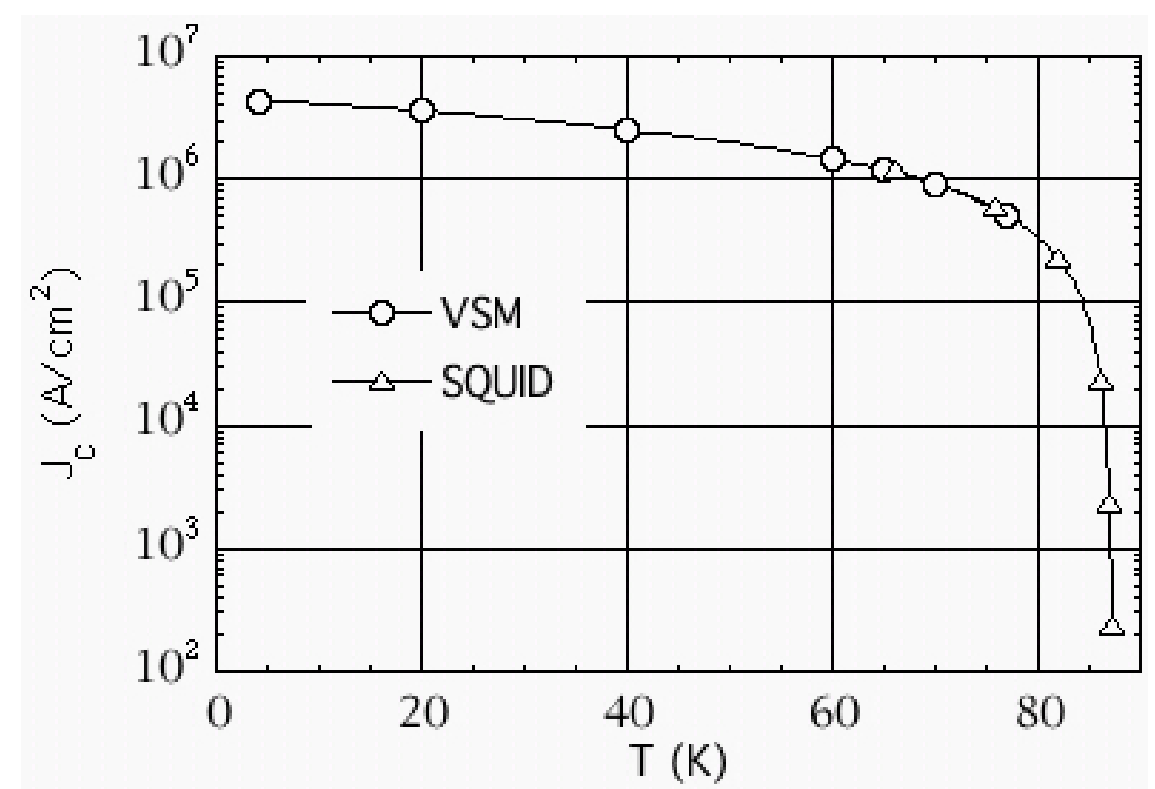

FIGURE 15 Critical current density of the sample in the $300^{\circ} \mathrm{C}$ state. The critical current density was obtained from the kink temperature and kink-field values in Fig. 14.

Alternatively, the induced current can be determined from the magnetic moment $\left(\mathrm{M}=\pi \mathrm{R}^{2} \mathrm{I}\right)$ it produces. The latter values for the critical current are about $20 \%$ lower than the ones obtained from the Brandt formula. This relatively small difference could be due to the fact that the VSM was calibrated with a Ni cylinder, not a thin-film ring. Also, the formula used by Brandt to calculate the induced current is an approximation for a very narrow ring [20].

Measurements like those presented in Fig. 14 were performed at all oxidation states shown in Fig. 13. The results are summarized in Fig. 16. Figure 16a shows the critical current versus temperature in the as-made state and after oxygenation at various temperatures. A clear trend is apparent, the lower the oxidation temperature (i.e., the higher the oxygen concentration), the higher the critical current. The highest critical current is observed in the as-made state, which corresponds closely to the $300^{\circ} \mathrm{C}$ oxidation state. The critical current for the $250^{\circ} \mathrm{C}$ state (not shown) is identical to the as-made state. The crossover of the $\mathrm{J}_{\mathrm{C}}$ curves above $77 \mathrm{~K}$ is due to the proximity to $\mathrm{T}_{\mathrm{C}}$, which decreases with increasing oxygenation in the over-doped regime (see Fig. 13).

Figure $16 \mathrm{~b}$ shows a plot of $\mathrm{J}_{\mathrm{C}}$ at a given temperature versus the oxygenation temperature of the sample. The lines drawn through the data points are quadratic polynomial fits. Also shown is the superconducting transition temperature (solid points, right scale) determined from Fig. 13 (onset temperature). As the state of the sample is changed from under-doped (at high oxygenation temperatures) to over-doped (low oxygenation temperatures), $\mathrm{T}_{\mathrm{C}}$ displays the usual maximum at optimal doping. However, $\mathrm{J}_{\mathrm{C}}$ continues to increase with the maximum $\mathrm{J}_{\mathrm{C}}$ observed for the most over-doped state. This trend is reduced near $77 \mathrm{~K}$ and even reversed at $85 \mathrm{~K}$ due to the closeness of the measurement temperature to the decreasing $T_{C}$ in the over-doped regime. 

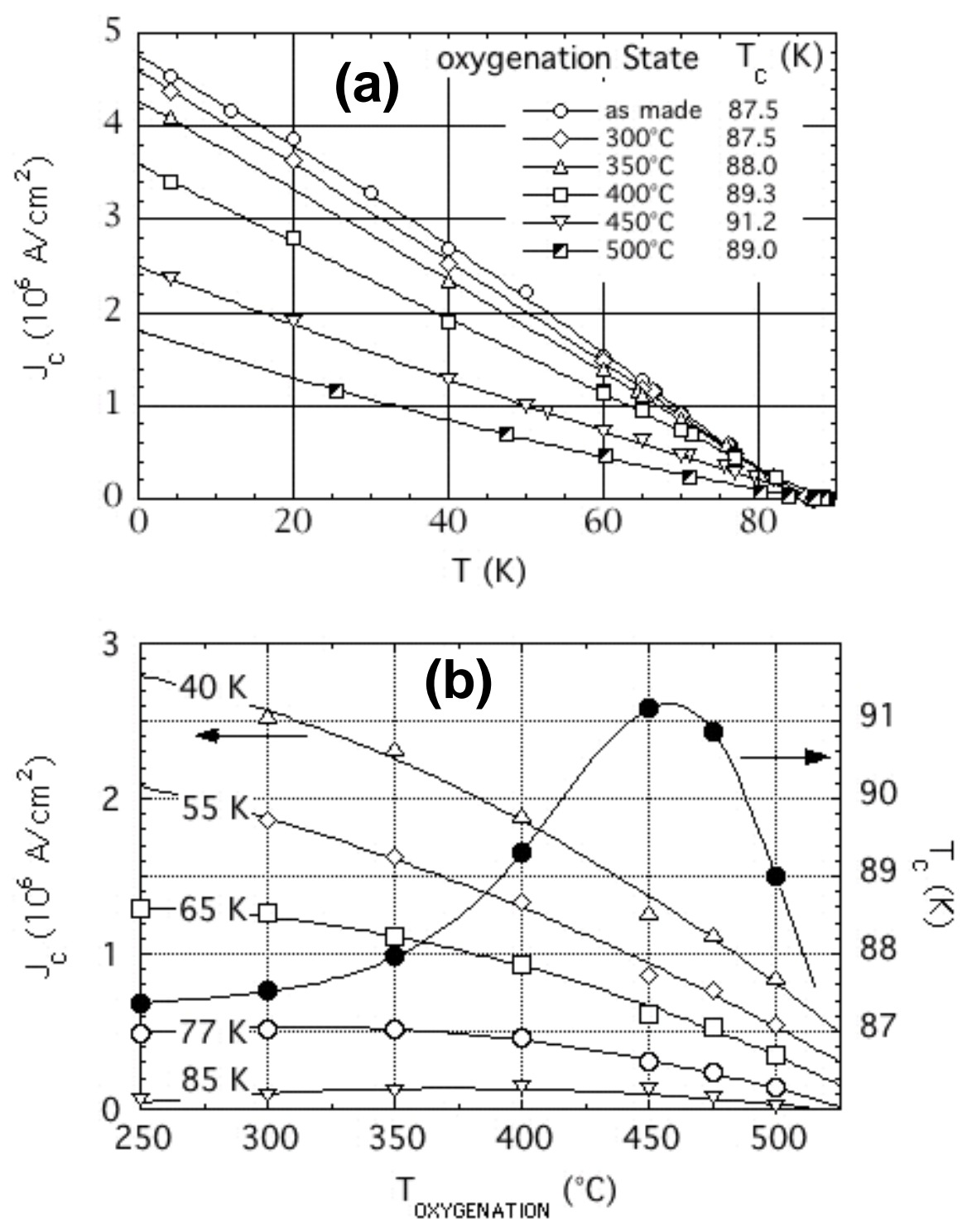

FIGURE 16 a. Critical current density versus temperature for the sample prepared in states with various oxygen concentrations, obtained by processing at various temperatures. The data were obtained from measurements like those in Figs. 14 and 15. b. Current density at various temperatures as function of the oxygenation temperatures. The $\mathbf{J}_{\mathrm{C}}$ data are obtained from Fig. 16a. Solid symbols represent $T_{C}$ versus oxygenation temperature (right scale), taken from Fig. 13. 
It is tempting to further increase the oxygen concentration beyond the level achieved so far, with the expectation of increasing $\mathrm{I}_{\mathrm{C}}$, at least below $77 \mathrm{~K}$. However, annealing the sample in flowing $\mathrm{O}_{2}$ at lower temperatures than presented here did not further change $\mathrm{T}_{C}$. This could be due either to a very low oxygen diffusion rate at this low temperature or to the lack of dissociation of the $\mathrm{O}_{2}$ molecule. To test for the latter, an oxygen/ozone mixture [21] was tested, but at the ozone concentration used, the protective Ag film and the YBCO film were destroyed at temperatures as low as $200^{\circ} \mathrm{C}$.

It should be pointed out that the ring method described above probes the weakest regions of the ring sample, i.e., the regions with the lowest $\mathrm{J}_{\mathrm{C}}$. Because of the nature of the ISD deposition of the film, there is an inherent transport anisotropy in the plane of the film. Transport measurements on typical samples revealed a factor-of-two anisotropy in the critical current density, with the current parallel to the ridges being the larger of the two. To check if this anisotropy changes with oxygen concentration, the flux distribution in two states with different oxygen concentration was imaged using the MOI technique. The first state investigated was obtained by oxygenating the sample at $475^{\circ} \mathrm{C}$, the other at $300^{\circ} \mathrm{C}$. The magnetization measurements showed that at $77 \mathrm{~K}$, the $300^{\circ} \mathrm{C}$ state has a factor of 2.4 larger $\mathrm{J}_{\mathrm{C}}$ value than the $475^{\circ}$ state. The two states were obtained in the last two oxygenation steps of the present investigation, with the $300^{\circ} \mathrm{C}$ state being the last one. $\mathrm{J}_{\mathrm{C}}$ measurements in this last $300^{\circ} \mathrm{C}$ state agree well with the results obtained in the first $300^{\circ} \mathrm{C}$ state shown in Fig. 14, reflecting the reversibility of the oxygenation procedure used.

Figure 17a (upper two panels) shows the trapped flux patterns in the ring in the last two oxygenation states at $77 \mathrm{~K}$ after application and switching off a $0.1 \mathrm{~T}$ field perpendicular to the ring plane. The higher intensities in patterns correspond to the stronger normal component of the magnetic flux in the sample. The picture reveals the critical state of the ring where $\mathrm{J}_{\mathrm{C}}$ near the external perimeter circulates in one direction, and it flows in the opposite direction near the internal edge of the ring. The boundary between the regions with opposite current orientations is the bright line with a strong flux concentration. Dark lines at the external and internal edges of the ring correspond to a concentration of a negative field. These features are typical for thin film samples (see [17] and references therein). In an isotropic ring the boundary between opposite currents should be concentric with the sample boundaries. However, in a ring of an anisotropic superconductor it should form an ellipse with a shorter axis along the larger current direction. Such an ellipticity with a short axis approximately in the vertical direction is clearly observed in Fig. 17a (picture on the left). The anisotropy can be estimated from a simple relation:

$$
\mathrm{k}=\mathrm{J}_{\mathrm{C} 1} / \mathrm{J}_{\mathrm{C} 2}=\left(\mathrm{w}-2 \mathrm{a}_{2}\right) /\left(\mathrm{w}-2 \mathrm{a}_{1}\right)
$$

where $\mathrm{w}$ is the width of the ring, and $\mathrm{a}_{1}$ and $\mathrm{a}_{2}$ are distances from the inner boundary of the ring to the current reversal line (see b in Fig. 17). From this line in Fig. 17a one obtains the value $\mathrm{k} \sim 1.8$.

The specific shape of the sample used in this study allows independent estimates of the anisotropy. The external perimeter of the ring has three rectangular elements resulting from the shape of the mask used in the sand blasting (see $\mathbf{c}$ and $\mathbf{d}$ in Fig. 17). Here, the critical currents 
$450^{\circ} \mathrm{C}$

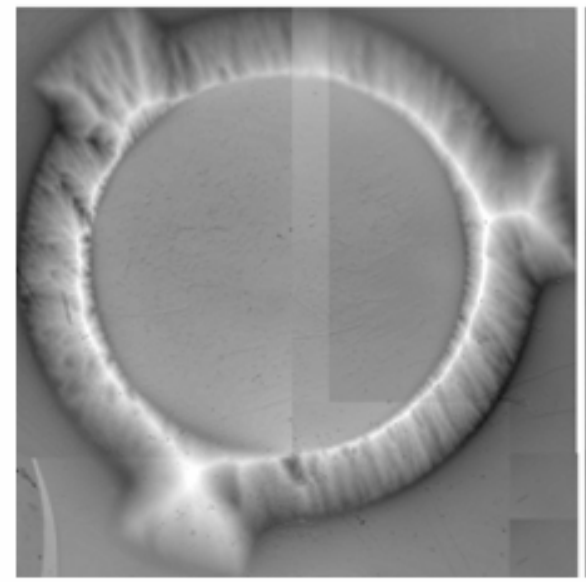

$300^{\circ} \mathrm{C}$

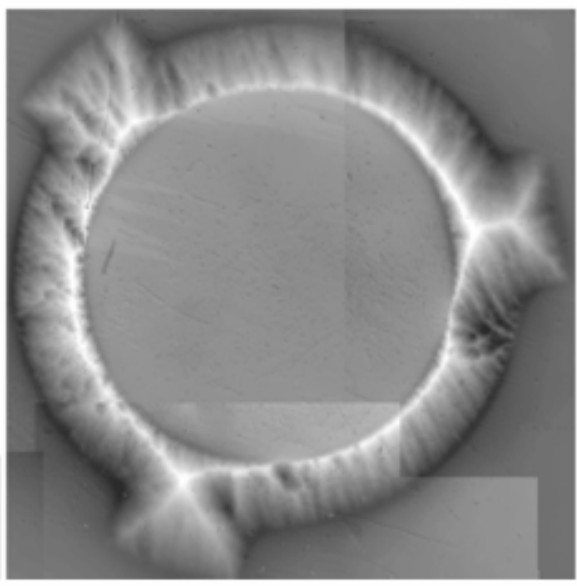

a

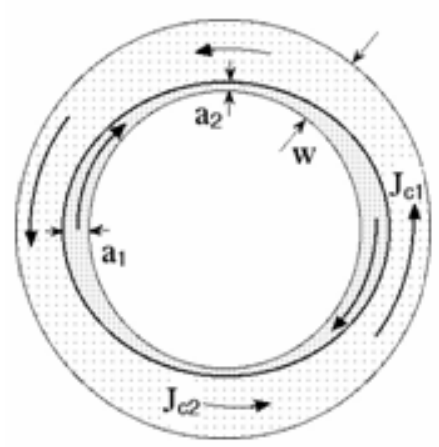

b

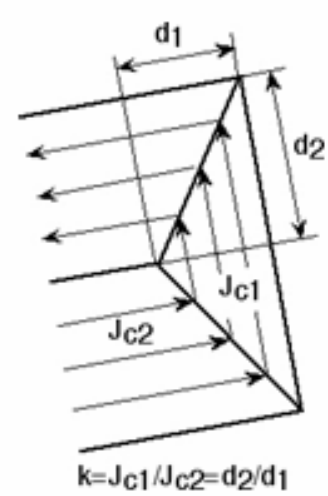

C

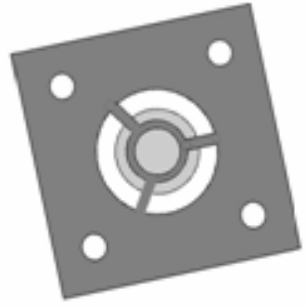

d

FIGURE 17 a. Magneto-optical image of the trapped magnetic field at 77 $\mathrm{K}$ in the ring after oxygenation at $450^{\circ} \mathrm{C}$ and $300^{\circ} \mathrm{C}$. The bright lines reflect trapped-field maxima, which occur where the persistent current suddenly changes direction. b. Schematic of current flow in an anisotropic ring. c. Schematic of current flow in the rectangular sections. d. Stainlesssteel mask (dark gray) on top of the round sample disk (light gray) showing the origin of the rectangular sections of the ring produced by sandblasting.

following the sample edges form envelope-like patterns with bright flux concentration lines in the corners. At these lines the currents experience a sharp turn, and their angles are defined by the ratio of currents along the perpendicular sides, as shown in $\mathbf{c}$ of Fig. 17 [17]. The symmetry of the pattern in the rectangle on the right-hand side of the ring in Fig. 17b shows that the maximum current is oriented parallel to the longer side of this rectangle. Distances of the crossing point of the field concentration lines from the sides of the rectangle yield $\mathrm{k}=1.7$, in good correspondence with the estimate from the current reversal line. Note that orientations of the lines in the corners of the other two rectangles (although less pronounced due to some imperfections in these areas) qualitatively correspond to the direction of current anisotropy determined from the elliptic reversal line and flux concentration lines in the right rectangle. 
Numerous fine streaks at some angle to the vertical direction in Fig. 17a indicate that the film has a texture in that direction, which is the reason for the observed anisotropy. The results presented here show that this texture-defined anisotropy is practically independent of the oxygen treatment.

The picture on the right in Fig. 17a shows the trapped flux pattern after the final $300^{\circ} \mathrm{C}$ annealing. A comparison with the pattern before the annealing (left side) indicates that the anisotropy of the sample did not change. However, the contrast became stronger due to the improved critical current density in accordance with the macroscopic measurements. As can be seen in Fig. 17a (right side), some damage occurred in the last experimental step (just below the right-hand rectangular section), which locally reduced the critical current density and pushed the current dividing line (bright line) toward the inner rim of the ring. This local damage did not affect the net critical current of the ring, as mentioned above. It also does not affect the conclusion about the anisotropy of the critical current.

\subsection{HIGH MAGNETIC FIELD MEASUREMENTS}

Experiments were also conducted to investigate how changes in the oxygen concentration affect the critical current in an applied magnetic field. It is well known that $I_{C}$ is rapidly suppressed as the magnetic field is increased [12,22]. For application purposes it is thus important to optimize the oxygen concentration to yield the smallest suppression.

Figure 18a (upper panel) demonstrates how the magnetic field suppresses the critical current in the as-made state. Magnetization data are taken after initially cooling in an applied magnetic field, as indicated, from above $91 \mathrm{~K}$ to the measurement temperature. The field is applied perpendicular to the plane of the ring. Because of the inclined nature of the film growth, the angle between the c-axis and magnetic field is about $30^{\circ}$. The magnetic moment arising from the Meissner effect (i.e., due the flux expelled from the sample during cooling) has been found to be negligibly small. After field cooling, the field was incrementally increased in small steps ranging between 0.15 and $1 \mathrm{mT}$, depending on the measurement temperature. After each current step, the system was allowed to stabilize between 5 and $20 \mathrm{~s}$ before the magnetization was recorded. As can be seen in Fig. 18a, the kink in M versus $\mathrm{H}$ is dramatically suppressed as the cooling field is increased. The critical currents determined from the kink fields, as described above, are displayed in Fig. 18b. A complete set of data is shown for 77, 70, and $65 \mathrm{~K}$. The socalled zero field-cooled (zfc) value (Fig. 18a) for the critical current is plotted at $1 \mathrm{mT}$, which corresponds to the estimated remnant field in the superconducting magnet. Just as in zero field, $\mathrm{J}_{\mathrm{C}}$ steadily improves as the temperature is lowered. At $77 \mathrm{~K}$ a dramatic drop-off in the critical current occurs at fields above $1 \mathrm{~T}$. This drop-off, which probably is due to the approaching irreversibility field, significantly shifts to higher fields as the temperature is lowered. Thus, dramatic improvement in $J_{\mathrm{C}}$ occurs in high fields as the temperature is lowered. Figure $18 \mathrm{~b}$ also shows two data points at $60 \mathrm{~K}$, for $1 \mathrm{mT}$ and $7 \mathrm{~T}$. By lowering the temperature by $5 \mathrm{~K}$ from 65 to $60 \mathrm{~K}$, the critical current in $7 \mathrm{~T}$ improves by about a factor of four.

Figure 19 shows how the critical current in an external field, $\mathrm{I}_{\mathrm{C}}(\mathrm{H})$, is affected by the oxygenation treatments. The upper panel is for $77 \mathrm{~K}$, the lower panel for $65 \mathrm{~K}$. Again, the 

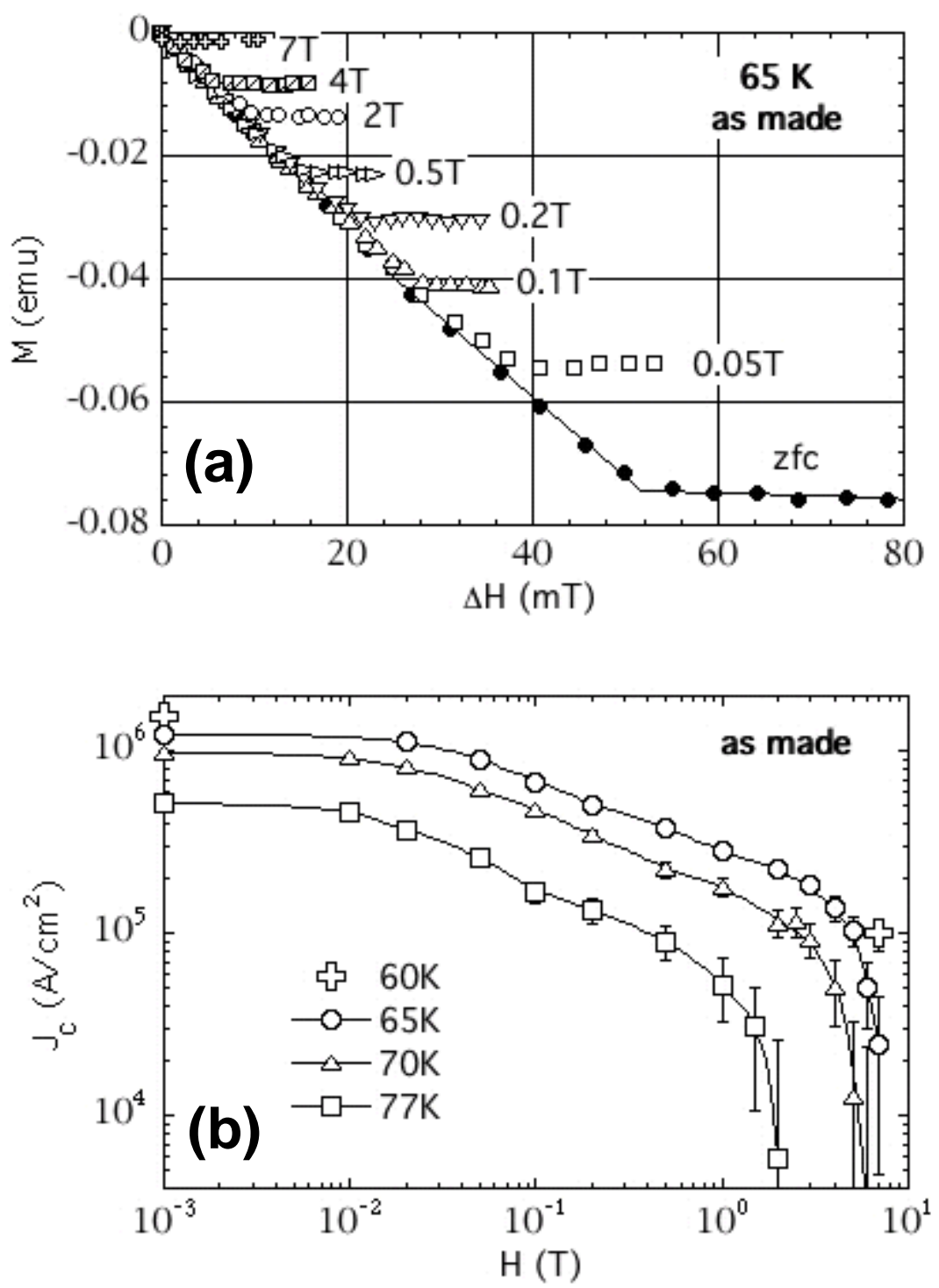

FIGURE 18 a. Magnetic moment of the sample after cooling to $65 \mathrm{~K}$ in an external field as indicated. $\Delta H$ is the increase in magnetic field above the field-cooled value. $b$. Critical current density versus the magnetic field applied during cooling. The data are obtained from measurements like those in Fig. 18a, but for different temperatures. For $60 \mathrm{~K}$, only two data points were obtained, at $\mathrm{H}=1 \mathrm{mT}$ and $\mathrm{H}=6 \mathrm{~T}$. 

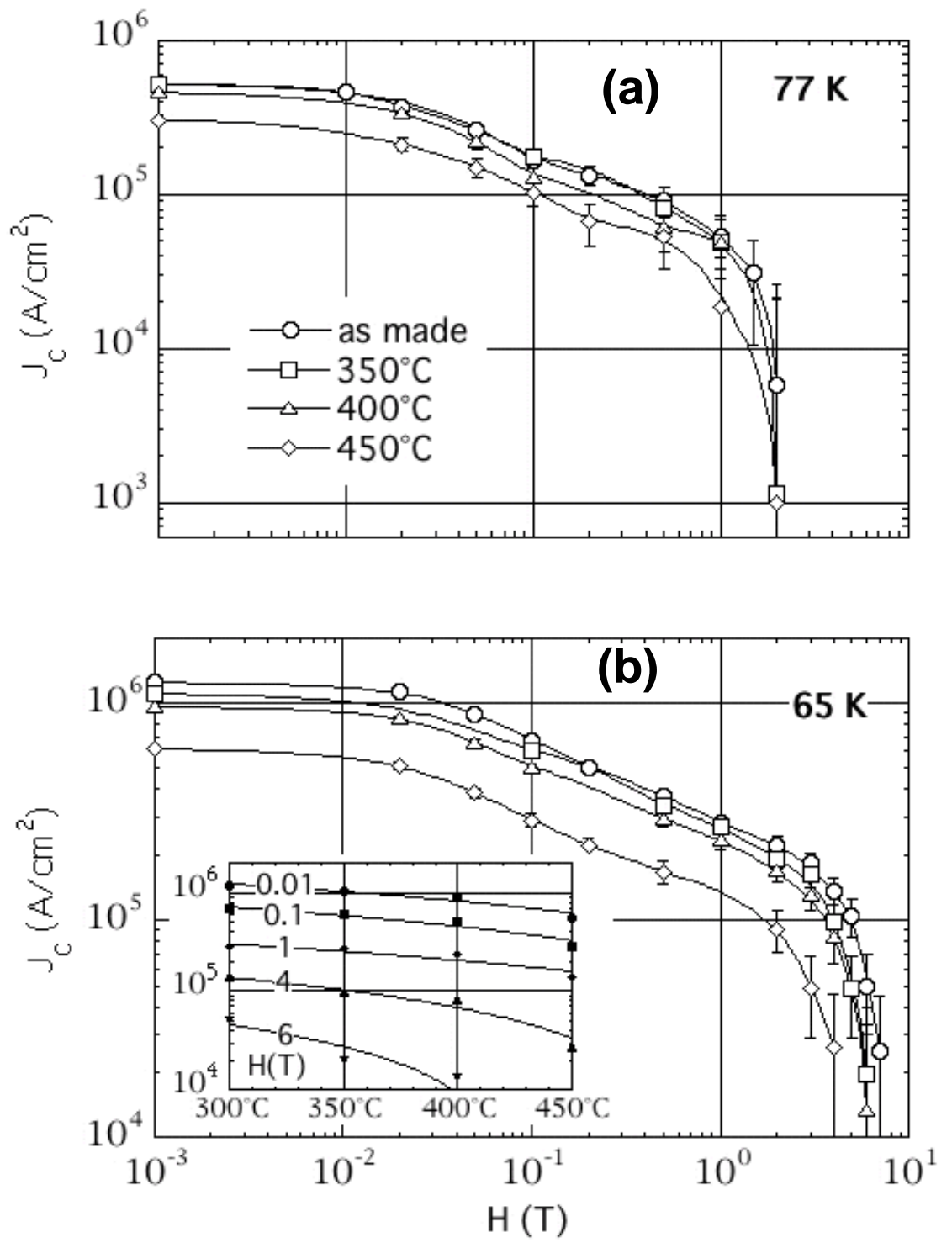

FIGURE 19 a. Critical current density at $77 \mathrm{~K}$ as function of the cooling field, in the as-made state and after oxygenation at various temperatures. b. Critical current density at $65 \mathrm{~K}$ as function of the cooling field, in the as-made state and after oxygenation at various temperatures. Inset: critical current density at various fields as function of the oxygenation temperature. 
highest critical currents are obtained in the state with the highest oxygen concentration. This effect can best be seen in the inset in Fig. 19b, which displays the critical current at selected external fields as a function of the oxygenation temperature (in the over-doped regime). The result clearly shows that the highest Jc in zero field as well as in high field is obtained in the most over-doped state (at $77 \mathrm{~K}$ and below).

The above presented results show how the contact-free ring technique can be used to evaluated electromagnetic properties of HTS embodiments and, more specifically, reveal how these properties are affected by changing the oxygen concentration of coated conductor samples from the under-doped to the over-doped regime. 


\section{RESIDUAL STRESSES IN MULTILAYERED COATED CONDUCTORS}

During the processing of coated conductors, residual stresses are developed in various buffer layers and in the superconducting film because of differing thermal expansion properties of the various layers. In addition, intrinsic stresses that develop during high-energy processing and layer growth may also contribute to residual stress. These residual stresses may lead to damage of the superconducting YBCO film, and thus to degradation of superconducting properties and service life. Therefore, it is critical to evaluate and understand residual stresses in coated conductors to optimize processing for the successful development of high- $J_{\mathfrak{c}}$ coated conductors.

\subsection{FINITE ELEMENT ANALYSIS OF COATED CONDUCTORS}

Residual stress $\left(\sigma_{\mathrm{f}}\right)$ in a thin film of thickness $t_{\mathrm{f}}$, deposited on a coated conductor substrate, can be estimated using Stoney's equation [23]:

$$
\sigma_{\mathrm{f}}=-\frac{\mathrm{E}_{\mathrm{s}} \mathrm{t}_{\mathrm{s}}^{2}}{6\left(1-v_{\mathrm{s}}\right) \mathrm{t}_{\mathrm{f}}} \Delta \kappa
$$

In the above equation, $\mathrm{E}_{\mathrm{s}}, \mathrm{t}_{\mathrm{s}}$, and $v_{\mathrm{s}}$ are the elastic modulus, thickness, and Poisson's ratio of the substrate, and $\Delta \kappa$ is the change in substrate curvature due to the presence of the film. Equation 3 essentially indicates that the stress in the film is proportional to the change of substrate curvature induced by that film. The change in substrate curvature can be measured by techniques such as laser scanning and optical interferometry [24,25]. Stoney [23] originally developed an equation for a thin, single layer of film on a much thicker substrate $\left(t_{f}<<t_{s}\right)$. For multilayered systems, the use of Stoney's equation is based on the premise that, during deposition of any specific layer, the change in substrate curvature is assumed to be caused only by a specific layer [26]. The equation does not consider the interlayer interactions [26]. Therefore, the stresses estimated by Stoney's equation in multilayered systems may not represent the actual values of stresses present in the specific layers. Thus, to assess the applicability of Stoney's equation for multilayered systems, a 3-D finite element analysis (FEA) was performed by considering the interaction between the layers and, subsequently, evaluating the residual stresses in the various layers of the coated conductor.

The 3-D FEA was performed with ABAQUS standard finite element software. The simulations were performed for an ISD-MgO buffered YBCO-coated conductor of the configuration $\mathrm{YBCO} / \mathrm{CeO}_{2} /$ yttria-stabilized zirconia (YSZ)/homoepitaxial MgO (HE-MgO)/ISD$\mathrm{MgO} /$ Hastelloy $\mathrm{C} 276$ (HC) substrate. For the analysis, the thickness of the HC substrate was taken to be $150 \mu \mathrm{m}$. Table 2 gives the thickness and deposition temperature of the buffer layers and the YBCO film that were used in the FEA. The elastic modulus and the coefficient of thermal expansion of the $\mathrm{HC}$ substrate, buffer layers, and the YBCO film are given in Table 3. 
TABLE 2 Thickness and deposition temperatures of various layers of the YBCO-coated conductor used in FEA.

\begin{tabular}{lcc}
\hline \multicolumn{1}{c}{ Layer } & Thickness $(\boldsymbol{\mu m})$ & $\begin{array}{c}\text { Deposition Temperature } \\
\left({ }^{\circ} \mathbf{C}\right)\end{array}$ \\
\hline $\mathrm{ISD}-\mathrm{MgO}$ & 2 & Room temperature \\
$\mathrm{HE}-\mathrm{MgO}$ & 0.5 & 700 \\
$\mathrm{YSZ}$ & 0.15 & 800 \\
$\mathrm{CeO}_{2}$ & 0.01 & 800 \\
$\mathrm{YBCO}$ & 0.3 & 760 \\
\hline
\end{tabular}

TABLE 3 Mechanical and physical properties of coated conductor materials [27-29].

\begin{tabular}{lcc}
\hline Material & $\begin{array}{c}\text { Elastic Modulus } \\
(\mathbf{G P a})\end{array}$ & $\begin{array}{c}\text { Coefficient of Thermal } \\
\text { Expansion }\left(\mathbf{1 0}^{-6} / \mathbf{K}\right)\end{array}$ \\
\hline $\mathrm{HC}$ & $170-220$ & 12.5 \\
$\mathrm{MgO}$ & 250 & 12.8 \\
$\mathrm{YSZ}$ & 200 & 9.7 \\
$\mathrm{CeO}_{2}$ & 200 & 11.3 \\
$\mathrm{YBCO}$ & $135-157$ & 13.4 \\
\hline
\end{tabular}

The coated conductor system was modeled as a rectangular geometry $(10 \mathrm{~mm} \times 5 \mathrm{~mm})$, and the simulations were performed so as to replicate the actual fabrication procedure of the multilayered coated conductor. The HC substrate was treated as a 3-D deformable body (with stress varying through the thickness), and all the other layers were considered as planar homogeneous shells, i.e., stress was assumed to be constant within each layer. The effects of intrinsic stresses developed during deposition and stress relaxation due to creep/plastic deformation were ignored in the analysis. Thermal interactions between the layers arising from differences in coefficient of thermal expansion and elastic interactions due to differences in elastic properties were both considered in the analysis. Residual stresses (at room temperature) in the individual layers of the YBCO-coated conductor were computed in a direction parallel to the plane of the coating layers after deposition of all the layers. Besides computing the residual stresses in the individual layers, finite element simulations were also performed to estimate the change in substrate curvature resulting from the sequential deposition of the individual layers. These computed curvature changes were used in Stoney's equation to evaluate the residual stresses in various layers of the YBCO-coated conductor. A comparison of the FEA-computed residual stresses in the individual layers with those estimated by Stoney's equation (using the computed curvature values) provided guidance on the applicability of Stoney's equation to residual stress evaluation in multi-layers. 
Figure 20 shows the change in substrate curvature during various deposition steps. The substrate curvature is considered to be zero at room temperature before deposition of any layer. A positive change (convex) in substrate curvature due to the deposition of a layer produces a compressive stress in the layer, whereas a negative change (concave) produces a tensile stress. The data points numbered $1,4,7,10$, and 13 in the figure correspond to substrate curvatures at room temperature subsequent to deposition of each layer. Because intrinsic stresses during layer growth have been neglected in the present analysis, the substrate curvature remains constant at each deposition temperature, i.e., at data points 2 and 3,5 and 6,8 and 9, and 11 and 12. Data point 13 corresponds to the final curvature of the multilayered coated conductor after all the layers have been deposited.

Figure 21 shows the residual stresses in the individual layers, calculated by substituting the change in substrate curvature (before and after deposition of a particular layer, as in Fig. 20) into Stoney's equation [23]. For example, the residual tensile stress $(\approx 137 \mathrm{MPa})$ in the YBCO film was estimated from Eq. 3 by using the difference in substrate curvature corresponding to data points 13 and 10 in Fig. 20. In using Stoney's equation, it is assumed that the change in substrate curvature between 13 and 10 was caused only by the YBCO layer, whereas in reality, the underlying layers also contributed to the curvature change. Figure 21 also shows the residual stresses at room temperature in the individual layers, computed directly by FEA. As seen from the figure, there is little difference between the residual stresses computed by FEA (which

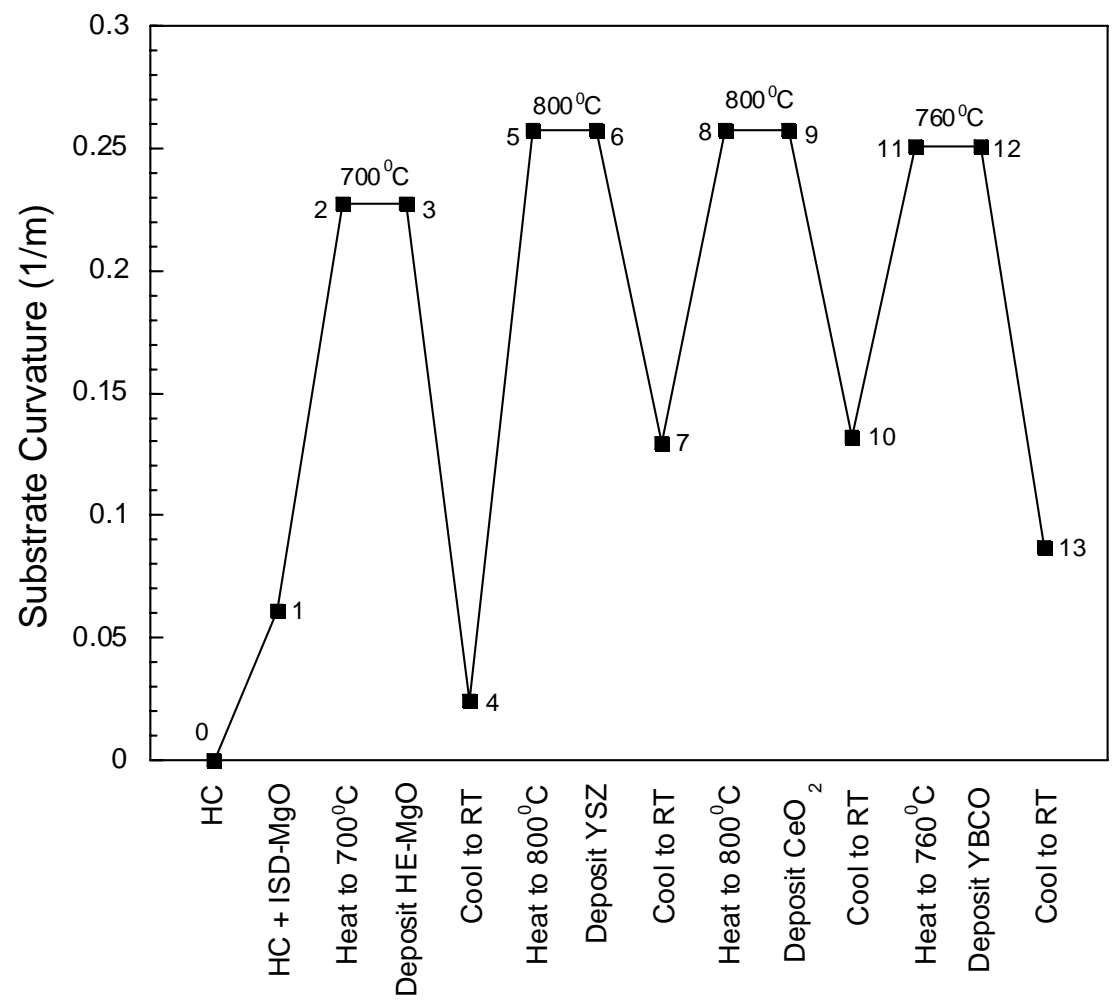

FIGURE 20 Substrate curvature in YBCO-coated conductor at various deposition steps as estimated by FEA $(\mathrm{RT}=$ room temperature). 


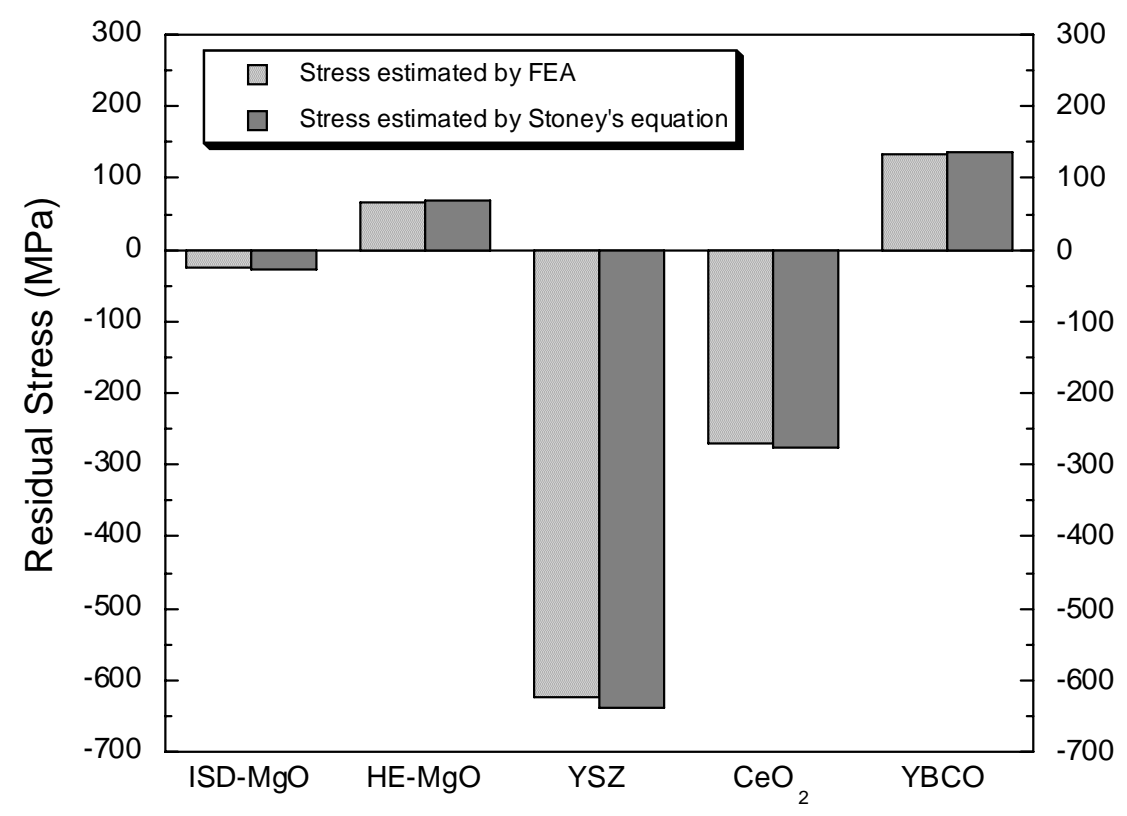

FIGURE 21 Residual stresses in various layers of YBCO-coated conductor as estimated by FEA and by Stoney's equation (using computed curvatures).

considers the interlayer interactions) and those estimated by Stoney's equation using the numerically calculated curvatures. This finding clearly suggests that interlayer interactions have negligible effects on the development of residual stresses in individual layers of a multilayered system. To confirm the negligible effect of interlayer interactions, the stress in each layer at each stage of deposition was computed by FEA. The computed values of stress at room temperature in each individual layer did not significantly vary at various deposition stages. Therefore, Stoney's equation can be used to estimate residual stresses in specific layers of multilayered coated conductors by measuring the changes in substrate curvature due to the presence of the layers.

\subsection{INFLUENCE OF PROCESSING METHODS ON RESIDUAL STRESS}

The purpose of this study was to evaluate the influence of different processing methods on residual stress evolution in various layers of YBCO-coated conductors. Specifically, residual stresses in YBCO films processed by sol-gel and pulsed laser deposition (PLD) techniques have been evaluated, as have YSZ films deposited by IBAD. The residual stresses were measured by $\mathrm{x}$-ray diffraction (XRD). The measured residual stresses were compared with the residual stresses calculated on the basis of thermal expansion mismatch to provide guidance on the nature of residual stress evolution during processing of coated conductors.

YBCO films on $\mathrm{LaAlO}_{3}$ substrate were processed by PLD and sol-gel techniques, and the YSZ films on Hastelloy $\mathrm{C}$ substrate were processed by the IBAD technique. The substrates $(15 \mathrm{~mm} \times 12 \mathrm{~mm})$ were polished to an approximately $1 \mu \mathrm{m}$ finish on both sides and were 
subsequently subjected to an ultrasonic cleaning to obtain flat and clean surfaces. The substrate thickness (ranging from $100 \mu \mathrm{m}$ to $200 \mu \mathrm{m}$ ) was measured by scanning electron microscopy.

Pulsed laser deposition of YBCO films on $\mathrm{LaAlO}_{3}$ was carried out with a Lambda Physik COMPex 201 excimer laser having a $\mathrm{Kr}-\mathrm{F}_{2}$ gas mixture as the laser medium [30]. The substrates were glued on a rotating inclined sample holder using a silver paste, and were heated to $700-800^{\circ} \mathrm{C}$ during the deposition. The target was commercial YBCO (Superconductive Components, Inc.), $25.4 \mathrm{~mm}$ in diameter and $6.4 \mathrm{~mm}$ thick, and the distance from target to substrate was maintained at $40-80 \mathrm{~mm}$. The oxygen partial pressure in the deposition chamber was maintained at $\approx 200$ mTorr by flowing ultra-high-purity oxygen through the chamber. The energy density for deposition was estimated to be $\approx 2 \mathrm{~J} / \mathrm{cm}^{2}$. The thickness of the deposited YBCO films was measured to be $\approx 300 \mathrm{~nm}$. Four PLD specimens were prepared for each substrate. Further details of the PLD process can be found elsewhere [30].

For the deposition of YBCO films on $\mathrm{LaAlO}_{3}$ by sol-gel processing [31], a mixture of yttrium, barium, and copper (1:2:3 molar ratio) was dissolved in trifluoroacetic acid and refluxed for $4 \mathrm{hr}$. The solution was dried in air to get a blue solid residue, and later, methanol was used to make a solution with a 1.5 mole cation concentration. The $\mathrm{LaAlO}_{3}$ substrates were soaked with the solution either by a dip or spin coating method. Two heat treatment steps at 400 and $780^{\circ} \mathrm{C}$ were performed with the samples under an atmosphere containing $99.996 \%$ argon with $10 \mathrm{ppm}$ oxygen. The thickness of the deposited YBCO film was $\approx 200-500 \mathrm{~nm}$.

Ion beam assisted deposition [32] was used to deposit the YSZ film on the Hastelloy C substrate. The substrate was placed on a rotating sample holder and was heated to $200-300^{\circ} \mathrm{C}$ during the coating process. Under $\mathrm{Ar} / 10 \% \mathrm{O}_{2}$ environment, an ion beam with energy of $300 \mathrm{eV}$ was impinged on the evaporated YSZ with an ion fluence of $200 \mu \mathrm{A} / \mathrm{cm}^{2}$. The ion bombardment angle (angle between the ion beam and the substrate) was varied from $23^{\circ}$ to $35^{\circ}$ to change the degree of texture of the deposited YSZ film. The thickness of the YSZ films was $\approx 1 \mu \mathrm{m}$. The details of the IBAD process have been described elsewhere [32]. In-plane texture of the YSZ films was evaluated by $\mathrm{x}$-ray pole figure analysis.

Residual stress in the YBCO and the YSZ films was measured by XRD $\left(\sin ^{2} \Psi\right.$ method) using a Philips diffractometer [33]. The co-ordinate system used in diffraction experiments is shown in Fig. 22. In this figure, $\sigma_{1}, \sigma_{2}$, and $\sigma_{3}$ are the principal stresses, where $\sigma_{3}(=0)$ is the stress normal to the sample surface, and $\sigma_{1}$ is parallel to the longest dimension of the sample; also, $\sigma_{\phi}$ is the residual stress in the sample surface at an angle $\phi$ from $\sigma_{1}$, and $\varepsilon_{\phi \psi}$ is the strain in a direction defined by $\phi$ and $\psi$, where $\psi$ is the tilt angle between $\sigma_{3}$ and the incident $x$-ray beam. The lattice spacing, $d$ for a particular (hkl) reflection, was measured as a function of $\psi$ by performing x-ray $\theta-2 \theta$ scans. The residual strain, $\Delta \mathrm{d} / \mathrm{d}$, associated with the (hkl) reflection of a particular film is given by [33],

$$
\frac{\Delta d}{d}=\left(\frac{d_{\psi}-d_{\perp}}{d_{\perp}}\right)=\sigma_{\phi} \frac{(1+v)}{E} \sin ^{2} \psi
$$




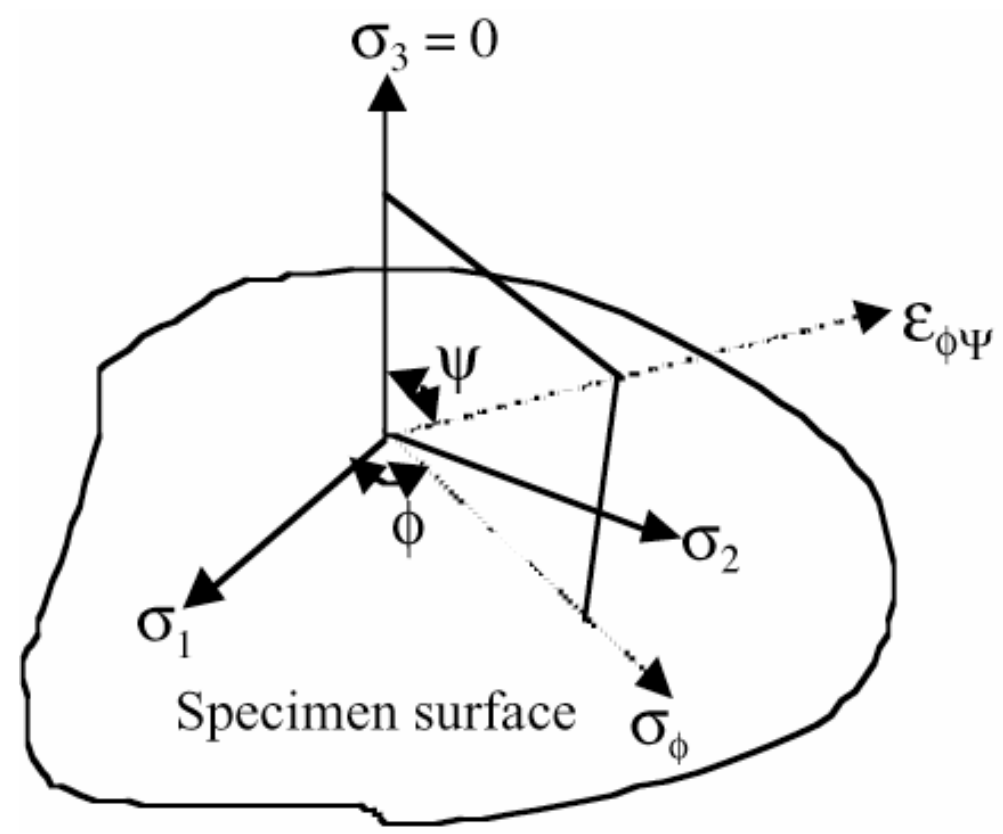

FIGURE 22 Co-ordinate system used for x-ray diffraction analysis.

where $d_{\psi}$ and $d_{\perp}$ are the measured lattice spacing of the film at angles $\psi$ and $0^{\circ}$ to $\sigma_{3}$, respectively, and E and $v$ are the elastic modulus and Poisson's ratio of the film, respectively. The residual stress $\sigma_{\phi}$ acting on the surface of the film in a direction $\phi$ from $\sigma_{1}$ can be calculated from the slope of the plot of $\left(\mathrm{d}_{\psi}-\mathrm{d}_{\perp}\right) / \mathrm{d}_{\perp}$ versus $\sin ^{2} \psi$. For the YBCO and the YSZ films, residual stresses were measured on three to four specimens, and in each specimen, the stress was measured at $\phi=0^{\circ}$ and $45^{\circ}$. An average value of residual stress for the YBCO and the YSZ films was determined by calculating the mean.

Figure 23 shows the XRD pattern of the YSZ films deposited on Hastelloy C substrate at ion bombardment angles of $23^{\circ}$ and $35^{\circ}$. As evident in Fig. 23a, the film deposited at $35^{\circ}$ exhibits a strong preferred orientation of the (200) planes, whereas the film deposited at $23^{\circ}$ (Fig. 23b) is non-textured with a relatively weak preferred orientation of (111) planes.

Figure 24 shows the (111) X-ray pole figures of the YSZ films deposited at $35^{\circ}$ and $23^{\circ}$ ion bombardment angles. As evident in Fig. 24a, the YSZ film deposited at $35^{\circ}$ exhibits four reflections of (111) planes, suggesting the presence of in-plane texture. In contrast, Fig. 24b shows a lack of any in-plane alignment in the YSZ film deposited at $23^{\circ}$. The ion bombardment angle of $35^{\circ}$ is consistent with the channeling direction [34] for the (111) in-plane orientation, resulting in the observed (111) in-plane texture in Fig. 24a, whereas the absence of any channeling effects at $23^{\circ}$ ion bombardment angle likely causes the lack of in-plane texture in Fig. 24b. The YSZ film deposited at $35^{\circ}$ will hereafter be referred to as textured film, and the film deposited at $23^{\circ}$ as non-textured film. 

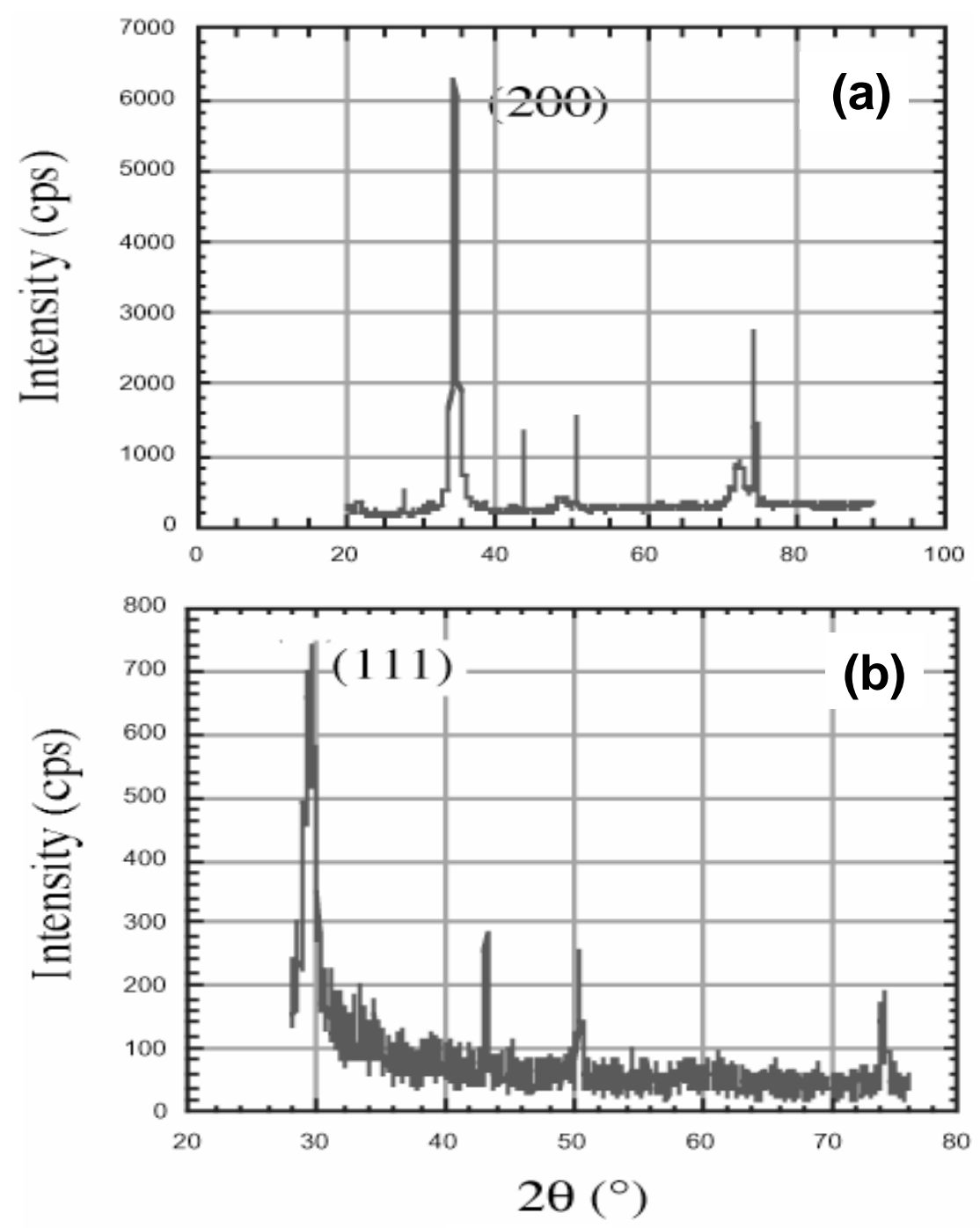

FIGURE 23 X-ray diffraction patterns of YSZ films deposited on Hastelloy $\mathrm{C}$ substrate at incidence angles of (a) $35^{\circ}$ and (b) $23^{\circ}$.

After texture characterization, the residual stresses in the textured and the non-textured YSZ films were measured by XRD using the procedure mentioned earlier. Figure 25 shows plots of $\left(d_{\psi}-d_{\perp}\right) / d_{\perp}$ as a function of tilt angle $\Psi$ for the (200) plane for a textured YSZ film. The slope of the plot for a given $\phi$ direction can be used to estimate the value of residual stress $\left(\sigma_{\phi}\right)$ from Eq. 4. The negative slope in the figure indicates a compressive stress in the sample. The average compressive residual stress in the textured YSZ film was estimated to be $365 \pm 41 \mathrm{MPa}$. The (111) reflection of the non-textured YSZ film was used to determine the average residual compressive stress to be $598 \pm 75 \mathrm{MPa}$.

Similarly, XRD was used to estimate residual stresses in the YBCO films deposited on $\mathrm{LaAlO}_{3}$ substrates by PLD and sol-gel techniques. The average residual tensile stress estimated in the YBCO film processed by the sol-gel technique was $450 \pm 80 \mathrm{MPa}$, whereas the tensile residual stress in the YBCO film processed by PLD was $178 \pm 53 \mathrm{MPa}$. 

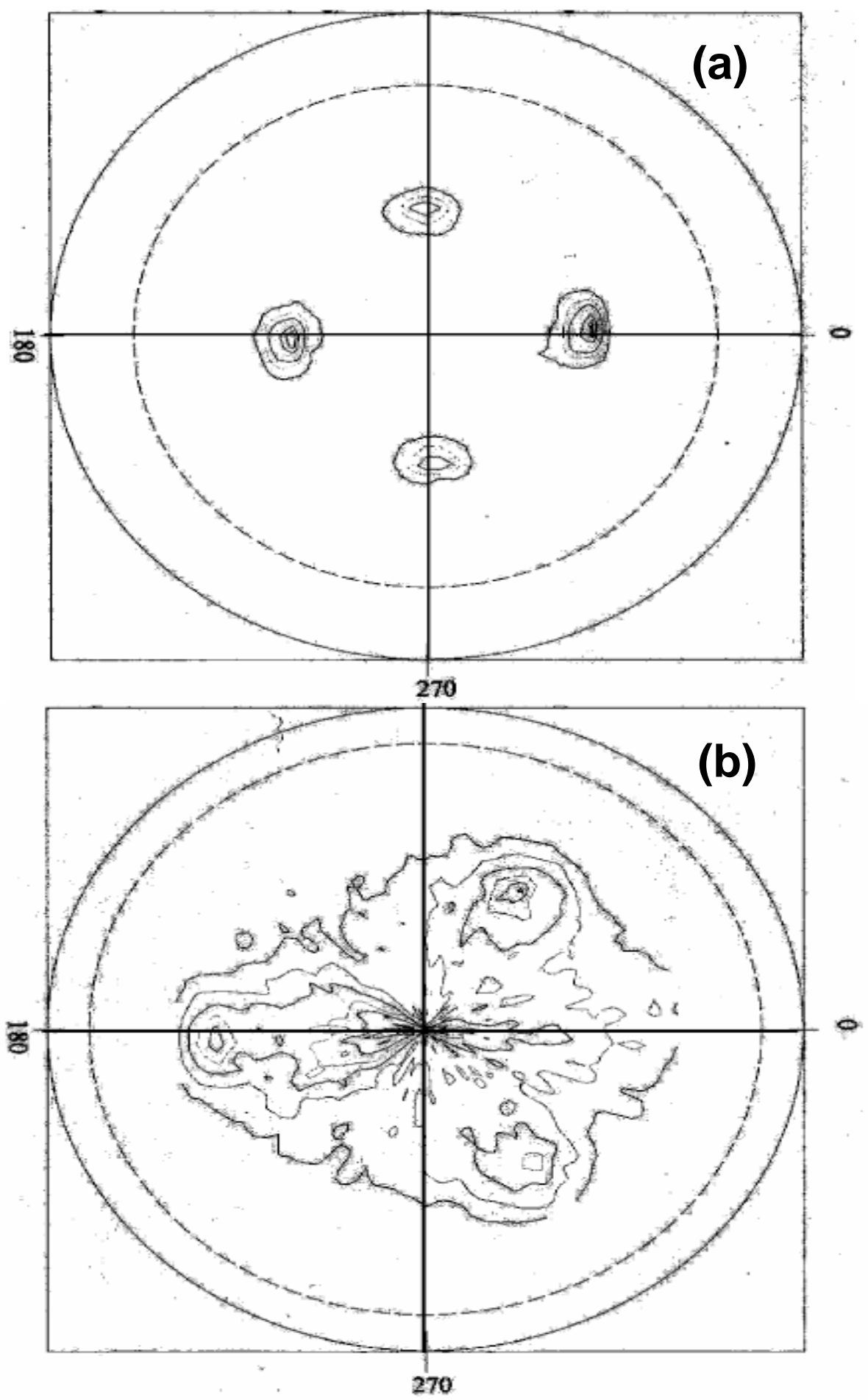

FIGURE 24 (111) X-ray pole figures of (a) textured (deposited at $35^{\circ}$ ion bombardment angle) and (b) non-textured (deposited at $23^{\circ}$ ion bombardment angle) YSZ films. 


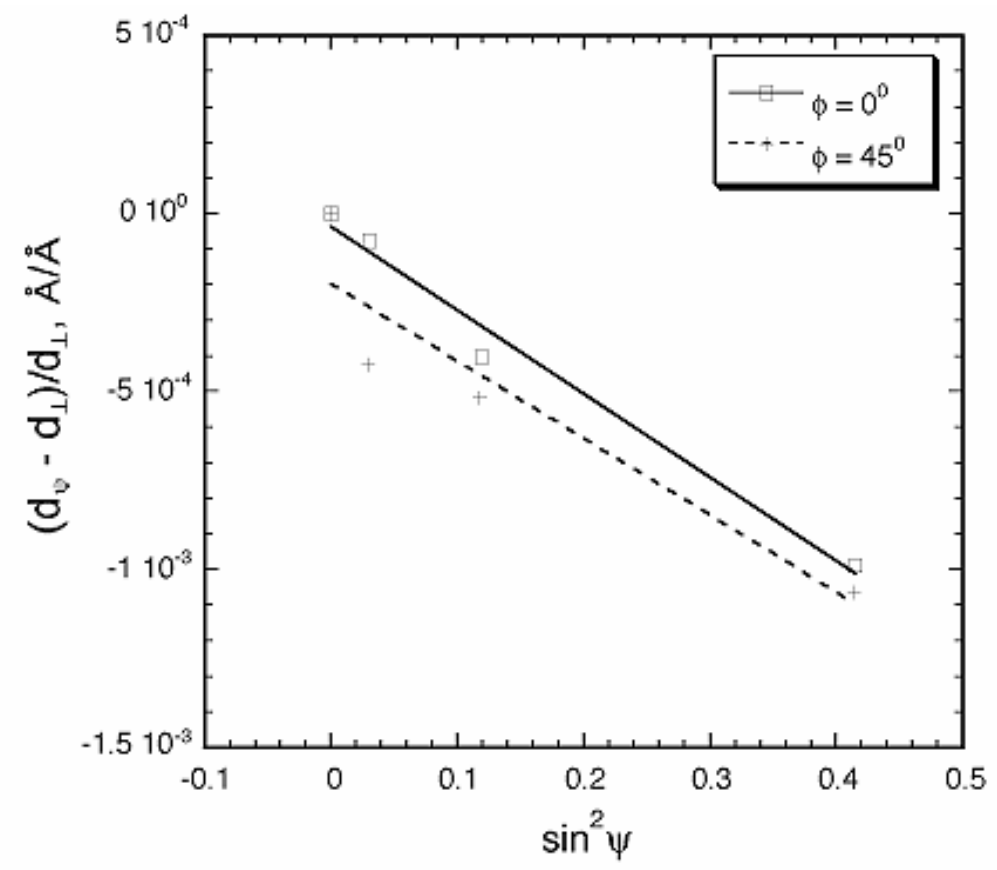

FIGURE 25 Variation of $\left(d_{\psi}-d_{\perp}\right) / d_{\perp}$ with tilt angle $\Psi$ in two $\phi$ directions for a textured YSZ film.

The residual stress $\left(\sigma_{\text {res }}\right)$ in thin films of a coated conductor may result from the thermal expansion mismatch between the films and the substrate as well as from the intrinsic stresses developed during the film growth. This relationship can be expressed as

$$
\sigma_{\text {res }}=\sigma_{\text {th }}+\sigma_{\text {int }} \text {, }
$$

where $\sigma_{\text {th }}$ is the thermal mismatch stress, and $\sigma_{\text {int }}$ is the intrinsic stress generated during the growth of the film. The thermal mismatch stress $\left(\sigma_{\text {th }}\right)$ in a film can be calculated by an analytical approach [35]:

$$
\sigma_{t h}=\frac{E}{(1-v)} \Delta \alpha \Delta T
$$

where E and $v$ are the elastic modulus and Poisson's ratio of the film, respectively, $\Delta \alpha$ is the difference in thermal expansion coefficients between the substrate and the film, and $\Delta \mathrm{T}$ is the difference between room and processing temperature. The elastic moduli and thermal expansion coefficients of the materials used in the present study (Hastelloy $\mathrm{C}, \mathrm{LaAlO}_{3}$, YSZ, and YBCO) are given in Table 4. For most ceramic oxides, Poisson's ratio is $v \approx 0.3$ [36]; hence, $v$ of YSZ and YBCO films was assumed to be 0.3 in the present study. 
TABLE 4 Elastic modulus and thermal expansion coefficient of coated conductor materials [27-29,37].

\begin{tabular}{lcccc}
\hline \multicolumn{1}{c}{ Material Property } & Hastelloy C & LaAlO $_{3}$ & YSZ & YBCO \\
\hline & & & & \\
Elastic Modulus (GPa) & $170-220$ & 500 & 200 & 157 \\
Thermal Expansion Coefficient $\left(10^{-6} / \mathrm{K}\right)$ & 12.5 & 10.0 & 9.7 & 13.4 \\
\hline
\end{tabular}

Equation 6 and the data given in Table 4 were used to calculate the thermal expansion mismatch stress between YSZ and Hastelloy C-the resultant value being $140 \mathrm{MPa}$. In Fig. 26, the calculated value of thermal expansion mismatch stress is compared with the measured residual stress in YSZ film.

The data indicate that the magnitude of measured residual stresses is much larger than the calculated thermal mismatch stress for both the textured and the non-textured YSZ films. This difference is believed to result from intrinsic compressive stresses developed during IBAD processing due to argon (Ar) ion-peening effects [38,39]. During IBAD processing, energized Ar ions impinge on the YSZ film and get peened on the YSZ surface, inducing intrinsic compressive stress in the film [38]. The superposition of this intrinsic compressive stress on the thermal mismatch stress results in a larger measured residual stress in the YSZ films, as shown in Fig. 26. Although both the textured and the non-textured YSZ films were processed by IBAD, the ion bombardment angle was $35^{\circ}$ for the textured film, as compared to $23^{\circ}$ for the non-textured film. The ion bombardment angle of $23^{\circ}$ corresponds to a non-channeling direction, which results in an increased number of ions getting peened at the surface of the YSZ film. In contrast, the bombardment angle of $35^{\circ}$ corresponds to a channeling direction, which is believed to minimize the ion-peening effects. The increased ion peening at the surface of the film, apparently, induces a larger intrinsic compressive stress and thus a higher measured residual compressive stress in the non-textured film compared to the textured film.

Figure 27 compares the measured residual stress in the YBCO films (deposited on $\mathrm{LaAlO}_{3}$ substrate by PLD and sol-gel techniques) with the calculated value of thermal mismatch stress $(515 \mathrm{MPa})$ between $\mathrm{YBCO}$ and $\mathrm{LaAlO}_{3}$. This bar graph indicates a significant difference between the calculated thermal mismatch stress $(515 \mathrm{MPa})$ and the measured residual stress $(178 \pm 53 \mathrm{MPa})$ in the YBCO film deposited by the PLD technique. Similar to IBAD processing, it is believed that intrinsic compressive stresses are induced in the YBCO film during PLD processing [40,41]. During PLD processing, the ablated species in the laser plume have high kinetic energies, ranging from a few tenths to several hundreds of $\mathrm{eV}$ [40]. It has been reported $[40,41]$ that the condensation of these energetic species results in intrinsic compressive stresses in thin films deposited by PLD. A similar mechanism may cause intrinsic compressive stress in the YBCO films, leading to a reduction in the tensile residual stress caused by thermal expansion mismatch. Thus, the measured residual stress is less tensile compared to the thermal mismatch stress, as shown in Fig. 27. However, in contrast to PLD and IBAD, the absence of any kind of surface damage in sol-gel processing [31] contributes little intrinsic stress to the total residual stress. Thus, the measured residual stress is expected to be approximately the same as the 


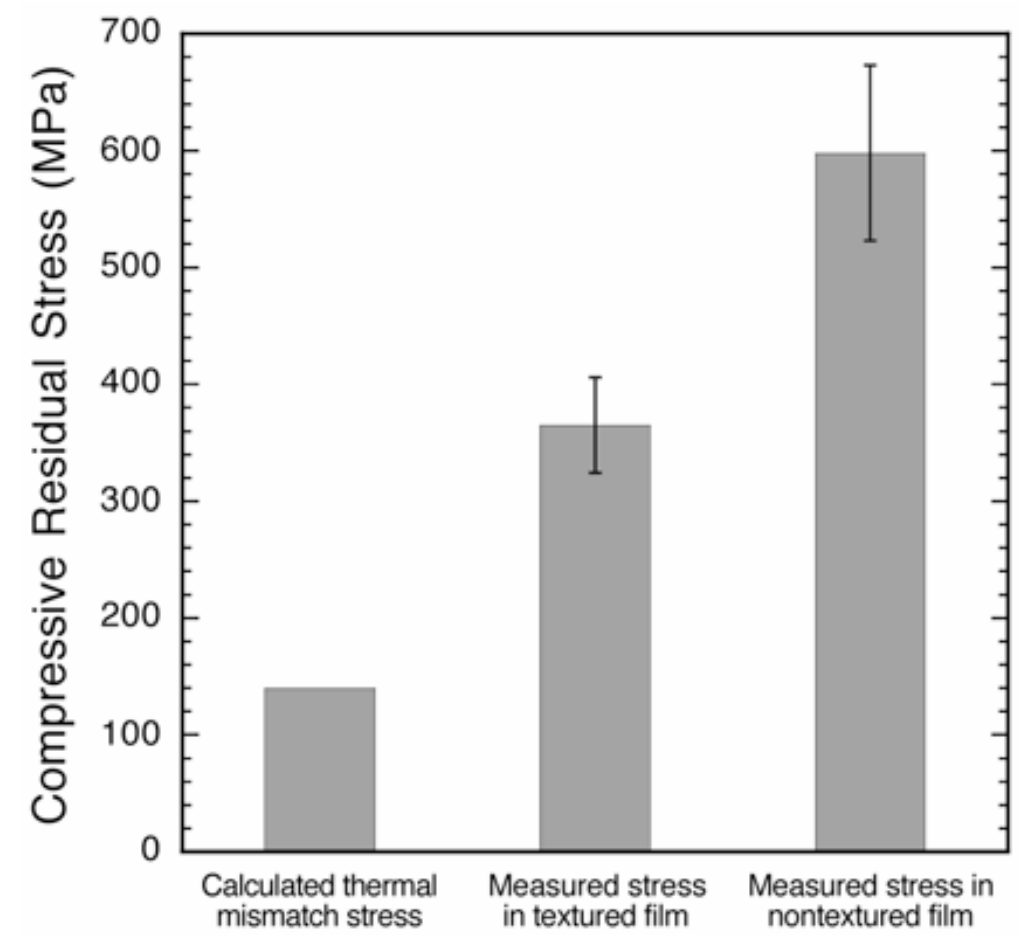

FIGURE 26 Measured and calculated values of residual stresses in YSZ film deposited on Hastelloy C substrate.

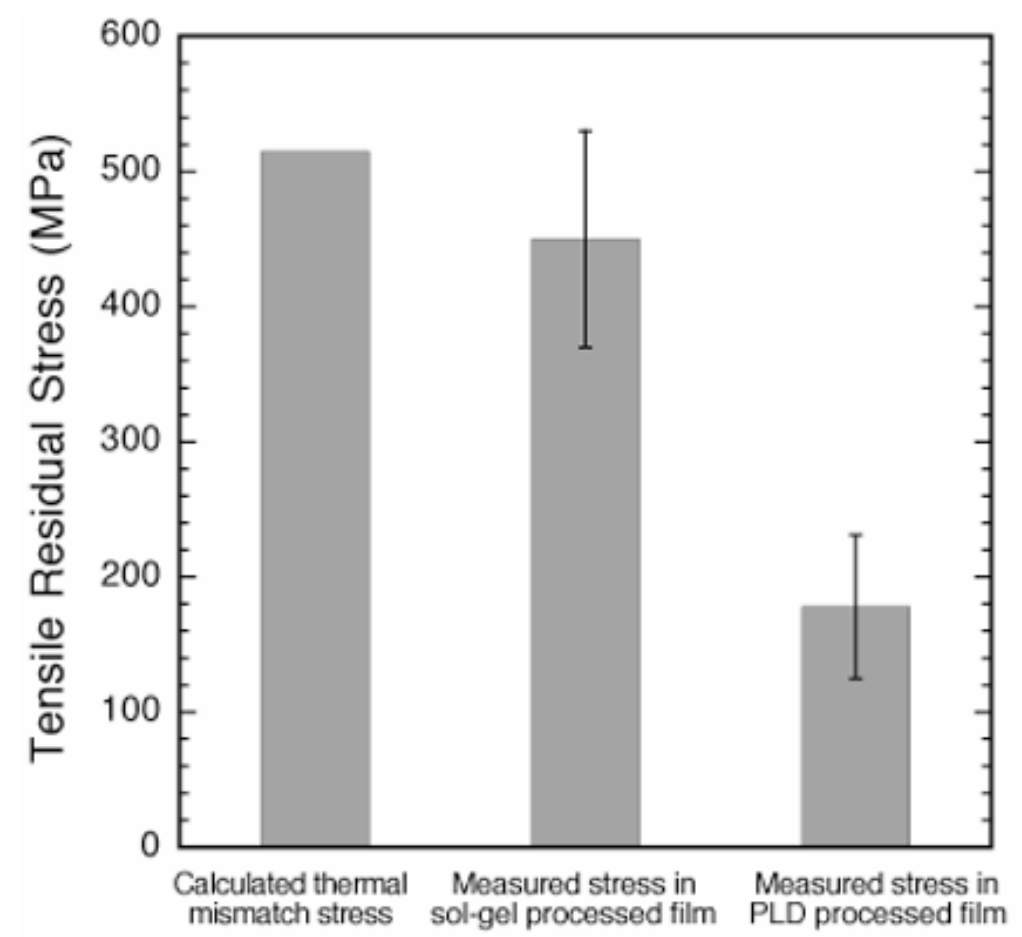

FIGURE 27 Measured residual stresses in YBCO film deposited by sol-gel and PLD techniques. Calculated thermal mismatch stress is also shown in the figure for comparison. 
thermal mismatch stress. The measured residual stress in the YBCO film deposited by sol-gel processing was $450 \pm 80 \mathrm{MPa}$, which agrees reasonably well with the calculated thermal mismatch stress (515 MPa).

The processing techniques chosen for thin film deposition of coated conductors appear to influence the nature and magnitude of intrinsic stresses (generated during film growth), which can significantly alter the net residual stress in the films. IBAD processing of YSZ films on Hastelloy C substrate led to intrinsic compressive stresses in these films due to Ar ion peening. This resulted in a higher compressive residual stress in the YSZ films than the calculated thermal mismatch stress between YSZ and Hastelloy C. The textured YSZ film had a lower intrinsic compressive stress than the non-textured film, resulting in a relatively low compressive residual stress in the textured film. As in the case of thin film processing by IBAD, PLD also led to generation of intrinsic compressive stresses in YBCO films deposited on $\mathrm{LaAlO}_{3}$ substrates. Thus, the resulting residual stress in the YBCO film was less tensile than the calculated thermal mismatch stress between YBCO and $\mathrm{LaAlO}_{3}$. In contrast to IBAD and PLD processing, sol-gel processing generated negligible intrinsic stress in $\mathrm{YBCO}$ films deposited on $\mathrm{LaAlO}_{3}$ substrate. The measured residual stress in the sol-gel-processed YBCO film was, thus, consistent with the calculated thermal mismatch stress between $\mathrm{YBCO}$ and $\mathrm{LaAlO}_{3}$. 


\section{HTS PROGRAM TECHNICAL EVALUATION/SUPPORT}

During FY 2005, peer review and concomitant revision were completed for the report:

HTS Cable: Status, Challenges and Opportunities (December 2, 2004), 408 pages, prepared by A.M. Wolsky for the participating signatories of the International Energy Agency's Implementing Agreement on Cooperative Program for Assessing the Impacts of High Temperature Superconductivity on the Electric Power Sector.

Input for particular sections of the report was provided by a broad spectrum of individuals. The peer review embraced the opinions of nearly 20 experts. The report was disseminated within the U.S. by mailing CDs bearing it to a distribution list that includes about 30 individuals actively involved in the OE/HTS program. Thanks to the assistance of J. Badin (Energetics) and his support staff, the report is now posted on the DOE HTS website. Table 5 indicates some of the information in the full report. A few comments about the information presented in the table and its likely significance follow. The report also describes situations and places where the adoption of HTS cable is more likely than elsewhere.

The table presents information about efforts now under way to demonstrate an HTS AC cable. Two projects are being pursued in Europe, four in North America (three in the U.S. and one in Mexico), and five in northern Asia (one in Japan, two in Korea, and two in China). The highest voltage prototype is to operate at $135 \mathrm{kV}$, while most projects aim at $45 \mathrm{kV}$ or less. This emphasis is consistent with the likely market. Currents (rms within each conductor) range from $0.8 \mathrm{kA}$ to $2.4 \mathrm{kA}$. Most conventional cable is used for voltages less than $22 \mathrm{kV}$, not high voltages.

Most conductor materials comprise Bi-2223 and silver alloy. The longest cable will traverse $610 \mathrm{~m}$. However, three projects plan to construct 30-m cable segments incorporating $\mathrm{REBaCuO}(\mathrm{RE}=$ rare earth) conductor (also called "second generation conductor" or "coated conductor"). Nexans' $3 \mathrm{C} \mathrm{REBaCuO}$ cable project (funded by the European Economic Community), though long delayed by the inability of team members to agree on intellectual property issues, is still expected to proceed.

Besides the ability to carry its nominal or rated current for the cable's intended life (3040 years), a cable must be able to carry far greater currents for brief times. This requirement is made explicit by the over-current specifications in the table. These requirements are met in most HTS cables by incorporating enough copper (or aluminum) to handle the excess current. (HTS is too expensive to be put in place for only occasional duty.) Thus, the total space devoted to conductor is determined by how much cold copper (or aluminum) is embodied by the cable. Copper is preferred to aluminum because $\mathrm{Al}_{2} \mathrm{O}_{3}$ is an excellent insulator, not a desirable property for material at the HTS/stabilizer interface.

As is typical of electric power equipment, a cable requires electrical insulation (also called "dielectric") between the conductors. One family of designs puts the conductor, but not the dielectric, in a cryostat. The dielectric is meant to operate at ambient temperature - thus the name "warm dielectric cable." The goal is to use dielectrics having well-known properties and 
reliability attested to by power engineering experience. Some say that this strategy complicates the cable's terminations compared with those required by the alternative strategy, "cold dielectric," in which both the conductor and the electrical insulation are within the cryostat. Coaxial cable provides an example. Many groups plan to use polypropylene-laminated paper (PPLP) for their dielectric, but alternatives are being investigated.

The table also shows that most cables will incorporate flexible cryostats made by Nexans-Hannover, the only commercial supplier. Indeed, Nexans-Hannover has accumulated experience that others might have to duplicate before achieving the combination of reliability and price necessary for future commercial cable.

Most cable projects will depend on off-the-shelf refrigeration technology. However, two projects (SuperPower, Inc., and AMSC) plan to test prototype acoustic cryocoolers. These raise the hope for more reliable, lower-maintenance refrigeration, which is an important goal. CFIC has delivered one of its acoustic cryocoolers to Toshiba for testing and use in Toshiba's labs near Tokyo.

Finally, the outer diameter of these various cables deserves attention. Some utilities seek to put more power through existing infrastructure, rather than excavating new space and constructing infrastructure within it. For example, the diameter of Japan's existing ducts is $150 \mathrm{~mm}$, and so their interest has been in putting more power through this diameter (or smaller). Other benchmarks are provided by the diameters of commercial cable. In 1990, Okonite Corporation supplied a high-pressure oil-filled cable having a 219-mm outer diameter. That cable operates at $345 \mathrm{kV}$ and guides up to $765 \mathrm{MW}$ from Westchester to Long Island. Since 1990, utilities have increasingly preferred solid dielectric (XLPE) cables to eliminate the possibility of oil leaking to the environment. Nonetheless, oil-filled cables are still offered for sale. At high voltages, HTS cable (e.g., AMSC's Long Island cable, 325-mm OD) has not yet been demonstrated to be as compact as HPOF cable (Okonite's HPOF cable, 219-mm OD). 
TABLE 5 HTS cable projects underway around the world (as of 03 December 2004).

\begin{tabular}{|c|c|c|c|c|c|c|c|c|c|c|c|}
\hline $\begin{array}{c}\text { Project } \\
\text { Management } \\
\text { Characteristic }\end{array}$ & Innopower $^{5}$ & $\begin{array}{c}\text { Chinese } \\
\text { Academy of } \\
\text { Science }\end{array}$ & KERI & KEPRI & SuperAce & ConduMex & Tratos Cavi & SuperPower & $\begin{array}{c}\text { American } \\
\text { Superconductor }\end{array}$ & Ultera $^{2,3}$ & Nexans \\
\hline Financial Status & Funded & Funded & Funded & Funded & Phase-I Funded & Funded & Funded & Funded & Funded & Funded & Funded \\
\hline Utility & $\begin{array}{l}\text { Yunnan Electric Power } \\
\text { Group }\end{array}$ & none & KEPCO & KEPCO & TEPCO, ChubuE, \& KEPCO & $\begin{array}{l}\text { Commission Federal } \\
\text { de Electricidad (CFE) }\end{array}$ & none & $\begin{array}{l}\text { Niagara-Mohawk } \\
\text { (a National Grid } \\
\text { Company) }\end{array}$ & $\begin{array}{l}\text { Long Island } \\
\text { Power Authority }\end{array}$ & $\begin{array}{l}\text { American Electric } \\
\text { Power }\end{array}$ & E.On \\
\hline $\begin{array}{l}\text { Planned Start } \\
\text { of Operation }\end{array}$ & April 2004 & Winter 2004-2005 & July 2004 & Summer 2005 & March, 2004 & $\begin{array}{l}\text { Phase I: } 2005 \\
\text { Phase II: } 2006 \text { (start) }\end{array}$ & Spring 2005 & $\begin{array}{l}\text { Jan-2006 Bi-2223 } \\
\text { Dec-06 YBaCuO }\end{array}$ & April, 2006 & Spring 2006 & ?2007? \\
\hline Type & $\mathrm{AC}$ & $\mathrm{AC}$ & $\mathrm{AC}$ & $\mathrm{AC}$ & $\mathrm{AC}$ & $\mathrm{AC}$ & $\mathrm{AC}$ & $\mathrm{AC}$ & $\mathrm{AC}$ & $\mathrm{AC}$ & $\mathrm{AC}$ \\
\hline Phases & 3 & 3 & 3 & 3 & 1 & 1 (Phase I) \& 3 (Phase II) & 3 & 3 & 3 & 3 & 1 \\
\hline $\begin{array}{c}\text { Voltage } \\
\text { (phase-to-phase) }\end{array}$ & $35 \mathrm{kV}$ & 15 & $22.9 \mathrm{kV}$ & $22.9 \mathrm{kV}$ & $77 \mathrm{kV}$ & $23 \mathrm{kV}$ & $45 \mathrm{kV}$ & $34.5 \mathrm{kV}$ & $138 \mathrm{kV}$ & $13.5 \mathrm{kV}$ & $10 \mathrm{kV}$ \\
\hline $\begin{array}{c}\text { Current } \\
\text { (within phase) }\end{array}$ & $2 \mathrm{kA}$ & $1.5 \mathrm{ka}$ & $1.2 \mathrm{kA}$ & $1.2 \mathrm{kA}$ & $1.0 \mathrm{kA}$ & $2 \mathrm{kA}$ & $2 \mathrm{kA}$ & $0.8 \mathrm{kA}$ & $2.4 \mathrm{kA}$ & $3.0 \mathrm{kA}$ & $1 \mathrm{kA}$ \\
\hline Length & $33.5 \mathrm{~m}$ & $75 \mathrm{~m}$ & $30 \mathrm{~m}$ & $100 \mathrm{~m}$ & $500 \mathrm{~m}$ & $\begin{array}{c}5 \mathrm{~m} \& 10 \mathrm{~m} \text { Phase I } \\
100 \mathrm{~m} \text { Phase II }\end{array}$ & $50 \mathrm{~m}$ & $350 \mathrm{~m}$ & $660 \mathrm{~m}$ & $200 \mathrm{~m}$ & $30 \mathrm{~m}$ \\
\hline \multirow[t]{3}{*}{ Design } & & \multirow[t]{3}{*}{ Warm dielectric } & \multirow{3}{*}{$\begin{array}{l}\text { Cold Dielectric } \\
\text { PPLP } \\
\\
\\
\text { Triad HTS } \\
3 \text { cores, } \\
\text { in one cryostat }\end{array}$} & \multirow{3}{*}{$\begin{array}{l}\text { Cold Dielectric } \\
3 \text { coaxial cores, } \\
\text { in one cryostat } \\
\text { OD Cable Fits } \\
\text { in } 175 \mathrm{~mm} \text { Duct } \\
\text { Fault Spec: } \\
5 \text { cycles, } 25 \mathrm{kA}\end{array}$} & \multirow{3}{*}{$\begin{array}{c}\text { Cold Dielectric } \\
\text { PPLP } \\
\text { one coaxial in cryostat } \\
\text { OD cable } \\
133 \mathrm{~mm} \\
\text { Fault Spec: } \\
25 \text { cylls, } 31.5 \mathrm{kA} \\
\text { (500 millisec) }\end{array}$} & \multirow{3}{*}{$\begin{array}{l}\text { Warm Dielectric } \\
\text { Polyethylene } \\
\text { other participants in } \\
\text { component design \& } \\
\text { selection } \\
\text { IPN } \\
\text { (Mxico City) } \\
\text { VNIIIIP) } \\
\text { (Moscow) }\end{array}$} & \multirow{3}{*}{$\begin{array}{c}\text { Warm Dielectric } \\
\text { and } \\
5 \mathrm{~m}, 45 \mathrm{kV} \\
\text { cold dielectric }\end{array}$} & \multirow{3}{*}{$\begin{array}{l}\text { Cold Dielectric } \\
\text { Triad HTS } \\
3 \text { coaxial cores, } \\
\text { in one cryostat } \\
\text { Fault Spec: } \\
38 \text { cycles, } 23 \mathrm{kA} \\
\text { (633 millisec) }\end{array}$} & \multirow{3}{*}{$\begin{array}{l}\text { Cold Dielectric } \\
\text { each coaxial core } \\
\text { in own cryostat } \\
\text { (all in } 355 \text { mm pipe) } \\
\text { Fault Spec: } \\
15 \text { cycles, } 69 \mathrm{kA} \\
(250 \text { millisec) }\end{array}$} & $\begin{array}{l}\text { Cold Dielectric } \\
\text { CryoflexTM } 4\end{array}$ & \multirow{3}{*}{$\begin{array}{c}\text { Cold Dielectric } \\
\text { coaxial } \\
\text { HTS }\end{array}$} \\
\hline & \multirow{2}{*}{$\begin{array}{c}\text { XLPE } \\
4 \text { HTS layers per phase } \\
\text { one phase per cryostat } \\
\text { OD HTS phase } 44 \mathrm{~mm} \\
\text { OD cable } 112 \mathrm{~mm}\end{array}$} & & & & & & & & & in one cryostat, $\mathrm{OD}$ & \\
\hline & & & & & & & & & & $\begin{array}{l}\text { Fault } \operatorname{mpcc} 15 \\
\text { cycles, } 156 \mathrm{kA} \\
(250 \text { millisec) }\end{array}$ & \\
\hline HTS & $\mathrm{Bi}-2223$ & Bi-2223 & Bi-2223 & $\begin{array}{c}\text { Bi-2223 } \\
\text { (SEl's CT-OPT, } \\
\text { Controlled Over Pressure) }\end{array}$ & $\begin{array}{l}\text { Bi-22223 suitable for } \mathrm{AC} \\
\text { (short sample of REBaCuO, } \\
\text { if available) }\end{array}$ & Bi-2223 & Bi-2223 & $\begin{array}{c}\text { Bi-2223 } \\
\text { (SEl'r ST-OPT, } \\
\text { Controlled Over Pressure) } \\
\text { subsequent 30-m section of } \\
\text { YbaCuO }\end{array}$ & Bi-2223 & Bi-2223 & $\begin{array}{c}\text { REBaCuO } \\
\text { on Stainless Steel }\end{array}$ \\
\hline AC Loss Goal & $<1.0 \mathrm{~W} / \mathrm{m}$ per phase & ? & $1 \mathrm{~W} / \mathrm{m}$ per phase & $50 \%$ of Conventional & $\begin{array}{l}\text { measured value given here } \\
1.3 \mathrm{~W} / \mathrm{m} / \text { phase } @ 1 \mathrm{kA}\end{array}$ & ? & ? & $<0.5 \mathrm{~W} / \mathrm{m}$ per phase & ? & ? & ? \\
\hline \multirow{3}{*}{$\begin{array}{l}\text { Conductor Supplier } \\
\text { Cable Fabricator }\end{array}$} & \multirow{3}{*}{$\begin{array}{c}\text { InnoST } \\
\text { Nexans provided } \\
\text { Electrical Insulation } \\
\text { within Cryostat } \\
\\
\text { Shanghai Cable Works } \\
\text { (terminations' } \\
\text { goal }<\text { 120W/unit } \\
\text { Inst. Of Plasma Physics at } \\
\text { Academia Sinica) }\end{array}$} & \multirow[t]{2}{*}{ AMSC } & \multirow[t]{2}{*}{ AMSC } & \multirow[t]{2}{*}{ SEI } & Furukawa & AMSC & \multirow{2}{*}{$\begin{array}{l}\text { AMSC } \\
\text { Trithor }\end{array}$} & \multirow{2}{*}{$\begin{array}{c}\text { SEI } \\
\text { Bi-2223, } \\
\text { SuperPower } \\
\text { YBaCuO }\end{array}$} & \multirow[t]{2}{*}{ AMSC } & \multirow[t]{2}{*}{ to be determined } & \multirow{2}{*}{$\begin{array}{c}\text { EAS } \\
\text { Nexans SC }\end{array}$} \\
\hline & & & & & SRL- REBaCuO & Nexans provides former & & & & & \\
\hline & & $\begin{array}{l}\text { Chang Tong Cable } \\
\text { Company }\end{array}$ & LG Cables & $\begin{array}{l}\text { SEI } \\
\text { via Turnkey Contract }\end{array}$ & Furukawa & ConduMex & Tratos Cavi & SEI & Nexans & Ultera & Nexans \\
\hline $\begin{array}{l}\text { Cryostat Type } \\
\& \text { Supplier }\end{array}$ & $\begin{array}{c}\text { flexible } \\
\text { goal }<1.5 \mathrm{~W} / \mathrm{m} \\
\text { Nexans-Hanover }\end{array}$ & flexible & ? & included in Turnkey & $\begin{array}{l}\text { flexible } \\
1.0 \mathrm{~W} / \mathrm{m} \text { Straight Section } \\
\text { Furukawa }\end{array}$ & $\begin{array}{c}\text { flexible } \\
\text { Nexans-Hanover, } 5 \mathrm{~m} \\
\text { Condumex, } 10 \mathrm{~m}\end{array}$ & $\begin{array}{l}\text { flexible } \\
\text { Tratos Cavi }\end{array}$ & $\begin{array}{c}\text { flexible } \\
2.5 \mathrm{~W} / \mathrm{m} \\
\mathrm{SEI}\end{array}$ & $\begin{array}{c}\text { flexible } \\
\sim 5 \mathrm{~W} / \mathrm{m} 2 \\
\text { Nexans-Hanover }\end{array}$ & $\begin{array}{c}\text { flexible } \\
\sim 5 \mathrm{~W} / \mathrm{m}^{2} \\
\text { Nexans-Hanover }\end{array}$ & $\begin{array}{c}\text { flexible } \\
\sim 5 \mathrm{~W} / \mathrm{m}^{2} \\
\text { Nexans-Hanover }\end{array}$ \\
\hline
\end{tabular}


TABLE 5 (Cont.)

\begin{tabular}{|c|c|c|c|c|c|c|c|c|c|c|c|}
\hline $\begin{array}{c}\text { Project } \\
\text { Management } \\
\text { Characteristic }\end{array}$ & Innopower $^{5}$ & $\begin{array}{l}\text { Chinese } \\
\text { Academy of } \\
\text { Science }\end{array}$ & KERI & KEPRI & SuperAce & ConduMex & Tratos Cavi & SuperPower & $\begin{array}{c}\text { American } \\
\text { Superconductor }\end{array}$ & Ultera $^{2,3}$ & Nexans \\
\hline $\begin{array}{c}\text { Cryogen } \\
\text { Refrigeration } \\
\& \text { Supplier }\end{array}$ & $\begin{array}{l}\mathrm{LN}_{2} 70-80 \mathrm{~K}, \\
\text { seven, } 300 \mathrm{~W}-\mathrm{GM} \\
\text { CryoMech }\end{array}$ & $\begin{array}{l}\mathrm{LN}_{2} \\
\text { CAST }\end{array}$ & $\begin{array}{l}\mathrm{LN}_{2} 70-80 \mathrm{~K} \\
\text { Tank }\end{array}$ & included in Turnkey & $\begin{array}{c}\mathrm{LN}_{2} \\
4 \mathrm{~kW} \text { cable }+2 \mathrm{~kW} \\
\text { terminations } \\
\text { Suzuki Shoukan Aishin } \\
\text { Sterling-cooler }\end{array}$ & $\begin{array}{c}\mathrm{LN}_{2} \\
\text { Phase II-Air Products, } \\
4 \mathrm{~kW}\end{array}$ & $\begin{array}{l}\mathrm{LN}_{2} \\
\text { Stirling }\end{array}$ & $\begin{array}{l}\mathrm{LN}_{2} \\
6 \mathrm{~kW} @ 77 \mathrm{~K} \\
\text { closed loop } \\
\text { BOC }\end{array}$ & $\begin{array}{c}\mathrm{LN}_{2} \\
5 \mathrm{~kW} @ 70 \mathrm{~K} \\
\text { Air Liquide } \\
\text { AMSC-pulse tube }\end{array}$ & $\begin{array}{c}\mathrm{LN}_{2} \\
\text { Praxair } \\
\text { \& Praxair-QDrive }\end{array}$ & $\begin{array}{c}\mathrm{LN}_{2} \\
\text { Air Liquide }\end{array}$ \\
\hline $\begin{array}{l}\text { I Ultera is a joint ventur } \\
{ }^{2} \text { Southwire continues to } \\
\text { coaxial, Bi-2223, cold } \\
{ }^{3} \text { It is a coincidence that } \\
{ }^{4} \text { InnoPower expects to }\end{array}$ & $\begin{array}{l}\text { f NKT and Southwire } \\
\text { pply electric power (2 } \\
\text { lectric, } \mathrm{LN}_{2} \text { cooling, } \\
\text { xans' cryostat's trade } \\
\text { Id a } 110-\mathrm{kV}, 1-2 \mathrm{kA} \text { c }\end{array}$ & $\begin{array}{l}0 \text { hours at } 100 \% \text { load } \\
\mathrm{V} \text { phase-to-phase, } 1.2 \mathrm{2} \\
\text { ne is the same as the } \mathrm{n} \\
\text { of several hundred } \mathrm{m}\end{array}$ & $\begin{array}{l}\text { to its cable man } \\
\text { A } 27 \text { MVA. } \\
\text { me of the dielec } \\
\text { ters length in the }\end{array}$ & $\begin{array}{l}\text { turing plant through an } 1 \\
\text { naterial used by Ultera. } \\
\text { inity of Beijing during o }\end{array}$ & $\begin{array}{l}\text { three-phase, 30-m cable of } \\
\text { use different materials. } \\
\text { g years. }\end{array}$ & construction (each ph & & & & & \\
\hline Table prepar & 30 November 2004 b & M. Wolsky, Operating & Agent for Intern & al Energy Agency's Im, & inting Agreement & & & & & & \\
\hline
\end{tabular}




\section{CONCLUSION}

The key findings in this report are summarized as follows:

1. Electron microscopy and Raman spectroscopy examinations of SuperPower's long-length MOCVD-coated conductor tapes show that the MOCVD-type deposition process is capable of producing a dense (low porosity), uniform YBCO film. These films exhibit domains of columnar grain growth (a-axis grains) that increase in number through thickness from substrate to surface. Grain boundary connectivity appears well developed, with little tangible evidence of meandering boundaries. Relatively small amounts of carbon-containing phases are observed in a uniformly distributed pattern throughout most of the films examined to date.

2. $\mathrm{Er}^{3+}$ addition to the MOD-type YBCO precursor used by American Superconductor increases flux pinning in the $\mathrm{H} / / \mathrm{c}$ orientation but concomitantly decreases flux pinning for $\mathrm{H} / / \mathrm{ab}$. $\mathrm{C}^{4}$ examination of samples with and without added $\mathrm{Er}^{3+}$ shows that $\mathrm{Er}^{3+}$ addition leads to $(\mathrm{Y}, \mathrm{Er})_{2} \mathrm{O}_{3}$ nano-dot precipitates in the (Y,Er)BCO matrix, but with a corresponding steady decrease in the number of planar defects as the $\mathrm{Er}^{3+}$ content is increased.

3. A systematic investigation was made to determine how changes of the oxygen concentration affect the temperature and magnetic field dependence of the critical current in YBCO films. At temperatures of $77 \mathrm{~K}$ and below, the highest values for the critical current in zero field and in high field as well were obtained in the most over-doped state, i.e., in the state with the highest oxygen concentration.

4. A finite element analysis (FEA) was performed to assess the applicability of Stoney's equation (Eq. 3) to residual stress evaluation of individual layers of a multilayered YBCOcoated conductor. The values of residual stresses estimated by Stoney's equation were similar to those directly computed by FEA, indicating that Stoney's equation can be used to estimate residual stresses in multilayered coated conductors.

5. The processing techniques chosen for thin film deposition of YBCO coated conductors influence the nature and magnitude of intrinsic stresses (generated during film growth), and therefore can significantly alter the net residual stress in the films. IBAD processing of YSZ films on Hastelloy $\mathrm{C}$ substrate led to intrinsic compressive stresses in these films due to Ar ion peening. This resulted in a higher compressive residual stress in the YSZ films than the calculated thermal mismatch stress between YSZ and Hastelloy C. The textured YSZ film had a lower intrinsic compressive stress than the non-textured film, resulting in a relatively low compressive residual stress in the textured film. Similar to thin-film processing by IBAD, PLD also led to generation of intrinsic compressive stresses in YBCO films deposited on $\mathrm{LaAlO}_{3}$ substrate. Thus, the resulting residual stress in the YBCO film was less tensile than the calculated thermal mismatch stress between $\mathrm{YBCO}$ and $\mathrm{LaAlO}_{3}$. In contrast to IBAD and PLD, sol-gel processing generated negligible intrinsic stress in YBCO films deposited on $\mathrm{LaAlO}_{3}$ substrate. The measured residual stress in the sol-gel-processed YBCO film was, thus, consistent with the calculated thermal mismatch stress between $\mathrm{YBCO}$ and $\mathrm{LaAlO}_{3}$. 
6. The significant progress made worldwide in demonstrating HTS technology for AC cables has been comprehensively summarized. 


\section{REFERENCES}

1. V.A. Maroni, K. Venkataraman, D.J. Miller, S. Trasobares, Y. Lei, J.M. Hiller, K.E. Gray, V.K. Vlasko-Vlasov, H. Claus, J. Reeves, M.W. Rupich, W. Zhang, T. Kodenkandath, and X. Li, IEEE Trans. Appl. Supercond. 15 (2005) 2798.

2. (a) V. Selvamanickam, Y. Xie, J. Reeves, and Y. Chen, MRS Bull. 29 (2004) 579; (b) V. Selvamanickam, Y.-Y. Xie, and J. Reeves, "Progress in Scale-up of 2G Conductor at SuperPower," 2005 DOE/OE Superconductivity for Electric Systems Annual Peer Review, August 2-4, 2005, Washington, DC (available at the DOE/OE Website).

3. (a) M.W. Rupich, D.T. Verebelyi, W. Zhang, T. Kodenkandath, and X. Li, MRS Bull. 29 (2004) 579; (b) S. Fleshler, D.T. Verebelyi, and M.W. Rupich, "Scale-up of Second Generation HTS Wire (2G-YBCO Coated Conductor), 2005 DOE/OE Superconductivity for Electric Systems Annual Peer Review, August 2-4, 2005, Washington, DC (available at the DOE/OE Website).

4. K. Venkataraman, R. Baurceanu, and V.A. Maroni, Appl. Spectro. 59 (2005) 639.

5. M.N. Iliev, "Raman spectroscopy of phase separation and reordering processes in YBCOtype compounds," Spectroscopy of Superconducting Materials, American Chemical Society Symposium Series 730 (1999) 107.

6. (a) P. Kisliuk, W.F. Krupke, and J.B. Gruber, J. Chem. Phys. 40 (1964) 3606; (b) J.R. Dean and D. Bloor, J. Phys. C: Solid State Phys. 5 (1972) 2921.

7. A. Schmehl, B. Goetz, R.R. Schulz, C.W. Schneider, H. Bielefeldt, H. Hilgenkamp, and J. Mannhart, Europhys. Lett. 47 (1999) 110.

8. G. Hammerl, A. Schmehl, R.R. Schulz, B. Goetz, H. Bielefeldt, C.W. Schneider, H. Hilgenkamp, and J. Mannhart, Nature 407 (2000) 162.

9. B. Holzapfel, D. Verebelyi, C. Cantoni, M. Paranthaman, B. Sales, R. Feenstra, D. Christen, and D.P. Norton, Physica C 341-348 (2000) 1431.

10. H. Claus, Beihai Ma, A.P. Paulikas, Y. Tang, R. Nikolova, B.W. Veal, and K.E. Gray, "Oxygen Doping of Grain Boundaries in $\mathrm{YBa}_{2} \mathrm{Cu}_{3} \mathrm{O}_{\mathrm{x}}$ Bicrystal Films," Proceedings of the Sixth European Conference on Applied Superconductivity, Sorrento, Italy, September 14-18, 2003, Edited by A. Andreone, G. P. Pepe, R. Cristiano and G. Masullo, Institute of Physics Conference Series Number 181, (2004), page 89 (Institute of Physics Publishing, Bristol and Philadelphia).

11. G.A. Daniels, A. Gurevich, and D.C. Labalestier, Appl. Phys. Lett. 77 (2000) 3251.

12. R. Feenstra, D.K. Christen, C.E. Klabunde, and J.D. Budai, Phys. Rev. B 13 (1992) 7555. 
13. W. Weber, G. Hammerl, A. Schmehl, C.W. Schneider, J. Mannhart, B. Schey, M. Kuhn, R. Nies, B. Utz, and H.W. Neumueller, Appl. Phys. Lett. 82 (2003) 772.

14. B. Ma, M. Li, Y.A. Jee, R.E. Koritala, B.L. Fisher, and U. Balachandran, Physica C 366 (2002) 270.

15.B. Ma, K.K. Uprety, B.L. Fisher, R.E. Koritala, S.E. Dorris, and U. Balachandran, Supercond. Sci. Tech. 17 (2004) S477.

16. H. Claus, U. Welp, H. Zheng, L. Chen, A.P. Paulikas, B.W. Veal, K.E. Gray, and G.W. Crabtree, Phys. Rev. B 64 (2001) 144507-1.

17. V.K. Vlasko-Vlasov, U. Welp, G.W. Crabtree, and V.I. Nikitenko, in Physics and Materials Science of Vortex States, Flux Pinning and Dynamics, NATO Science Series E, Vol. 356, ed., R. Kossowsky et al. (Dordrecht: Kluwer, 1999), p. 205

18. V. Breit, P. Schweiss, R. Hauff, H. Wühl, H. Claus, H. Rietschel, A. Erb, and G. MüllerVogt, Phys. Rev. B 52 (1995) R15727.

19. H. Zheng, M. Jiang, B.W. Veal, H. Claus, and B. Obst, Physica C 301 (1998) 147.

20. Th. Herzog, H.A. Radovan, P. Ziemann, and E.H. Brandt, Phys. Rev. B 56 (1997) 2871.

21. A commercial ozone generator (Triogen) was used for the ozone treatments. At the settings used it yielded less than $0.5 \% \mathrm{O}_{3}$ according to the company's specification.

22. See for example: D. T. Verebelyi, C. Prouteau, R. Feenstra, and D. K. Christen, IEEE Trans. Appl. Supercond. 9 (1999) 2655.

23. G.G. Stoney, Proc. Royal. Soc. Lond. Series A 82 (1909) 172.

24. P.A. Flinn, Proc. MRS 130 (1989) 41.

25. R.E. Cuthress, D.M. Mattox, C.R. Peeples, P.L. Dreike, and K.P. Lamppa, J. Vac. Sci. Technol. A 6 (1988) 2914.

26. W.D. Nix, Metall. Trans. 20A (1989) 2217.

27. A.S. Raynes, S.W. Freiman, F.W. Gayle, and D.L. Kaiser, J. Appl. Phys. 70 (1991) 5254.

28. J. Kawashima, Y. Yamada, and I. Hirabayashi, Physica C 306 (1998) 114.

29. J.H. Cheon and J.P. Singh, Ceramic Transactions 140 (2003) 219.

30. B. Ma, M. Li, R.E. Koritala, B.L. Fisher, A.R. Markowitz, R.A. Erck, R.Baurceanu, S.E. Dorris, D.J. Miller, and U. Balachandran, Supercond. Sci. Technol. 16 (2003) 464. 
31. Y-A Jee, B. Ma, V.A. Maroni, M. Li, B.L. Fisher, and U. Balachandran, Supercond. Sci. Technol. 14 (2001) 285.

32. Y. Iijima, N. Tanabe, O. Kono, and Y. Ikeno, Appl. Phys. Lett. 60 (1992) 769.

33. I.C. Noyan and J.B. Cohen, Residual Stress (New York: Springer-Verlag, 1987).

34. K.G. Ressler, N. Sonnenberg, and M.J. Cima, IEEE Trans. Appl. Supercond. 7 (1997) 1432.

35. D. Burgreen, Elements of Thermal Stress Analysis (New York: C. P. Press, 1971).

36. Y.J. Tian, S. Linzen, F. Schmidl, A. Matthes, H. Schneidewind, and P. Seidel, Thin Solid Films 338 (1999) 224.

37. S.G. Ghonge, E. Goo, and R. Ramesh, Appl. Phys. Lett. 62 (1993) 1742.

38. J.J. Cuomo, J.M.E. Harper, C.R., Guarnieri, D.S. Yee, L.J. Attanasio, J. Angilelio, and C.T. Wu, J. Vac. Sci. Technol. 20 (1982) 349.

39. K.H. Muller, J. Appl. Phys. 62 (1987) 1796.

40. D.P. Norton, C. Park, J.D. Budai, S.J. Pennycook, and C. Proteau, Appl. Phys. Lett. 74 (1999) 2134.

41. J.D. Budai, W. Yang, N. Tamura, J.S. Chung, J.Z. Tischler, B.C. Larson, G.E. Ice, C. Park, and D.P. Norton, Nature Materials 2 (2003) 487. 


\section{PUBLICATIONS, PATENTS, REPORTS, KEY INTERACTIONS IN FY 2005}

\subsection{PEER REVIEWED PUBLICATIONS IN FY 2005}

(1) T.G. Holesinger, J.A. Kennison, S. Liao, Y. Yuan, J. Jiang, X.Y. Cai, E.E. Hellstrom, D.C. Larbalestier, R.M. Baurceanu, V.A. Maroni, and Y. Huang, "A Shell Model for the Filament Structure of Bi-2223 Conductors,” IEEE Trans. Appl. Supercond. 15 (2005) 2514-2517

(2) J. Jiang, X.Y. Cai, Y. Yuan, A.A. Ployanskii, E.E. Hellstrom, D.C. Larbalestier, V.A. Maroni, T.G. Holesinger, and Y. Huang, "Long Term Anneal Study and Composition Variation for Reducing Residual $\mathrm{Bi}_{2} \mathrm{Sr}_{2} \mathrm{CaCu}_{2} \mathrm{O}_{\mathrm{x}}$ (2212) in ( $\left.\mathrm{Bi}, \mathrm{Pb}\right)_{2} \mathrm{Sr}_{2} \mathrm{Ca}_{2} \mathrm{Cu}_{3} \mathrm{O}_{\mathrm{x}}$ (2223) Wires," IEEE Trans. Appl. Supercond. 15 (2005) 2526-2529

(3) V.A. Maroni, K. Venkataraman, D.J. Miller, S. Trasobares, Y. Lei, J.M. Hiller, K.E. Gray, V.K. Vlasko-Vlasov, H. Claus, J. Reeves, M.W. Rupich, W. Zhang, T. Kodenkandath, and X. Li, "Coordinated Characterization of Coated Conductors $\left(\mathrm{C}^{4}\right)$," IEEE Trans. Appl. Supercond. 15 (2005) 2798-2802

(4) B. Ma, K.K. Uprety, R.E. Koritala, B.L. Fisher, S.E. Dorris, D.J. Miller, V.A. Maroni, and U. Balachandran, "Growth and Properties of YBCO-Coated Conductors Fabricated by InclinedSubstrate Deposition,” IEEE Trans. Appl. Supercond. 15 (2005) 2970-2973

(5) R.E. Koritala, B. Ma, D.J. Miller, K.K. Uprety, B.L. Fisher, and U. Balachandran, "Surface Roughness of Magnesium Oxide Buffer Layers Grown by Inclined Substrate deposition," IEEE Trans. Appl. Supercond. 15 (2005) 3031-3033

(6) K. Venkataraman, R. Baurceanu, and V.A. Maroni, "Characterization of $\mathrm{MBa}_{2} \mathrm{Cu}_{3} \mathrm{O}_{7-\mathrm{x}}$ Thin Films by Raman Microspectroscopy,” Applied Spectroscopy 59 (2005) 639-649

(7) D.J. Miller, S. Trasobares, R. Koritala, B. Ma, K. Uprety, and U. Balachandran, "Microstructural Aspects of Inclined Substrate Deposition Templates for Coated Conductors," Ceramic Transactions 169 (2005) 79-85

(8) T.P. Weber, B. Ma, U. Balachandran, and M. McNallan, "Fabrication of Biaxially-Textured Magnesium Oxide Thin Films by Ion-Beam-Assisted Deposition,” Thin Solid Films 476 (2005) $79-83$

(9) P.S. Shankar, S.H. Majumdar, S. Majumdar, and J.P. Singh, "Finite Element Modeling of Residual Stresses in Multilayered Coated Conductors," Ceramic Transactions 160 (2005) 21-25

(10) J.H. Cheon, P.S. Shankar, and J.P. Singh, "Influence of Processing Methods on Residual Stress Evolution in Coated Conductors," Supercond. Sci. Technol. 18 (2005) 142-146 
(11) V.F. Solovyov, H.J. Wiesman, L.-J. Wu, M. Suenaga, K. Venkataraman, and V.A. Maroni, "A New Technique for the Growth of Epitaxial YBCO Using Spray Pyrolysis," Physica C 415 (2004) 125-132

(12) Y. Yuan, J. Jiang, X.Y. Cai, T.G. Holesinger, Y. Huang, R. Parrella, V.A. Maroni, D.C. Larbalestier, and E.E. Hellstrom, "Recent Processing Advances for Increased Jc in (Bi,Pb) ${ }_{2} \mathrm{Sr}_{2} \mathrm{Ca}_{2} \mathrm{Cu}_{3} \mathrm{O}_{\mathrm{x}}$ Tapes," Transactions of the Materials Research Society of Japan 29 (2004) 1235-1239

(13) H. Claus, B. Ma, A.P. Paulikas, Y. Tang, R. Nikolova, B.W. Veal, and K.E. Gray, "Oxygen Doping of Grain Boundaries in YBa2Cu3Ox Bicrystal Films," Proceedings of the Sixth European Conference on Applied Superconductivity, Sorrento, Italy, September 14-18, 2003, Edited by A. Andreone, G. P. Pepe, R. Cristiano and G. Masullo, Institute of Physics Conference Series Number 181, (2004) page 89, Institute of Physics Publishing, Bristol and Philadelphia

(14) H. Claus, K.K. Uprety, B. Ma, A.P. Paulikas, V.K. Vlasko-Vlasov, U. Welp, B.W. Veal, and K.E. Gray, "Reversible Oxidation and Critical Current of $\mathrm{YBa}_{2} \mathrm{Cu}_{3} \mathrm{O}_{\mathrm{x}}$ Coated Conductors," Physica C 416 (2004) 1-10

(15) M.W. Rupich, W. Zhang, X. Li, T. Kodenkandath, D.T. Verebelyi, U. Schoop, C. Thieme, M. Teplitsky, J. Lynch, N. Nguyen, E. Siegal, J. Scudiere, V. Maroni, K. Venkataraman, D. Miller, T.G. Holesinger, "Progress on MOD/RABiTS 2G HTS Wire," Physica C 412-414 (2004) 877-884

(16) U. Balachandran, B. Ma, M. Li, B.L. Fisher, R.E. Koritala, D.J. Miller, "Development of Coated Conductors by Inclined Substrate Deposition," Advances in Cryogenic Engineering 50A \& B (2004) 637-644

\subsection{PATENTS ISSUED IN FY 2005}

(1) "Method for Forming Bismuth-Based Superconducting Ceramics," V.A. Maroni, N.N. Merchant, R.D. Parrella, Patent No. 6,894,006, issued May 17, 2005

\subsection{REPORTS ISSUED IN FY 2005}

(1) A.M. Wolsky, "HTS Cable-Status, Challenge, and Opportunity," prepared in accordance with the International Energy Agency Implementing Agreement for a Cooperative Programme for Assessing the Impacts of High-Temperature Superconductivity on the Electric Power Sector, December 2004 (408 pages)

(2) U. Balachandran et al., "Practical Superconductor Development for Electric Power Applications: Annual Report for FY 2004," Argonne National Laboratory Report ANL-04/21 (October 2004) 


\subsection{KEY INTERACTIONS IN FY 2005}

(1) Victor Maroni attended a Wire Development Group meeting November 30-December 1, 2004 in Westborough, MA. The meeting covered progress and issues involving both $1 \mathrm{G}$ and $2 \mathrm{G}$ conductor development and was attended by participants from AMSC, ANL, LANL, ORNL, and UWM.

(2) Alan Wolsky facilitated the introduction of IEA ExCo to work by American Superconductor, Southwire, and Oak Ridge National Laboratory, during October 11-13, 2004 meetings held in Gatlinburg and Oak Ridge, TN.

(3) Alan Wolsky participated in discussions of a future workshop on Cryogenic Dielectrics with Mike Gouge (ORNL) and promised to further same. (This workshop is intended to enhance awareness of the importance of topics opened by the IEA-SCENet workshop, Low-TemperatureHigh-Voltage Dielectrics, held on March 3-4, 2004 in Grenoble, FR. The latter workshop was initiated by A.M. Wolsky.) The IEA Executive Committee has expressed interest in helping stimulate participation.

(4) Alan Wolsky was invited to prepare a review article on HTS cables for Advances in High Temperature Superconductivity. Alan was also named a Member of the Institute of Physics and was nominated for Senior Member of IEEE by persons in the electric power sector.

(5) George Crabtree, Ken Gray, Dean Miller, and Vic Maroni were active participants in the 2005 Wire Development Workshop held in St. Petersburg, FL, January 19-20, 2005. George Crabtree made a presentation in the Flux Pinning Session (Session III); Vic Maroni and Dean Miller served as chair persons of Sessions V and VII, respectively.

(6) Argonne hosted a Wire Development Group (WDG) Meeting April 21 and 22, 2005. WDG collaborators from American Superconductor, Los Alamos National Laboratory, Oak Ridge National Laboratory, and the University of Wisconsin/Madison were in attendance. 


\section{Distribution for ANL-05/62}

Internal:
U. Balachandran
J.R. Hull
W.J. Shack
H. Claus
S. Lake
J.P. Singh
G.W. Crabtree
D. Lewis
V. Vlasko-Vlasov
S.E. Dorris
B. Ma
B.L. Fisher
V.A. Maroni
K.E. Gray
D.J. Miller
D. Graziano
R.B. Poeppel
U. Welp
A.M. Wolsky
TIS files

\section{External:}

DOE-OSTI

ANL Research Library

U.S. Department of Energy, Washington:

Office of Electricity Delivery and Energy Reliability

W. Parks

G. Bindewald

J. Daley

D. Haught

H. Chhabra

Basic Energy Sciences-Material Sciences:

T.J. Fitzsimmons

B. Strauss

A. Dragoo

H. Kung

Other - Industry - University - Laboratory

S. Ahmed, Southern California Edison, Rosemead, CA

J. Badin, Energetics, Inc., Columbia, MD

P. Barnes, Air Force Research Laboratory, Wright-Patterson Air Force Base

R. Bhattacharya, National Renewable Energy Laboratory

P. Chu, University of Houston

P. Clem, Sandia National Laboratories

C. Cox, Bob Lawrence and Associates, Inc., Alexandria, VA

J. Ekin, National Institute of Standards and Technology, Boulder, CO

P.M. Grant, W2AGZ, San Jose, CA

D. Gubser, Naval Research Laboratory

P. Haldar, University at Albany, State University of New York

R. Hammond, Laboratory for Advanced Materials, Stanford University

R.A. Hawsey, Oak Ridge National Laboratory

P. Herz, TMS, Inc., Gaithersburg, MD 
D. Lindsay, Southwire Co., Carrollton, GA

Y. Iwasa, Francis Bitter National Magnet Lab., Massachusetts Institute of Technology

D.C. Larbalestier, University of Wisconsin - Madison

A. Malozemoff, American Superconductor Corp., Westborough, MA

K. Marken, Oxford Instruments, Inc., Carteret, NJ

B. McCallum, Ames Laboratory, Ames, IA

S. Mehta, Waukesha Electric Systems, Waukesha, WI

C. Oberly, Wright Air Force Laboratory, Dayton, $\mathrm{OH}$

P. Pellegrino, IGC-SuperPower, Schenectady, NY

D. Peterson, Los Alamos National Laboratory

J. Schwartz, Florida State University

V. Selvamanickam, IGC-SuperPower, Schenectady, NY

M. Strasik, Boeing Corp., Seattle

M. Suenaga, Brookhaven National Laboratory

H. Weinstock, Air Force Office of Scientific Research, Arlington, VA

D.O. Welch, Brookhaven National Laboratory

W. Wong-Ng, NIST, Gaithersburg, MD 


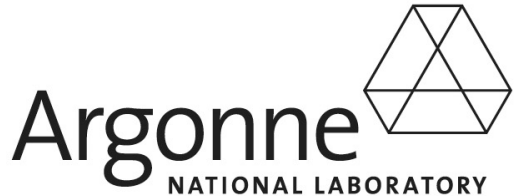

\section{Materials Science Division}

Argonne National Laboratory

9700 South Cass Avenue, Bldg. 223

Argonne, IL 60439-4845

www.anl.gov

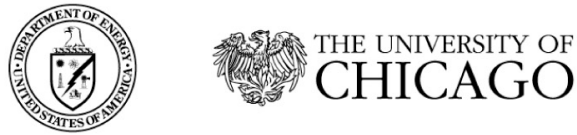

A U.S. Department of Energy laboratory managed by The University of Chicago 